\title{
Risk- and social preferences of individual investors
}

Citation for published version (APA):

Smeets, P. M. A. (2012). Risk- and social preferences of individual investors. [Doctoral Thesis, Maastricht University]. Datawyse / Universitaire Pers Maastricht. https://doi.org/10.26481/dis.20120615ps

Document status and date:

Published: 01/01/2012

DOI:

$10.26481 /$ dis.20120615ps

Document Version:

Publisher's PDF, also known as Version of record

\section{Please check the document version of this publication:}

- A submitted manuscript is the version of the article upon submission and before peer-review. There can be important differences between the submitted version and the official published version of record.

People interested in the research are advised to contact the author for the final version of the publication, or visit the DOI to the publisher's website.

- The final author version and the galley proof are versions of the publication after peer review.

- The final published version features the final layout of the paper including the volume, issue and page numbers.

Link to publication

\footnotetext{
General rights rights.

- You may freely distribute the URL identifying the publication in the public portal. please follow below link for the End User Agreement:

www.umlib.nl/taverne-license

Take down policy

If you believe that this document breaches copyright please contact us at:

repository@maastrichtuniversity.nl

providing details and we will investigate your claim.
}

Copyright and moral rights for the publications made accessible in the public portal are retained by the authors and/or other copyright owners and it is a condition of accessing publications that users recognise and abide by the legal requirements associated with these

- Users may download and print one copy of any publication from the public portal for the purpose of private study or research.

- You may not further distribute the material or use it for any profit-making activity or commercial gain

If the publication is distributed under the terms of Article $25 \mathrm{fa}$ of the Dutch Copyright Act, indicated by the "Taverne" license above, 


\section{Risk- and Social Preferences of Individual Investors}

Paul Smeets 
(C) Copyright Paul Smeets, Maastricht 2012.

All rights reserved. No part of this thesis may be reproduced of transmitted in any form of by any means, electronic or mechanical, including photocopying, recording, or any information storage or retrieval system without permission from the author, or when appropriate, from the publishers of the publications.

Production: Datawyse | Universitaire Pers Maastricht ISBN 9789461591579 


\title{
Risk- and Social Preferences of Individual Investors
}

\author{
DISSERTATION \\ to obtain the degree of Doctor at Maastricht University, \\ on the authority of the Rector Magnificus, Prof. Dr. G.P.M.F. Mols \\ in accordance with the decision of the Board of Deans, \\ to be defended in public \\ on Friday June 15, 2012, at 12:00 hours \\ by \\ Paul Smeets \\ born on June 11, 1985 (Kerkrade, The Netherlands)
}

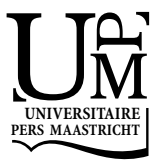


Ph.D. Supervisors

Prof. Dr. Rob Bauer

Prof. Dr. Piet Eichholtz

\section{Evaluation Committee}

Prof. Dr. Dennis Bams

Dr. John Beshears, Stanford Graduate School of Business

Prof. Dr. Thomas Dohmen

Dr. Stephan Meier, Columbia Business school 
Aan mijn ouders 



\section{Contents}

Chapter 1 Introduction 9

Chapter 2 Individuals' Risk Preferences and Mutual Fund 19 Investments

Chapter 3 Strategic and Intrinsic Pro-Social Behavior of 55 Individual Investors

Chapter 4 Social Preferences and Investor Loyalty 85

$\begin{array}{lll}\text { Chapter } 5 & \text { Summary } & 109\end{array}$

Samenvatting (Summary in Dutch) 113

$\begin{array}{ll}\text { References } & 119\end{array}$

$\begin{array}{ll}\text { Acknowledgements } & 125\end{array}$

$\begin{array}{ll}\text { Curriculum Vitae } & 128\end{array}$ 



\section{Chapter 1 \\ Introduction}

In March 2011, about 1,000 Dutch individuals closed their current account at ING Bank and switched to ASN Bank and Triodos Bank, which are two socially responsible banks (De Ondernemer, 2011). In that same month, at ASN Bank and Triodos Bank, the amount of newly opened current accounts doubled and tripled respectively. A likely reason was that ING Bank kept on paying large bonuses to its board of management, while it received a capital injection of 10 billion euro from the Dutch government in October 2008. So, tax payers were indirectly financing the bonuses. The clients who switched their current account to a socially responsible bank perceived the bonus payments at ING Bank as unethical. One might argue that 1,000 clients are in fact not that many. However, the switchers gave a very clear signal by voting with their feet, which sparked the interest of newspapers and other media. As a result of the bad publicity, the members of the board of management paid back their bonus. This example illustrates that it is important for banks to act in accordance with the preferences of their clients. In this example there is a mismatch between the social preferences of clients and the social values at ING Bank. The switching clients probably found a better match between their individual social values and the values that underlie the business at ASN Bank and Triodos Bank.

This example is a rather extreme illustration of the way social preferences influence financial decisions. However, in this dissertation I show that social preferences more generally affect financial decisions and investor loyalty. I demonstrate that most individual investors behave pro-socially even if this behavior is personally costly. These social preferences strongly influence investor loyalty and bank revenue. In classical portfolio choice models, social preferences do not influence investment decisions. Moreover, in recent years, part of society perceived investors as self-interested individuals. Kaustia and Torstila (2011) write: "the stock market, or its near synonym Wall Street, has a rather questionable image among part of the public. Negative associations with greed, speculation, or even amoral behavior have been common place for decades." Kaustia and Torstila find that many individuals perceive a mismatch between their own values and those of the stock market and therefore decide not to invest. This suggests that some socially minded individuals stay out of the stock market and 
that stock market investors are therefore primarily selfish types. Yet, my results show that this does not imply that only selfish types invest.

Why do social preferences influence investment decisions? In daily life, social preferences have an important influence on choices such as whether to help friends or strangers, how much to donate to charity and whether or not to do voluntary work. Social preferences also seem to have played an important role in human evolution. For instance, altruistic societies had a better chance to survive than do egoistic societies (Henrich et al., 2001). Previous research in finance also shows a relation between social preferences and investment decisions. For example, Hong and Kostovetsky (2011) find that even professional investors are influenced by social preferences when they select stocks. Mutual fund managers who donate to the Republican Party select more stocks from "sin" industries - weapons, alcohol, tobacco and gambling - than do managers who donate to the Democratic Party.

I will address the following research questions dealing with social preferences: do investors behave purely selfishly, or do most investors behave prosocially? Do investors buy socially responsible mutual funds because of strategic (financial) reasons, or because of intrinsic (non-strategic) pro-social motivations? Is pro-social behavior context specific, or do intrinsic socially responsible investors also, for instance, donate more to charity and do more voluntary work? What is the impact of social preferences on the relationship of an investor with a mainstream broker and with socially responsible banks?

I analyze pro-social behavior in different contexts, with a particular focus on socially responsible investments. In contrast to classical portfolio models, mutual funds can be seen as consumer goods. People with strong social preferences can buy many different types of consumer goods that are perceived as socially responsible, like fair trade coffee, organic food and green cars. Similarly, individuals have the choice to invest in socially responsible (SRI) mutual funds. These are investment products that comprise a basket of stocks that fund managers select not only on the basis of financial indicators, but also on criteria such as good human rights and environmental policies. In recent years, socially responsible investing has been growing rapidly, both in Europe (EUROSIF, 2010) and in the United States (SIF, 2010). In the Netherlands, one in every six investors owns a SRI mutual fund (Millward Brown, 2011). In addition to the two Dutch socially responsible banks, many mainstream providers of mutual funds included SRI funds in their menu.

The second main topic of this dissertation is risk preferences, which also play an important role in the choices of daily life. For example, it is obvious that risk preferences influence the demand for insurance and casino gambling. It is less obvious that risk preferences influence the sales of theater tickets, but someone who buys a ticket for a theatre play takes the risk that she will actually dislike the performance. Risk preferences are in particular a major driver of investment decisions and they are a fundamental parameter in classical portfo- 
lio choice models. It is a solid finding that there is substantial heterogeneity in the level of risk aversion among individuals (e.g. Barsky et al. (1997), Holt and Laury (2002), Dohmen et al. (2011)). This heterogeneity can have consequences for the way different individuals make investment decisions. Examples of questions concerning risk preferences that I will answer are: how do risk preferences influence the relationship between individual investors and mutual fund brokers? Do risk preferences impact the frequency with which individuals trade mutual funds? Do men trade more in mutual funds than do women, after controlling for differences in risk preferences? Given that investors are generally experienced with financial risk taking, are they still risk averse in small stakes lotteries, like they are in the study of Holt and Laury (2002)?

This dissertation consists of three empirical chapters. The first two are based on data from a large Dutch mainstream mutual fund broker that offers both conventional mutual funds and SRI mutual funds. The third empirical chapter is based on data from two socially responsible banks in the Netherlands. Chapter 2 mainly focuses on the way risk preferences influence the relationship between individual investors and mutual fund brokers. Chapter 3 shows that intrinsic socially responsible investors behave more consistently pro-social among different domains than strategic SR investors and conventional investors do. Chapter 4 provides evidence that individual investors with strong social preferences are more loyal and generate substantially more revenue for socially responsible banks than investors with weaker social preferences do. Chapter 5 gives a summary of this dissertation. The remainder of this introduction is not structured by chapter, but rather by the two main topics of this dissertation. I will first discuss risk preferences and then social preferences.

\section{Risk preferences and investment decisions}

In the second chapter of this dissertation, I investigate how risk preferences influence the relationship between individual investors and mutual fund brokers. I use individual investor trading data from a large mainstream mutual fund broker (Robeco) in the Netherlands that cover more than 45,000 investors from January 1992 to June 2010. These individuals buy funds directly on-line without the interference of an intermediary. Robeco is primarily a mutual fund family and offers a menu that comprises more than 100 different in-house mutual funds. To determine the risk preferences of an investor, I make use of a Dutch law introduced in 2003 that requires brokers to ask each investor to fill out a risk profile questionnaire upon the opening of an investment account.

I estimate the monthly probability that an investor leaves the mutual fund broker. I find that highly risk averse and highly risk tolerant investors close their brokerage account early. This effect holds after controlling for possible confounds such as portfolio returns, gender, age, wealth and trading frequency. 
This evidence suggests that several groups of investors mismatch their portfolio risk to their risk preferences and leave because they are not satisfied. The finding is surprising, because the broker offers many different products that range from risk-free products (that guarantee $100 \%$ of the invested money) to high risk equity funds (e.g. emerging markets funds). Investors therefore have the possibility to find products with the right level of risk to match their individual preferences. A second reason why it is surprising is that the broker website gives explicit advice on portfolio risk and portfolio composition.

There can be several reasons why investors mismatch their level of portfolio risk to their individual risk preferences. I cannot explicitly distinguish between these reasons, but the finance literature provides several possibilities. First, overconfidence could induce investors to take excessive risk (Odean, 1998). Second, investors might not understand how to map their risk preferences into portfolio choices. Third, Hong, Kubik and Stein (2004) show that social interaction has a large impact on stock market participation. Similarly, social pressure can induce investors to take suboptimal portfolio risks that do not match their own risk preferences well, but that are closer to the risks taken by peers.

I also find that risk tolerance is positively related to the frequency with which individuals trade mutual funds. This is an important finding, because individual investors increasingly hold mutual funds (French, 2008), but most research on individual investor behavior focuses on common stock trading at discount brokers. My evidence corroborates previous research that shows a positive correlation between risk tolerance and trading in common stocks (Dorn and Huberman, 2005). I further document that men trade substantially more in mutual funds than do women, even after controlling for risk preferences. This is also in line with individual investor trading in common stocks (Barber and Odean, 2001). Overall, I am the first to show that investor characteristics impact the trading frequency in mutual funds in a similar way as they impact trading in common stocks.

\section{Social preferences and socially responsible investments}

The previous section documents that risk preferences have an important influence on the relationship of individual investors with their broker and this section shows that the same holds for social preferences. Chapter 4 concludes that investors with strong social preferences are more loyal to a socially responsible bank than investors with weaker social preferences are. This relates back to the example of ING Bank in the beginning of this chapter. Many investors walked away because of a mismatch between their social values and the values at ING Bank. They switched to one of the two socially responsible banks. The study in Chapter 4 is based on an experiment and a survey that I did with investors from both the ASN Bank and Triodos Bank. The stronger the social preferences of an 
investor, the longer she stays at the bank, the less investment accounts she holds at competing banks and the larger is the portfolio held at the socially responsible bank.

Chapter 4 also shows that investors with strong social preferences generate substantially more revenue for the socially responsible bank. However, social preferences have a negative impact on the length of the investor-broker relationship for the mainstream mutual fund broker, as is shown in Chapter 2. At the mainstream mutual fund broker, socially responsible investors are substantially more likely to close their brokerage account than conventional investors are. I explain this large difference in the effect of social preferences on investor loyalty in Chapter 2 and 4.

In Chapter 3, I conduct artefactual field experiments with a large subset of the investors in the trading database of the mainstream mutual fund broker (Robeco). An artefactual field experiment is a laboratory experiment that is conducted in a field setting with the relevant population (investors), instead of conducting it with students (Harrison and List, 2004). By linking the experiments to a survey and to the investor trading database, they allow me to get a deeper understanding of the different motivations of investors to buy SRI mutual funds. The trading data allow me to observe whether an investor holds a socially responsible mutual fund in her portfolio. This rules out potential problems of a bias due to self-reported social behavior in the investment domain. Individual investors in the field experiments participated via an internet survey that I conducted in spring 2011. Subjects were paid by bank transfer according to the decisions they made in the experiments. This increases the likelihood that participants take their decisions seriously and provides investors with real monetary incentives.

Each subject participated in an experiment to elicit her social preferences. This experiment was randomly determined to be either a trust game or a public goods game. The anonymity and one-shot nature rules out reputation effects by design. That is, investors cannot strategically benefit from behaving pro-socially in the first rounds as to increase the likelihood that investors will behave cooperative in later rounds. Neither can investors make a good impression on others by signaling that they are a social type, because their identity is not revealed.

Chapter 3 shows that about $90 \%$ of the second-movers in the trust game send back a positive amount to the first mover. Hence, most investors do not behave purely selfishly, but rather behave intrinsically pro-socially. A large group equally divides the money on the table, so that both investors end up with 100 euro. In fact, the level of intrinsic pro-social behavior that I identify among individual investors is similar and sometimes even slightly higher than that found in other subject pools (Glaeser et al. (2000), Fehr and List (2004), Falk and Zehnder (2007)). This is interesting, because investors can be experienced as financial decision makers that arguably behave more like homo economicus. In addition, many investors deal a lot with money and there is evidence that 
reminders of money reduce people's helpfulness to others. Vohs, Mead and Goode (2006) conduct nine experiments in which the treatment group is reminded of money and the control group is not. The participants in the treatment group behave significantly less pro-socially than the people in the control group behave.

An important question in economics and social psychology is whether people behave consistently pro-socially across different domains (Batson et al. (1978), Cialdini et al. (1997), Benz and Meier (2008), Falk and Zimmerman (2010), Cesarini et al. (2011), Gneezy et al. (2012)). Overall, the literature suggests that pro-social behavior is partly stable across domains. However, it is still not clear under what conditions pro-social behavior is more or less consistent. Previous studies find some factors that determine the degree of consistency in pro-social behavior. For example, Cesarini et al. (2011) show that social preferences are partly genetically determined. Therefore, individuals might behave consistently pro-socially, because of their genes. Gneezy et al. (2012) argue that consistency in pro-social behavior is determined by the initial costs of this behavior. If the costs of behaving pro-socially are initially high, then the selfperception of individuals changes so that they feel a desire to behave consistently pro-social in the future. If the initial costs of pro-social behavior are low, people do not feel the need to behave consistently pro-socially.

Chapter 3 argues that consistency in pro-social behavior is driven by the strategic benefits offered by different domains of pro-social behavior. If signaling and reputation building are equally difficult in two domains, then I expect behavior to be more consistent among these domains than if one domain clearly offers more signaling benefits than the other does. For instance, I expect a relatively high correlation between anonymous donations to charity via internet and anonymous on-line purchases of socially responsible mutual funds. However, I expect a lower correlation between the donations to charity (few signaling benefits) and voluntary work (many signaling benefits).

To test this hypothesis, I distinguish between strategic (financially motivated) and intrinsic socially responsible investors. I ask socially responsible investors what the most important reason is that they hold a SRI mutual fund. Strategic reasons include tax benefits, a higher expected return on SRI funds than on conventional funds and risk diversification. Intrinsic reasons include improving social welfare and improving the environment. I document that intrinsic socially responsible investors are also more likely to do voluntary work, to be registered as an organ donor and donate more to charity. However, the degree to which they behave pro-socially differs substantial between the different domains. Intrinsic socially responsible investors donate $68 \%$ more money to charity than do conventional investors, but intrinsic socially responsible investors only are $21 \%$ more likely to do voluntary work. This is consistent with my hypothesis, because donations to charity give fewer opportunities for signaling and reputation building than voluntary work does. 
One might be worried about the use of survey data on the self-reported prosocial behavior in some of the domains I report on. However, the fact that I use a survey to distinguish between strategic and intrinsic reasons to invest socially responsible means that I potentially underestimate the correlation with behavior in the trust game, because investors might answer in a socially desirable way. My estimates are therefore conservative. Moreover, I show that investors who indicate an intrinsic reason to invest socially responsible also behave more pro-socially as a second-mover in an incentivized trust game in which they can earn up to 200 euro. In contrast, strategic socially responsible investors are significantly less pro-social in the trust game.

The findings also give suggestions for interpreting conflicting evidence in studies that compare artefactual field experiments to field behavior (Levitt and List (2007), Falk and Heckman (2009)). My results show that intrinsic pro-social behavior in the trust game is positively related to intrinsic pro-social behavior in the field. However, there is less reason to expect that intrinsic pro-social behavior in experiments should be related to strategic pro-social behavior in the field.

\section{How can you as an individual benefit from this dissertation?}

This dissertation shows that a majority of individuals behave intrinsically prosocially in an incentivized trust game experiment that is fully anonymous. So, society is not that bad after all. Yet, in spite of the prevalence of social values among most investors, only one out of six Dutch investors holds a socially responsible mutual fund (Millward Brown, 2011). What could be the reason for this? One reason could be that subjects are 'forced' to make a choice in the experiment, but not making a decision in the field often implies not behaving prosocially. For instance, if you are already a client at a regular bank for many years and you take no action, the default option is that you will not become a socially responsible investor. Is this the optimal decision for you? Beshears et al. (2008) show that people not always reveal their normative preferences. This holds in particular if decisions are complex and if inertia is involved, which is the case for investments.

Are you just too lazy to change your bank account? My cousin generously admitted that he is. He also told me that he definitely would share the money at stake in the trust game experiment, but he is not registered as an organ donor, does not do voluntary work and almost never donates to charity. I was triggered by this seemingly inconsistent pro-social behavior and asked him for the reason. "Because I am generally too lazy, but you force me to choose in the experiment."

I find that strategic types behave less consistently among different domains than do intrinsic types. It is interesting for future research whether this is actually an optimal choice. Perhaps, strategic types could increase their signaling 
benefits further by behaving pro-socially in several domains. After all, the probability increases that this person is perceived as truly pro-social. For instance, a person who does voluntary work strategically might benefit by registering herself as an organ donor and tell this at cocktail parties. She might also decide to buy a green car to further strengthen the identity as a socially responsible person.

In contrast, it could also be that intrinsic pro-social types are behaving 'too' consistently. Someone who donates a lot to charity might feel morally obliged to also behave pro-socially in another domain, because her self-perception has changed (Benabou and Tirole, 2011). Intrinsic pro-social types can ask themselves the question: where does my preference to donate, do voluntary work and buy green products come from? Do I really want to do all, or am I caught in the consistency trap? Marketers often abuse the desire of people to behave consistently. Some time ago, I walked through the city of Maastricht and I was stopped by a young lady from the World Wildlife Fund. She asked me whether I like animals. At this point, I figured out what her goal was. Most people tend to answer this question with "yes". After all, why would you say "no" to the charming lady of the WWF? Yet, that is exactly what the marketers want. If you answer "yes", the young lady has a foot-in-the-door and can now exploit your desire to appear consistently. Her next sentence is: "Sir, that is so nice to hear. I am sure you want to make a small donation to the WWF." Caught in the consistency trap, many people will say yes again, take their wallet and make a donation.

I have shown that the results on risk preferences suggest that several groups of investors mismatch their portfolio risk to their risk preferences. As an individual you can ask yourself the question whether you understand investment products well enough to select the right ones that match your personal preferences. If the answer is no, then relying on independent, professional advice could be helpful. Peers could also provide investment advice, but they might recommend products based on their own risk preferences. Independent professionals are often better able to provide advice based on your preferences by asking explicitly about investment goals, the investment horizon and by carefully eliciting your risk preferences. In fact, the mainstream broker in this study offers free on-line advice to individuals. You might sometimes be tempted to ignore this advice, but might regret later that you took more risk than you preferences suggest. Predominantly risk averse investors hold a higher fraction of equity funds in their portfolio than what is recommended to them. So, if you are risk averse, it is particularly important to stick to a defensive investment strategy. Peers will often tell stories about the great returns they made in the stock market, which might trigger you to take risk yourself. However, they might be less inclined to talk about their huge investment losses. 


\section{Implications for banks and other financial institutions}

Chapter 4 shows that investors with strong social preferences are loyal and generate more bank revenue. Moreover, Chapter 3 documents that social preferences are widespread among both socially responsible and conventional investors. Therefore, there are opportunities for banks and mutual fund brokers to create business with socially responsible investments. However, banks and mutual fund brokers should carefully consider the decision to offer SRI funds. Chapter 2 documents that socially responsible investors at a mainstream broker are more likely to close their brokerage account than conventional investors are. Perhaps it is not the optimal strategy for brokers to just add a couple of SRI funds to their menu, but it would be better if the whole organization embraces the topic of corporate social responsibility. Brokers should therefore ask themselves the question whether they want to offer SRI funds at all. If they decide that they do, then they should think about how to implement it, so that investors can identify with the company and remain loyal. Maybe they are best off by creating a specific socially responsible subsidiary instead of integrating socially responsible investing into the main organization. In fact, this already happens in practice. For instance, the socially responsible ASN Bank is a subsidiary of the SNS Real group, which is a broadly diversified mainstream financial service provider.

During the relationship with clients, banks can monitor the extent to which social preferences of their clients match their products. For example, banks can conduct surveys to measure how individuals perceive their SRI funds. The ASN Bank and Triodos Bank also regularly inform their clients how their banking improves social welfare by giving concrete examples on-line and via their magazine.

Most investors behave pro-socially in one way or the other, but Chapter 4 also shows that even within the clientele of socially responsible banks, there is substantial heterogeneity in social preferences. Moreover, Chapter 3 documents that there are intrinsic pro-social types and strategic pro-social types. Banks can use this information in their product development and marketing. For a long time, the two socially responsible banks of this study focused their advertisements almost solely on the social side of their business, but not on the returns of their products or on tax benefits. They use quotes like: "Make your money make a difference" and "For the world of tomorrow". However, strategic types might be more convinced by a quote such as "Same return, change the world" or "Financial returns today for a social world of tomorrow." Banks can also give strategic types the opportunity to signal pro-sociality to others. They can organize events for socially responsible investors in which they can bring friends. Another example is that ASN Bank issues debit and credit cards that display a large whale. 
My findings are relevant for mutual funds. However, they also have implications for other financial institutions. Most invested money in the Netherlands and other countries is managed by pension funds. In the Netherlands, most people are obliged to save for their pension and they have no choice regarding the pension fund or the investments of the pension fund. Pension funds typically report vaguely about social responsibility. The question is whether pension funds should be more explicit on their social responsibility given that social preferences are important for many investors.

Chapter 2 finds evidence that several groups of investors mismatch their portfolio risk to their individual preferences. Mutual fund brokers could set defaults that vary per risk profile. Risk tolerant investors get a default with a high equity component and risk averse investors get a default with a large wealth invested in bond funds. There is solid evidence that defaults are effective in influencing people's choice, but they still give complete freedom to individuals. By default, I recommend you to enjoy the rest of this dissertation. 


\section{Chapter 2 \\ Individuals' Risk Preferences and Mutual Fund Investments ${ }^{1}$}

\section{Introduction}

Most mutual funds are part of a mutual fund family in which many strategic decisions are taken at the fund family level ${ }^{2}$. Massa (2003) shows that mutual fund families can benefit from offering a large fund menu to satisfy the preferences of their heterogeneous clientele. It is important for fund families to carefully consider which mutual funds to offer, because aggregate fund-flow studies find that there are often spill-over effects from the fund level to the fund family level (e.g. Nanda, Wang and Zheng (2004)). Investors with heterogeneous preferences choose different funds from the menu and investors can therefore differ in the extent to which they are satisfied with their portfolio. This prompts the question how investor preferences impact the relationship of investors with their mutual fund broker.

Specifically, this chapter investigates the relation between risk preferences and the monthly probability that an investor closes the brokerage account. Risk tolerance is a fundamental parameter in classical portfolio choice models. If investors would sort into portfolios with the right level of risk, then we expect that, all else equal, there is no relation between risk preferences and the probability that an investor closes the brokerage account. However, if several groups of investors systematically mismatch their portfolio risk to their individual preferences, then these investors can become unsatisfied with their mutual fund broker. In that case, we do expect risk preferences to predict the probability that an investor closes the brokerage account.

A reason why investors might mismatch their risk preferences could be that they do not understand which portfolio choices fit to their preferences. Second, investors could be affected by social pressure, which is shown to influence stock market participation (Hong, Kubik and Stein (2004), Brown et al. (2008)). Simi-

\footnotetext{
${ }^{1}$ This chapter is based on Bauer, Rob, Paul Smeets and Leonard Wolk, 2012, Individuals' Risk Preferences and Mutual Fund Investments, working paper.

${ }^{2}$ Massa (2003), Johnson (2004), Nanda, Wang and Zheng (2004), Gaspar, Massa and Matos (2006)
} 
larly, social pressure could induce risk averse investors to take more risk than suggested by their risk preferences and risk tolerant investors to take too little risk. Third, Odean (1998) argues that overconfident investors take more risk than do non-overconfident investors given the same risk preferences.

We use individual-level data from a large mutual fund broker that give detailed insights into the life cycle of investors and their relationship to the broker from January 1992 to June 2010. The broker is primarily a mutual fund family that offers more than 100 different in-house mutual funds and a variety of funds from other families. Their products cover a broad range of investment categories from bond funds to emerging market funds. Investors can therefore match their level of portfolio risk to their risk preferences by choosing the adequate funds from the menu. Investors not only have many funds available to match their risk preferences, but they can also get on-line advice on the level of risk in their portfolio, based on a risk profile questionnaire they filled out. However, the advice is in no way binding and investors are personally responsible for their decisions, without the interference of an intermediary.

We determine risk preferences by making use of the outcome of a mandatory risk preference questionnaire introduced in the Netherlands in 2003. The law stipulates that anyone who opens an investment account has to give information on the level of risk he is willing to take through a questionnaire. The broker uses the information on the risk preferences of investors to give advice on the level of portfolio risk. The risk profiles range from very risk averse (one) to very risk tolerant (six) and we can distinguish between investors who indicate that they want or do not want advice on their portfolio risk. We validate the survey by showing that the risky share (equity to wealth ratio) increases with risk tolerance. Moreover, our data show that men and younger investors are more risk tolerant than older women, which resembles the findings in previous research.

Studying Dutch investors offers several advantages. First, unlike most other countries, the Netherlands has a law that requires banks and brokers to elicit investors' risk preferences by a questionnaire. The fact that every investor completes the risk questionnaire, limits the effect of a potential response bias. Second, the Netherlands does not have capital gains taxes or dividend taxes, but rather has a flat wealth tax $(1.2 \% \text { of wealth })^{3}$. Trading in our data is therefore not driven by tax considerations, which often is the case (e.g. Ivković and Weisbenner (2009)). Third, there are no transaction costs involved in the trading of the funds within the family, because it is a no-load family. Barber, Odean and Zheng (2005) and Ivković and Weisbenner (2009) find that loads have a large impact on individual investor trading in mutual funds. The absence of capi-

\footnotetext{
${ }^{3}$ The fixed wealth tax was introduced in January 2001 . We run our main set of analyses for the sample of investors who joined since January 2003 when the risk profiles became mandatory. In this sample, the flat wealth tax was therefore in place for the entire sample period.
} 
tal gains taxes, dividend taxes and transaction costs implies that we can rule out these motivations as determinants of the probability that an investor closes the brokerage account. For instance, tax considerations could confound the effect of risk preferences on account closure if risk tolerant investors were more aware of tax incentives than risk averse investors were.

Our main finding is that highly risk averse and highly risk tolerant investors close their account early, which holds after introducing controls like portfolio returns, wealth, gender and age. The finding suggests that several groups of investors do not match the level of risk in their portfolio correctly to their risk preferences. This is surprising, because investors have the possibility to choose from a broad fund menu at the broker and can get on-line advise on their level of portfolio risk.

An alternative explanation to the risk mismatching hypothesis is that risk averse investors are affected differently by stock market and bond market developments than risk tolerant investors. For example, in the credit crisis, risk tolerant investors are more heavily exposed to equity than risk averse investors who primarily hold bond funds. Consequently, risk tolerance impacts the portfolio returns of investors during different periods. These portfolio returns can affect the level of satisfaction with the broker and the probability that an investor closes the investment account. However, we find that the effect of risk preferences on survival becomes even stronger after we explicitly control for portfolio returns.

A second alternative explanation for the risk mismatching hypothesis is that the risk profiles pick up the effect of other (unobserved) variables. For example, wealth can be positively correlated to risk tolerance. Even though we cannot fully exclude this possibility, it is not likely that omitted variables drive our results. We use a rich set of control variables that comprises portfolio returns, time-varying wealth, gender, age, purchase intensity, first number of funds bought, first amount transferred to the account, a preference for local funds and social preferences.

The survey that is used by the broker to determine risk profiles comprises eight questions. Some of these questions are direct proxies for risk preferences. Yet, for instance one of the questions addresses the investment horizon of an investor. We do not have data on each of the eight survey questions individually and we can only observe the total risk profile score. We can therefore not perfectly distinguish between risk preferences and time horizon effects. However, the fact that men have higher risk profile scores (higher risk tolerance) than women points into the direction that the risk profiles really capture risk preferences and not only investment horizon. There is evidence of a positive correlation between being male and risk tolerance in the literature, but we are not aware of evidence that men have a longer investment horizon. Moreover, we show significant effects both for risk averse and for risk tolerant investors, which cannot be explained by a pure time horizon effect. 
We also show that investors who ever held a local fund are substantially more likely to keep their account, which complements the literature on local bias and home bias ${ }^{4}$. Bailey, Kumar and Ng (2010) document that investors are less likely to sell local mutual funds than other funds. We show that holding a local fund has spill-over effects to the broker level. In addition to the extensive literature on local bias, there is a growing literature on socially responsible investing (Bollen (2007), Hong and Kacperczyk (2009) and Hong and Kostovetsky (2011)). We show that investors who ever held a socially responsible (SRI) mutual fund are substantially more likely to close their account.

The decision to close the brokerage account completely is arguably a big decision for investors. In addition, the data cannot tell us what investors do after they leave the broker. It could be that they stop investing completely, or that they continue investing at another broker. We therefore also study how risk preferences impact the frequency with which individuals trade mutual funds. We find that the more risk tolerant an investor is, the more frequently he readjusts his portfolio. This finding is in line with Dorn and Huberman (2005), who show that there is a relation between risk preferences and trading frequency in common stock. Our evidence also again points into the direction that the risk profiles really capture risk preferences and not only differences in investment horizons. If anything, a shorter horizon should motivate investors to trade more times per year than a longer horizon. However, we find the opposite effect.

We also find that men trade substantially more in mutual funds than do women and this effect holds after controlling for risk preferences and other potential confounds. This evidence shows that gender influences trading in mutual funds in a similar way as it impacts trading in common stocks (Barber and Odean, 2001).

Understanding individual investor trading in mutual funds is important. In recent years, investments in mutual funds have grown to a substantial share of individual investors' portfolios. French (2008) shows that in the U.S. $4.6 \%$ of total stock market wealth was invested in mutual funds in 1980 and this grew to $32.4 \%$ in 2007. In Sweden, investors are more likely to hold mutual funds than to hold common stocks (Calvet, Campbell and Sodini, 2009). In the Netherlands, two third of all investors owns mutual funds and 32\% invested solely in mutual funds in 2011 (Millward Brown, 2011). Even though individuals invest substantial amounts in mutual funds, most research on individual investor behavior focuses on discount broker clients who primarily trade in common stocks.

Previous research shows that the performance of individual mutual funds can have spill-over effects to the fund family level (Nanda, Wang and Zheng, 2004). Our findings imply that spill-over effects from the fund level to the fund family level can also be caused by the matching of investor preferences to mutu-

\footnotetext{
${ }^{4}$ Coval and Moskowitz (1999), Grinblatt and Keloharju (2001), Huberman (2001), Ivković and Weisbenner (2005), Bailey, Kumar and Ng (2010)
} 
al fund portfolios. In particular, risk preferences have a large impact on account closure probabilities.

The remainder of this chapter is organized as follows. Section 2 describes the data and explains how we observe individual risk preferences. Section 3 presents the empirical results and section 4 concludes.

\section{Data and method}

\subsection{Individual investor data}

The data have been provided to us by a large mutual fund broker in the Netherlands and comprise the complete on-line individual investor database January 1992 to June 2010. The broker acts as a mutual fund family that offers more than 100 different in-house mutual funds. In addition, the broker offers a variety of mutual funds from other fund families. The data include investor starting and end dates, demographics, risk profiles, portfolio returns and a complete overview of all buy and sell transactions of funds.

The mutual fund broker serves both institutional and individual investors, but we study individual investors exclusively. Investors can buy a wide range of mutual funds in categories including equity funds, bond funds and balanced funds. Within these broad categories, many different funds are available, like global funds, region-specific funds and sector-specific funds. As the relevant unit of analysis, we focus on the account level. That is, if one account is shared with a spouse, we consider it as one account. For demographic variables like gender and age, we consider the characteristics of the person who opened the account. "Investor" in the remainder of the text means "account". We have data on a wide variety of variables that are defined in Table 1. 
Table 1 - Variable definition

\begin{tabular}{ll}
\hline Variable & Measurement \\
\hline Gender (male) & The investment account is opened by a man \\
Age at the start & $\begin{array}{l}\text { Age of the investor when opening the account. The variable age } \\
\text { in regressions always refers to age at the start }\end{array}$ \\
Wealth (exogenous proxy) & First amount transferred to the investment account in euro \\
First number of funds & $\begin{array}{l}\text { The first number of funds bought by the investor after the } \\
\text { opening of the account }\end{array}$ \\
Purchases per year & $\begin{array}{l}\text { The average number of mutual funds purchased per year } \\
\text { Sales per year }\end{array}$ \\
Preference for local funds & $\begin{array}{l}\text { The investor ever held the Holland fund, which only invests in } \\
\text { companies located in the Netherlands }\end{array}$ \\
Socially responsible investor (SRI) & $\begin{array}{l}\text { The investor ever held a socially responsible mutual fund } \\
\text { The risk preference of the investor measured on a scale from } \\
\text { Risk profile (1-7) }\end{array}$ \\
one to six. An investor with risk profile seven decides not to get \\
advice on the level of risk in his portfolio. See appendix A1 for \\
more details. \\
Euro amount held in equity funds divided by the total wealth \\
Monthly wealth
\end{tabular}

\subsection{Measuring risk preferences}

The Dutch government passed a law that became effective in December 2002 and requires investors to fill out a risk profile when they open an investment account. This gives us the unique possibility to elicit the risk preferences of each investor. The idea behind the law on risk profiles is that brokers should give advice to their investors on the riskiness of the investors' portfolio. The recommendation for risk tolerant investors is to hold a larger share of equity funds and for risk averse investors to hold a larger fraction of bond funds in their portfolio. However, the law leaves complete freedom of choice to investors and they are in no way restricted to follow the advice.

In the risk profile questionnaire, investors first determine whether they would prefer getting advice on the share of equity funds, bond funds and cash in their portfolio. There are two risk profiles that do not get advice. About $2.3 \%$ of the investors who joined since January 2003 choose risk profile one, which corresponds to holding a portfolio that guarantees $100 \%$ of the principal to be repaid and only comprises risk-free assets. Second, $29 \%$ of the investors choose for a portfolio that includes risky assets, but they do not get advice. The remaining $68.2 \%$ of individuals indicate that they do want advice on the level of portfolio risk and proceed with answering eight additional questions. A complete overview of the questions of the risk profile survey is available in the appendix. 
Based on the answers given by investors, they are classified in one out of five risk profiles. Profile two means that investors are very risk averse and profile six that they are very risk tolerant. On the website of the broker, recommendations are given for the percentage of equity in the portfolio given a certain risk profile. This advice is in not binding: investors buy and sell funds fully on their own account, without the interference of financial intermediaries. After the investor bought funds, the website indicates whether the percentage invested in equity matches the individual's risk profile. See Appendix $C$ for an overview of the recommended equity fractions (or allocation) for the different risk profiles. As an example, the recommendation for investors with risk profile two is to invest $10 \%$ in equity funds, for risk profile four to keep $45 \%$ in equity and for risk profile six to invest $90 \%$ in equity funds.

We are aware of the potential pitfalls of using surveys to elicit economic preferences. However, research shows that even a very simple single question about risk preferences can explain field behavior involving risky choices (Barsky et al. (1997), Dorn and Huberman (2010), Dohmen et al. (2011)). Second, we show that risk tolerant investors hold a larger fraction in risky assets than do risk averse investors. Third, we show that women and older investors are more risk averse, which is consistent with previous findings (Barsky et al. (1997), Dorn and Huberman (2005), Croson and Gneezy (2009), Dohmen et al. (2011)).

\subsection{Cox proportional hazard model - modeling the probability to close the investment account}

To estimate the probability that an investor leaves the mutual fund broker, we run a survival analysis. Specifically, we use the single-spell semi-parametric Cox proportional hazard model (Cox, 1975). The dependent variable is the monthly hazard rate, which represents the conditional probability that the investor will leave the broker. The conditioning variables include demographic variables, risk profiles and portfolio returns. The base rate is not directly estimated, but one can interpret the probability of drop out relative to this baseline (dummy variable equals zero) by using a hazard ratio. A hazard ratio larger than one means that the investor is more likely to leave the broker and a hazard rate smaller than one means that the investor is less likely to leave the broker.

We collected individual investor level data from January 1992 to June 2010. We drop all accounts opened before January 1992, because we do not have all relevant data available for the period before. We also delete accounts of investors aged below 18 years, because these accounts are managed by their parents. We focus on investors that made at least one trade and ignore empty accounts. In a large number of analyses, we only include variables that can be measured at account opening and satisfy the strict exogeneity condition of a survival analysis. These variables comprise gender, age, risk profiles, portfolio size as well as the number of funds bought at account opening. In later regressi- 
ons, we also include variables that we observe during the relation of the investor with the broker. These variables comprise the number of fund purchases and sales, whether an investor ever held a local fund or socially responsible fund and portfolio returns.

\section{Empirical findings}

\subsection{Summary statistics}

Table 2 presents the summary statistics of our sample. Panel A shows the statistics for our complete sample from January 1992 to June 2010. Panel B presents the statistics for each of the seven risk profiles separately for investors who joined since January 2003, when the law was effective. Panel C covers investors who joined before January 2003.

Panel A shows that $65.8 \%$ of the accounts is opened by men. Investors are on average 42.6 years old when they open an account. In the first transaction, investors buy on average 1.61 mutual funds and invest 11,113 euro. During their relation with the broker, investors buy on average 1.63 funds per year, $21.4 \%$ ever held the local fund and $12.5 \%$ ever held a socially responsible mutual fund. The local fund is called 'Holland fund' and it is an equity fund that solely comprises Dutch companies. We classify an individual as socially responsible investors if she owns one of the several socially responsible (SRI) mutual funds offered by the broker. The SRI fund managers select companies not only on the basis of financial criteria, but also consider environmental and / or ethical issues. The SRI fund can be broadly focused or for instance targeted specifically at the water sector. Investors stay at the broker for 12.6 years on average (right censored).

Panel B shows the summary statistics sorted by the risk profile of investors who joined since January $2003^{5}$. It shows that $2.4 \%$ of investors chooses for risk profile one, which means that they choose for a low risk portfolio that guarantees $100 \%$ of the principal. In addition, $29 \%$ of the investors chooses risk profile seven, which gives no advice to investors. The other $68.2 \%$ has a risk profile from two to six and receives advice by the broker. A risk profile of two implies that investors are very risk averse and a profile of six that they are very risk tolerant. The data show that there is substantial heterogeneity in risk preferences, which we exploit as a predictor of account closure probabilities.

Panel B also presents the average equity-to-wealth ratio for the seven different risk profiles. We measure the equity ratio as the amount invested in equity

\footnotetext{
${ }^{5}$ We take the cut-off at January 2003, because investors could fill out the questionnaire during the whole month of December 2002.
} 
mutual funds divided by the total wealth held at the broker in June $2010^{6}$. The advice given on the website of the fund broker is based on the same measure for the equity ratio. The panel shows that the equity ratio increases with a positive change in the risk profile. We use unpaired t-tests and find that the equity ratio is statistically different at the $1 \%$ significance level for all risk profile combinations, except for the difference between risk profile one and two.

\section{Table 2 - Risk preferences and summary statistics}

Panel A presents the summary statistics of our overall sample and all variables are defined in Table 1. Panel B and C present the means for these variables per risk profile. Investors can have a risk profile ranging from one to seven. A risk profile of seven means that the investor chooses not to get advice on the level of risk in her portfolio. A risk profile of one means that the investor chooses for a risk free portfolio that guarantees $100 \%$ of the principal. All other investors have a risk profile ranging from two (very risk averse) to six (very risk tolerant). Panel B presents the statistics for investors who joined since January 2003 when the law on risk profiles was effective. Panel C presents the statistics for investors who joined between January 1992 and January 2003.

Panel A: Descriptive statistics overall sample

\begin{tabular}{lccc}
\hline & Mean & S.D. & $\mathrm{N}$ \\
\hline Gender (male) & 0.66 & 0.47 & 45236 \\
Age at the start & 42.60 & 13.83 & 44720 \\
Wealth (1st amount invested) & 11113.43 & 41508.8 & 45239 \\
First number of funds & 1.61 & 1.70 & 45239 \\
Purchases per year & 1.63 & 3.46 & 45239 \\
Preference for local funds & 0.21 & 0.41 & 45239 \\
Socially responsible investor & 0.13 & 0.33 & 45239 \\
Years at broker & 12.59 & 4.87 & 45239 \\
\hline
\end{tabular}

\footnotetext{
${ }^{6}$ Preferably, we know the equity ratio for each month in our data set. However, the existence of balanced funds that have both a bond component and an equity component makes it challenging to get the equity ratio correct. We therefore asked the broker to construct these equity ratios for us for June 2010 by considering the proportion of equity in their balanced funds. Consequently, the equity ratio is available for investors who were in our data in June 2010 and not for investors who left the broker before. Still, the differences in equity ratios between risk profiles strongly point into the direction of a mismatch between risk preferences and portfolio risk.
} 


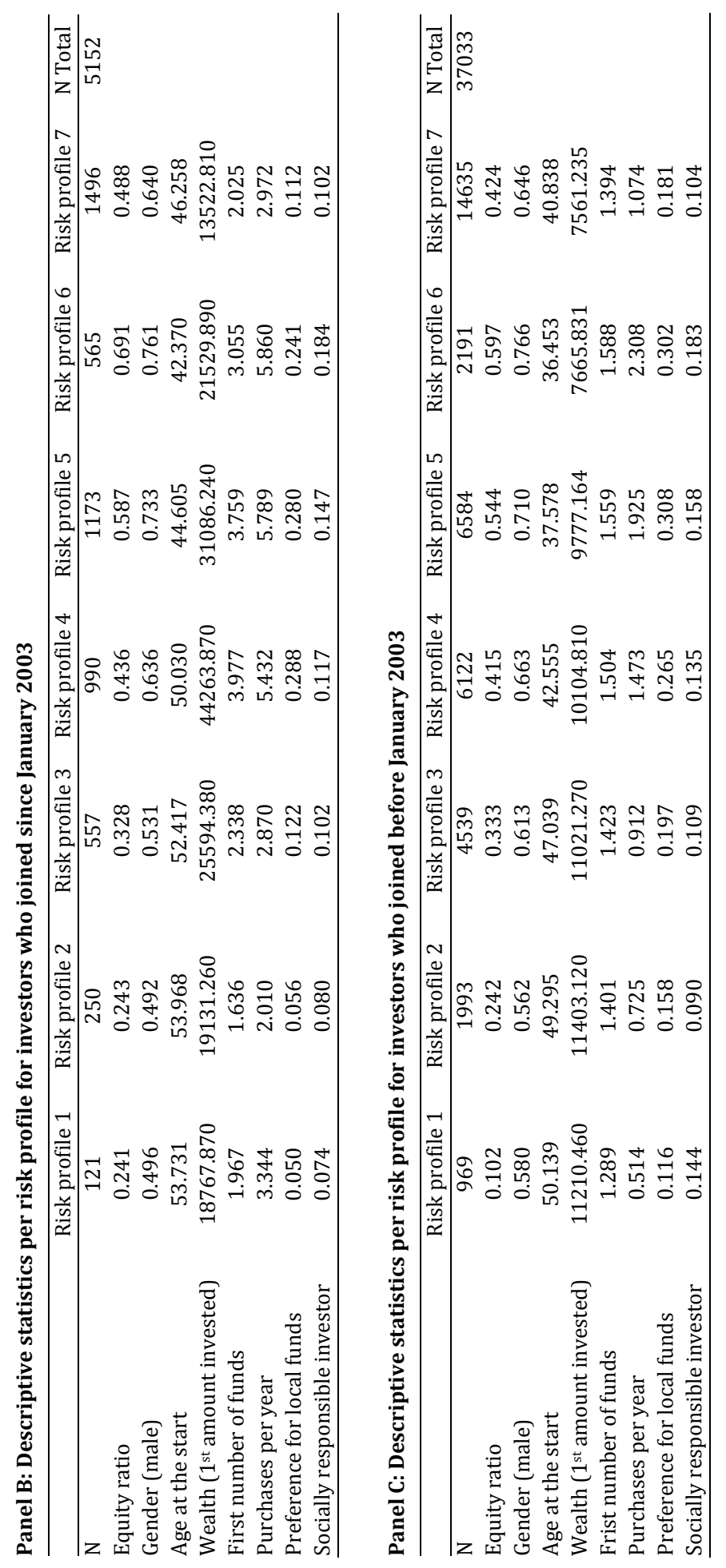


For some risk profiles, the equity ratio is close to the advice given on the website, but for some risk profiles it is far off. The advice of investors with risk profile three is to hold $30 \%$ in equity funds and they actually hold $32.8 \%$. Similarly, investors with risk profile four hold $43.6 \%$ in equity, which is very close to the advice of $45 \%$. However, there is a large mismatch for investors with risk profile one and two. Those with risk profile one on average hold $24.1 \%$ in equity fund, but they should hold $0 \%$ in equity given that they choose for a risk-free portfolio. Investors with risk profile two have an equity ratio of $24.3 \%$, which is substantially higher than the advice of $10 \%$. There is not only a mismatch between portfolio risk and risk preferences for highly risk averse investors, but also for highly risk tolerant investors. For example, investors with risk profile six are advised to hold $90 \%$ in equity funds, but they actually only invest $69.1 \%$ in equities. Investors in the extreme risk profiles therefore tend to choose an equity ratio that deviates from their advice into the direction of the equity ratio of the average investor. It could be that social pressure (Hong, Kubik and Stein, 2004) makes investors to focus on their peers (potentially the average investor) in determining their level of portfolio risk.

The data also show that women are more risk averse than are men, which is consistent with Barsky et al. (1997), Dorn and Huberman (2005), Croson and Gneezy (2009) and Dohmen et al. (2011). Risk tolerance decreases with age, which is also consistent with previous evidence (Dorn and Huberman (2005), Dohmen et al. (2011)). We generally document a positive relation between wealth and risk tolerance. Yet, investors with a very low wealth are disproportionately more likely to have a high risk tolerance level (corresponding to more than $70 \%$ in equity funds). Interestingly, investors who do not want advise on their portfolio risk (risk profile seven) have the lowest wealth. Campbell (2006) argues that low wealth investors are often unsophisticated and one would expect these investors to seek advice on the level of portfolio risk.

Investors with a preference for the local fund (Holland fund) tend to be more risk tolerant than investors without this preference. We analyze risk preferences and a preference for local funds jointly in the upcoming analyses. The data also show a positive relation between risk tolerance and the number of funds bought on the first transaction. Similarly, the average yearly number of fund purchases increases with risk tolerance. This shows that risk tolerant investors trade more than risk averse investors, which is consistent with common stock trading (Dorn and Huberman, 2005). We explore this relation in a multivariate setting in section 3.4.

Panel C of Table 2 shows the summary statistics per risk profile for investors who joined before January 2003 and already have investment experience when completing the risk profile questionnaire. Consistent with panel $B$, the equity ratio increases with risk tolerance. Results for gender and age are also consistent with those for investors who joined since January 2003. 


\subsection{Risk preferences and closure of the brokerage account}

In this section, we investigate the link between risk preferences and the decision to exit the mutual fund broker. We run a single-spell Cox proportional hazard model with robust standard errors. The dependent variable is the monthly probability that an investor closes the account at the broker. We use six dummies for the different risk profiles to allow for a non-linear effect of risk preferences on the exit probability. The baseline is the group of investors who choose not to get advice on the level of risk in their portfolio (risk profile seven).

The first two specifications of Table 3 provide results for investors who joined since January 2003, when the law on risk profiles was effective. We find that risk averse investors are more likely to exit. Investors in risk profile one are even $103.4 \%$ more likely to leave than are investors who do not get advice on the level of risk in their portfolio. Investors with risk profile one have a $59.2 \%$ higher probability to exit than have the most risk tolerant investors classified in risk profile six $\{[(2.0341-1.2781) / 1.2781]$ x $100 \%\}$. Also risk averse investors in risk profile two are significantly more likely to exit, but this effect is insignificant when introducing control variables in the second specification.

\section{Table 3 - Risk preferences and the decision to leave the broker}

This table presents estimates from a single-spell Cox proportional hazard model. The dependent variable is the monthly probability that an investor closes the account at the mutual fund broker. All independent variables are defined in Table 1. We include six dummies for different risk profiles and risk profile seven is the baseline that corresponds to investors who choose not to get advice on the level of risk in their portfolio. We clustered standard errors at the individual level, which are in parentheses. Specification one and two are for investors who joined the broker since January 2003 when the law on risk profiles was effective and specification three and four are for investors who joined before January 2003.

\begin{tabular}{lcccc}
\hline & Since Jan 2003 & Since Jan 2003 & Before Jan 2003 & Before Jan 2003 \\
& 1 & 2 & 3 & 4 \\
\hline Risk profile 1 & $2.034^{* * *}$ & $1.635^{* *}$ & $2.076^{* * *}$ & $2.080^{* * *}$ \\
& $(0.389)$ & $(0.361)$ & $(0.076)$ & $(0.087)$ \\
Risk profile 2 & $1.397^{*}$ & 1.319 & $1.307^{* * *}$ & $1.214^{* * *}$ \\
& $(0.242)$ & $(0.262)$ & $(0.059)$ & $(0.061)$ \\
Risk profile 3 & 0.917 & 0.770 & $1.273^{* * *}$ & $1.177^{* * *}$ \\
& $(0.185)$ & $(0.157)$ & $(0.047)$ & $(0.046)$ \\
Risk profile 4 & 1.123 & 0.991 & $0.849^{* * *}$ & $0.816^{* * *}$ \\
& $(0.163)$ & $(0.144)$ & $(0.037)$ & $(0.036)$ \\
Risk profile 5 & 1.217 & 0.960 & 1.045 & 0.991 \\
& $(0.166)$ & $(0.136)$ & $(0.041)$ & $(0.042)$ \\
Risk profile 6 & 1.278 & 1.058 & 1.079 & 1.035 \\
Gender (male) & $(0.223)$ & $(0.198)$ & $(0.068)$ & $(0.067)$ \\
& - & $1.241^{* *}$ & - & 0.984 \\
Age 18-30 & & $(0.136)$ & & $(0.027)$ \\
& - & 0.868 & - & $0.769^{* * *}$ \\
& & $(0.180)$ & & $(0.036)$
\end{tabular}




\begin{tabular}{|c|c|c|c|c|}
\hline & Since Jan 2003 & Since Jan 2003 & Before Jan 2003 & Before Jan 2003 \\
\hline & 1 & 2 & 3 & 4 \\
\hline Age $31-50$ & - & $\begin{array}{c}0.793 \\
(0.124)\end{array}$ & - & $\begin{array}{l}0.683^{* * *} \\
(0.026)\end{array}$ \\
\hline Age 51-65 & - & $\begin{array}{c}0.861 \\
(0.132)\end{array}$ & - & $\begin{array}{l}0.882^{* * *} \\
(0.035)\end{array}$ \\
\hline Wealth Q2 & - & $\begin{array}{c}1.045 \\
(0.185)\end{array}$ & - & $\begin{array}{c}0.985 \\
(0.041)\end{array}$ \\
\hline Wealth Q3 & - & $\begin{array}{c}1.338 \\
(0.252)\end{array}$ & - & $\begin{array}{l}0.852^{* * *} \\
(0.036)\end{array}$ \\
\hline Wealth Q4 & - & $\begin{array}{l}1.306 \\
(0.220)\end{array}$ & - & $\begin{array}{l}0.825^{* * *} \\
(0.034)\end{array}$ \\
\hline Wealth Q5 & - & $\begin{array}{c}1.259 \\
(0.189)\end{array}$ & - & $\begin{array}{l}0.885^{* * *} \\
(0.039)\end{array}$ \\
\hline $\begin{array}{l}\text { Preference for local } \\
\text { funds }\end{array}$ & - & $\begin{array}{l}0.220^{* * * *} \\
(0.065)\end{array}$ & - & $\begin{array}{l}0.678^{* * *} \\
(0.026)\end{array}$ \\
\hline $\begin{array}{l}\text { Socially responsible } \\
\text { investor }\end{array}$ & - & $\begin{array}{l}2.071^{\text {**** }} \\
(0.232)\end{array}$ & - & $\begin{array}{l}1.753^{* * *} \\
(0.057)\end{array}$ \\
\hline Purchase Q2 & - & $\begin{array}{l}1.969^{* *} \\
(0.545)\end{array}$ & - & $\begin{array}{l}1.340^{* * *} \\
(0.047)\end{array}$ \\
\hline Purchase Q3 & - & $\begin{array}{l}3.605^{* * * *} \\
(0.899)\end{array}$ & - & $\begin{array}{l}1.340^{* * *} \\
(0.052)\end{array}$ \\
\hline Purchase Q4 & - & $\begin{array}{l}4.371^{* * *} \\
(1.065)\end{array}$ & - & $\begin{array}{l}1.365^{* * *} \\
(0.061)\end{array}$ \\
\hline Purchase Q5 & - & $\begin{array}{l}4.694^{* * * *} \\
(1.114)\end{array}$ & - & $\begin{array}{l}1.422^{* * *} \\
(0.078)\end{array}$ \\
\hline $\begin{array}{l}\text { First number of } \\
\text { purchases }\end{array}$ & - & $\begin{array}{c}1.018 \\
(0.017)\end{array}$ & - & $\begin{array}{l}1.079^{* * *} \\
(0.013)\end{array}$ \\
\hline $\mathrm{N}$ & 5152 & 5151 & 37087 & 37085 \\
\hline
\end{tabular}

${ }^{* * *} 1 \%$ significance, ${ }^{* *} 5 \%$ significance, ${ }^{*} 10 \%$ significance

Specification (3) and (4) present the Cox proportional hazard estimates for investors who joined before January 20037. We again find that risk averse investors are more likely to exit the broker. In fact, the effect of risk preferences is even larger for investors who joined before January 2003 than it is for investors who joined since 2003. Specification (4) shows that after introducing control variables, risk averse investors with risk profile one, two and three are significantly more likely to close their account. The economic effects are $108 \%, 21.3 \%$

\footnotetext{
${ }^{7}$ Essentially, the survival analysis for investors who joined before 2003 only covers the period January 2003 to June 2010 and does not include the years before. The reason is that we can only include investors who joined before January 2003 that still had their brokerage account in January 2003, when the law on risk profiles became effective. This means that the estimates are potentially biased, because investors who left before January 2003 are not part of the estimation. However, we do want to show this analysis, because it gives insights into the effect of risk preferences on account closure for individuals who filled out the risk profile questionnaire when they already had investment experience.
} 
and $17.7 \%$ respectively per month. Investors with an intermediate level of risk tolerance (risk profile four) are significantly less likely to close their account.

The results on risk preferences suggest that several groups of investors do not adequately match the level of portfolio risk to their risk preferences. If all investors would perfectly match the level of portfolio risk to their individual preferences, then we do not expect an effect of risk preferences on the decision to leave the mutual fund broker. However, we find that risk preferences systematically predict the probability that an investor closes the account. This systematic effect of risk preferences could be due to the persistence in trading patterns. For instance, Dorn and Huberman (2010) find that investors tend to trade common stocks with a similar risk style instead of adjusting the risk level of the stocks they trade.

There are several reasons why investors might mismatch their portfolio risk to risk preferences. First, they might not understand how to map their preferences into portfolio choices. Beshears et al. (2008) show that complexity and limited personal experience are reasons why normative preferences and revealed preferences can differ substantially. Investment decisions are relatively complex and many individuals have only limited experience with matching their investments to risk preferences. Second, investors could hold a different fraction in risky assets than suggested by their risk preferences because of social pressure. For instance, Hong, Kubik and Stein (2004) and Brown et al. (2008) show that social interaction influences stock market participation. Social pressure could therefore result in investors (temporarily) holding more or less equity than their risk preferences suggest.

Third, overconfidence might explain why investors select a suboptimal portfolio risk level. Odean (1998) develops a theoretical model and shows that overconfident investors take more risk than non-overconfident investors for the same level of risk aversion. Risk averse individuals could end up with a too risky portfolio because of their overconfidence. If overconfidence would drive our results, we expect that mainly risk seeking investors would take excessive risk. For instance, Grinblatt and Keloharju (2009) find that sensation seeking investors are most overconfident in their common stock trading. However, we do not find support that overconfidence drives our results. First, Panel B and C of Table 2 show that risk tolerant investors take less instead of more risk than what is adviced to them based on their risk profile. Actually, risk averse investors take excessive risk: investors with risk profile one are advised to only hold fixed income, but in fact they hold $24 \%$ in equity funds. Risk averse investors with risk profile two are advised to hold $10 \%$ in equity, but also hold $24 \%$. Second, our results show that particularly these risk averse investors who took excessive risk are more likely to exit and not the risk tolerant (overconfident) investors as one would expect.

Next to risk preferences, we also investigate the effect of a preference for a local fund on investor survival. Figure 1 presents Kaplan-Meier graphs (Wool- 
ridge, 2002) for the survival of investors with and without a preference for local funds for January 1992 to June 2010. The graph shows that investors with a local preference are more likely to stay at the broker than are investors who never held the local fund.

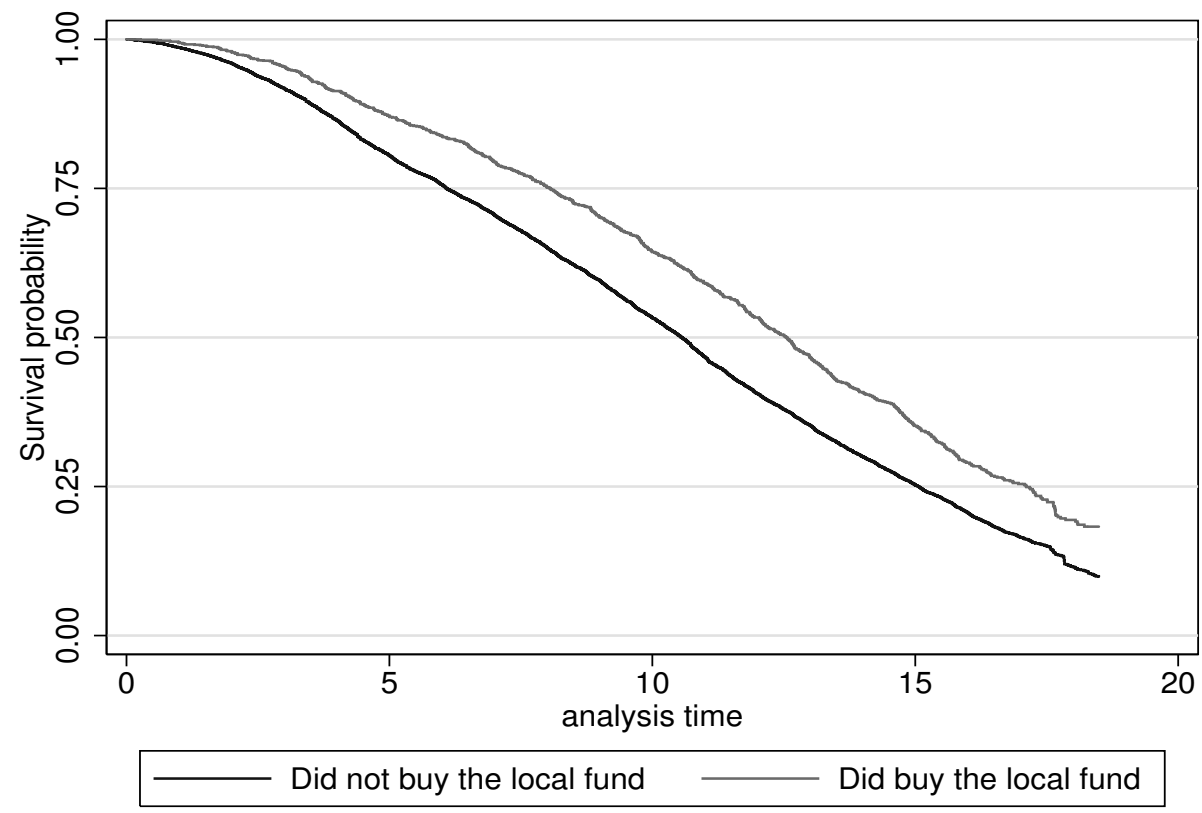

Figure 1 - Exit probabilities for investors with a preference for local funds and for investors without this preference

This figure presents Kaplan-Meier survival functions for investors who joined the mutual fund broker between January 1992 and June 2010. The red line corresponds to investors who ever held the local fund and the black line to investors who never held the local fund. Investors with a preference for local funds stay significantly longer at the broker than investors without this preference.

In specification two and four of Table 3, we use a multivariate test for the effect of a preference for a local fund on the probability to close the account. We use a dummy that has a value of one if the investor ever held a local fund at the broker. We find that investors with a preference for a local fund are significantly less likely to exit the broker. This effect holds after controlling for risk preferences, which is important because Table 2 shows that risk preferences and a preference for a local fund are correlated. The economic effect of the local preference is large. Investors with a preference for local funds who joined since 2003 are $78 \%$ more likely to keep their account than investors who do not hold the local fund. For investors who opened the account before 2003, the effect is $32 \%$.

These findings suggest that investors with a preference for a local fund hold a portfolio that matches their local preference well. Hence, they stay longer at 
the broker. It provides evidence that holding a local fund has positive spill-over effects to the fund family level. This complements the study of Bailey, Kumar and Ng (2010) who document that investors with a preference for a local fund hold on to this fund longer than do other investor types.

We also test for the effect of social preferences on the decision to close the account. We create a dummy that has a value of one if the investor ever held a socially responsible mutual fund at the broker. We find that socially responsible investors are significantly more likely to close their account than are conventional investors. The coefficient of 2.071 in the second specification indicates that socially responsible investors who joined since January 2003 are 107\% more likely to close their brokerage account than are conventional investors. This result is surprising, because Bollen (2007) and Bauer and Smeets (2012) find that social preferences have a positive effect on investor loyalty ${ }^{8}$. The difference in the findings is likely the result of the fact that the mutual broker in this study is a mainstream supplier of investment funds with a comprehensive menu that includes a couple of socially responsible (SRI) mutual funds, but also many other investment categories. Perhaps this broad fund menu makes it difficult to cater to specifically to the clientele of socially responsible investors. In the Netherlands, there are also two banks that are specialized in socially responsible investments and only offer in-house SRI mutual funds 9 .

Next, we test whether investors who trade a lot are more likely to exit the broker. A correlation between trading and exit probabilities could arise from investors having different levels of inertia (Agnew, Balduzzi and Sunden (2003), Ameriks and Zeldes (2004)). Those investors who trade a lot might therefore also be more likely to take the step to leave the broker. Alternatively, investors can trade a lot because they want to outperform the benchmark by either market timing or choosing specific sector or country funds. If investors are unable to achieve their expected outperformance, they might decide to exit. We created quintiles based on the purchasing frequency and use the quintile with the lowest purchase frequency as baseline. We find in specification two that investors who trade a lot are more likely to close their account. Investors in the highest purchase quintile are $369.4 \%$ more likely to exit than are investors in the lowest quintile. The coefficients in specification four are also significant and have the same sign, but they are smaller in magnitude.

Table 3 shows that gender does not have a strong effect on the decision to close the account. In the second specification, the coefficient on gender is significant but small and in the fourth specification it is not significant. The absence of a strong gender effect is interesting in light of previous evidence that shows a

\footnotetext{
${ }^{8}$ Loyalty and the closure of the brokerage account are not the same thing. Cohen (2009) defines investor loyalty as having an emotional tie to a company. However, investors can also stay at the mutual fund broker for other reasons than having an emotional tie like disappointing returns.

${ }^{9}$ For more details see Bauer and Smeets (2011) who conduct a study with the clientele of these two banks.
} 
large effect of gender on trading frequency in common stocks (Barber and Odean, 2001). We examine the effect of gender on trading frequency in mutual funds in section 3.4.

\subsection{Portfolio returns and time-varying wealth}

We have shown a robust relation between risk preferences and the decision to exit the broker. However, it is possible that risk preferences are correlated with portfolio returns or with time-varying wealth. In this case, the coefficients on the risk preference dummies might just pick up the effects of portfolio returns or wealth changes.

We explicitly control for portfolio returns, which allows us to test for an alternative explanation to the risk-mismatching hypothesis. It is possible that investors with different risk preferences are exposed to the stock market and bond market to a different extent. Therefore, risk averse investors might be more likely to close their account in a given period, because they are dissatisfied with portfolio returns, but risk tolerant investors are not. We show that the relation between risk preferences and account closure probabilities is robust and even becomes stronger after controlling for portfolio returns. This strengthens the risk mismatching explanation.

Table 4 presents Cox proportional hazard estimates for monthly exit probabilities and with portfolio returns as a control variable. The analyses are for investors who joined since January 2003 when risk profiles were introduced. We cluster standard errors at the individual level. The number of observations increased compared to previous analyses, because we have a panel set-up in this table, instead of a cross-sectional analysis. We lag portfolio returns by one, two and three months. 
Table 4 - Monthly portfolio returns, risk preferences and account closure

This table presents estimates from a single-spell Cox proportional hazard model. The dependent variable is the monthly probability that an investor closes the account at the mutual fund broker. All independent variables are defined in Table 1. We include six dummies for different risk profiles and risk profile seven is the baseline that corresponds to investors who choose not to get advice on the level of risk in their portfolio. We lag the log of the realized monthly portfolio returns by one, two and three months respectively. We clustered standard errors at the individual level, which are in parentheses. All specifications are for investors who joined the broker since January 2003 when the law on risk profiles was effective.

\begin{tabular}{|c|c|c|c|c|c|c|}
\hline & 1 & 2 & 3 & 4 & 5 & 6 \\
\hline $\log _{\text {Return }} \mathrm{t}-1$ & $\begin{array}{c}2586 \\
(2.648)\end{array}$ & $\begin{array}{l}2.480 \\
(2.60)\end{array}$ & - & - & - & - \\
\hline $\log _{\text {Return }}-2$ & - & - & $\begin{array}{c}0.514 \\
(0.220)\end{array}$ & $\begin{array}{c}0.498^{*} \\
(0.212)\end{array}$ & - & - \\
\hline $\log _{\text {Return }} \mathrm{t}-3$ & - & - & - & - & $\begin{array}{c}0.508^{*} \\
(0.206)\end{array}$ & $\begin{array}{c}0.477^{* *} \\
(0.179)\end{array}$ \\
\hline Risk profile 1 & $\begin{array}{l}2.562^{\text {*** }} \\
(0.549)\end{array}$ & $\begin{array}{l}2.315^{* * *} \\
(0.549)\end{array}$ & $\begin{array}{l}2.788^{* * *} \\
(0.605)\end{array}$ & $\begin{array}{l}2.482^{* * *} \\
(0.604)\end{array}$ & $\begin{array}{l}2.867^{\text {**** }} \\
(0.630)\end{array}$ & $\begin{array}{l}2.541^{\text {*** }} \\
(0.624)\end{array}$ \\
\hline Risk profile 2 & $\begin{array}{l}1.520^{* *} \\
(0.296)\end{array}$ & $\begin{array}{c}1.376 \\
(0.287)\end{array}$ & $\begin{array}{l}1.633^{* * *} \\
(0.332)\end{array}$ & $\begin{array}{c}1.467^{*} \\
(0.310)\end{array}$ & $\begin{array}{l}1.668^{* * * *} \\
(0.332)\end{array}$ & $\begin{array}{c}1.477^{*} \\
(0.314)\end{array}$ \\
\hline Risk profile 3 & $\begin{array}{c}1.013 \\
(0.208)\end{array}$ & $\begin{array}{c}0.944 \\
(0.195)\end{array}$ & $\begin{array}{c}1.089 \\
(0.225)\end{array}$ & $\begin{array}{c}1.009 \\
(0.210)\end{array}$ & $\begin{array}{c}1.112 \\
(0.231)\end{array}$ & $\begin{array}{c}1.026 \\
(0.215)\end{array}$ \\
\hline Risk profile 4 & $\begin{array}{c}1.133 \\
(0.174)\end{array}$ & $\begin{array}{c}1.164 \\
(0.180)\end{array}$ & $\begin{array}{c}1.218 \\
(1.883)\end{array}$ & $\begin{array}{c}1.251 \\
(0.195)\end{array}$ & $\begin{array}{c}1.243 \\
(0.193)\end{array}$ & $\begin{array}{c}1.277 \\
(0.200)\end{array}$ \\
\hline Risk profile 5 & $\begin{array}{c}1.193 \\
(0.170)\end{array}$ & $\begin{array}{c}1.183 \\
(0.171)\end{array}$ & $\begin{array}{c}1.281^{*} \\
(0.183)\end{array}$ & $\begin{array}{c}1.272^{*} \\
(0.185)\end{array}$ & $\begin{array}{c}1.278^{*} \\
(0.186)\end{array}$ & $\begin{array}{c}1.282^{*} \\
(0.187)\end{array}$ \\
\hline Risk profile 6 & $\begin{array}{c}1.370^{*} \\
(0.249)\end{array}$ & $\begin{array}{c}1.393^{*} \\
(0.258)\end{array}$ & $\begin{array}{l}1.471^{* *} \\
(0.269)\end{array}$ & $\begin{array}{l}1.498^{* *} \\
(0.279)\end{array}$ & $\begin{array}{l}1.438^{* *} \\
(0.267)\end{array}$ & $\begin{array}{c}1.479^{* *} \\
(0.281)\end{array}$ \\
\hline Gender (male) & - & $\begin{array}{c}1.198 \\
(0.135)\end{array}$ & - & $\begin{array}{c}1.167 \\
(0.134)\end{array}$ & - & $\begin{array}{c}1.148 \\
(0.133)\end{array}$ \\
\hline Age $18-30$ & - & $\begin{array}{c}0.709 \\
(0.158)\end{array}$ & - & $\begin{array}{c}0.642^{* *} \\
(0.148)\end{array}$ & - & $\begin{array}{c}0.643^{*} \\
(0.149)\end{array}$ \\
\hline Age $31-50$ & - & $\begin{array}{l}0.688^{* *} \\
(0.110)\end{array}$ & - & $\begin{array}{l}0.684^{* *} \\
(0.111)\end{array}$ & - & $\begin{array}{l}0.664^{* * *} \\
(0.109)\end{array}$ \\
\hline Age 51-65 & - & $\begin{array}{c}0.783 \\
(0.133)\end{array}$ & - & $\begin{array}{c}0.769 \\
(0.132)\end{array}$ & - & $\begin{array}{c}0.773 \\
(0.133)\end{array}$ \\
\hline $\begin{array}{l}\text { Preference for local } \\
\text { funds }\end{array}$ & - & $\begin{array}{l}0.277^{* * *} \\
(0.086)\end{array}$ & - & $\begin{array}{l}0.277^{* * *} \\
(0.086)\end{array}$ & - & $\begin{array}{l}0.250^{* * *} \\
(0.082)\end{array}$ \\
\hline $\begin{array}{l}\text { Socially responsible } \\
\text { investor }\end{array}$ & - & $\begin{array}{l}1.973^{* * *} \\
(0.227)\end{array}$ & - & $\begin{array}{l}0.277^{* * *} \\
(0.230)\end{array}$ & - & $\begin{array}{l}1.919^{* * *} \\
(0.225)\end{array}$ \\
\hline First number of funds & - & $\begin{array}{l}1.043^{* * *} \\
(0.0159)\end{array}$ & - & $\begin{array}{l}1.045^{* * *} \\
(0.016)\end{array}$ & - & $\begin{array}{l}1.047^{* * *} \\
(0.016)\end{array}$ \\
\hline $\mathrm{N}$ & 255495 & 255447 & 250394 & 250347 & 245331 & 245285 \\
\hline
\end{tabular}

*** $1 \%$ significance, ${ }^{* *} 5 \%$ significance, ${ }^{*} 10 \%$ significance

Table 4 shows that portfolio returns lagged one month are not significantly related to the probability to exit the mutual fund family. This might be because 
investors do not act immediately on bad returns, but adjust slowly. However, column (3) and (5) show that portfolio returns lagged two and three months are related to exit probabilities. An investor who had 10\% higher returns two months before is $4.86 \%$ [(1-0.514) x 10\%] less likely to leave the mutual fund broker. It is interesting that portfolio returns have a small effect on the probability to close the brokerage account. Johnson (2004) uses data from a U.S. fund broker that only offers about ten different mutual funds and no large cap equity funds. Even though the clientele in his study is very different, he finds a similar small effect of portfolio returns on account closure ${ }^{10}$.

Most importantly, the finding that risk averse investors are more likely to close their account is robust to the controls for monthly portfolio returns. Interestingly, after controlling for monthly portfolio returns, the most risk tolerant investors with risk profile five and six are also significantly more likely to close their account. Table 3 shows that investors with these risk profiles also mismatch their portfolio risk to risk preferences, by taking less risk than suggested by their risk preferences. Also the effect of a preference for local funds is not affected by the control for realized returns, which suggests that the local preference is rather a psychological effect than a return maximization strategy.

In Table 5, we run Cox proportional hazard models with time-varying proxies for wealth, which we lag one, two and three months. So far, we controlled for wealth by using the first amount transferred to the investment account by the individual, because this satisfies the strict exogeneity assumption of a Cox proportional hazard model. We measure time-varying wealth by the monthly size of the portfolio held at the broker in euro. The results for our time-varying measure of wealth are more stable and economically more significant than are the results for portfolio returns. Regardless of the time we lag the variable, the economic and statistical significance is almost identical. Investors with a $10 \%$ higher wealth in the previous month (log wealth $\left.\mathrm{t}_{\mathrm{t}-1}\right)$ are $16.4 \%$ less likely to close their account $(\mathrm{p}=0.000)$. This suggests that wealthier investors are more long term investors, which is consistent with Campbell (2006) who finds that wealthier investors are more sophisticated.

Again, we find that highly risk averse and highly risk tolerant investors are most likely to close their investment account. Investors with an intermediate level of risk preferences seem to match their portfolio risk better to their risk preferences.

\footnotetext{
${ }^{10}$ Seru, Shumway and Stoffman (2010) find with Finnish data that investors with good performance are less likely to stop trading in common stocks. This suggests that portfolio returns have a different effect on the decision to stop trading in common stocks than to stop trading in mutual funds.
} 
Table 5 - Time-varying wealth, risk preferences and account closure

This table presents estimates from a single-spell Cox proportional hazard model. The dependent variable is the monthly probability that an investor closes the account at the mutual fund broker. All independent variables are defined in Table 1. We include six dummies for different risk profiles and risk profile seven is the baseline that corresponds to investors who choose not to get advice on the level of risk in their portfolio. We lag the log of the monthly wealth by one, two and three months respectively. We clustered standard errors at the individual level, which are in parentheses. All specifications are for investors who joined the broker since January 2003 when the law on risk profiles was effective.

\begin{tabular}{|c|c|c|c|}
\hline & 1 & 2 & 3 \\
\hline Log Wealtht -1 & $\begin{array}{l}0.836^{* * *} \\
(0.016)\end{array}$ & - & - \\
\hline Log Wealtht-2 $_{t}$ & - & $\begin{array}{l}0.843^{* * *} \\
(0.016)\end{array}$ & - \\
\hline Log Wealtht-3 & - & - & $\begin{array}{l}0.842^{* * *} \\
(0.017)\end{array}$ \\
\hline Risk profile 1 & $\begin{array}{l}3.021^{* * *} \\
(0.703)\end{array}$ & $\begin{array}{l}3.192^{* * *} \\
(0.766)\end{array}$ & $\begin{array}{l}3.272^{* * *} \\
(0.793)\end{array}$ \\
\hline Risk profile 2 & $\begin{array}{c}1.427 \\
(0.357)\end{array}$ & $\begin{array}{l}1.526^{*} \\
(0.379)\end{array}$ & $\begin{array}{c}1.546^{*} \\
(0.385)\end{array}$ \\
\hline Risk profile 3 & $\begin{array}{c}1.008 \\
(0.218)\end{array}$ & $\begin{array}{c}1.076 \\
(0.235)\end{array}$ & $\begin{array}{c}1.101 \\
(0.243)\end{array}$ \\
\hline Risk profile 4 & $\begin{array}{c}1.157 \\
(0.201)\end{array}$ & $\begin{array}{c}1.253 \\
(0.216)\end{array}$ & $\begin{array}{c}1.279 \\
(0.222)\end{array}$ \\
\hline Risk profile 5 & $\begin{array}{c}1.318^{*} \\
(0.190)\end{array}$ & $\begin{array}{l}1.422^{* *} \\
(0.205)\end{array}$ & $\begin{array}{l}1.435^{* * *} \\
(0.207)\end{array}$ \\
\hline Risk profile 6 & $\begin{array}{l}1.617^{* * *} \\
(0.289)\end{array}$ & $\begin{array}{l}1.741^{* * *} \\
(0.311)\end{array}$ & $\begin{array}{l}1.726^{* * *} \\
(0.317)\end{array}$ \\
\hline Gender (male) & $\begin{array}{c}1.077 \\
(0.126)\end{array}$ & $\begin{array}{c}1.058 \\
(0.124)\end{array}$ & $\begin{array}{c}1.042 \\
(0.124)\end{array}$ \\
\hline Age 18-30 & $\begin{array}{l}0.428^{* * *} \\
(0.104)\end{array}$ & $\begin{array}{l}0.398^{* * * *} \\
(0.097)\end{array}$ & $\begin{array}{l}0.397^{* * *} \\
(0.980)\end{array}$ \\
\hline Age $31-50$ & $\begin{array}{l}0.494^{* * *} \\
(0.088)\end{array}$ & $\begin{array}{l}0.502^{* * *} \\
(0.088)\end{array}$ & $\begin{array}{l}0.488^{* * *} \\
(0.871)\end{array}$ \\
\hline Age 51-65 & $\begin{array}{l}0.656^{* *} \\
(0.122)\end{array}$ & $\begin{array}{l}0.651^{* *} \\
(0.121)\end{array}$ & $\begin{array}{l}0.656^{* *} \\
(0.123)\end{array}$ \\
\hline Preference for local funds & $\begin{array}{l}0.328^{* * *} \\
(0.102)\end{array}$ & $\begin{array}{l}0.323^{* * *} \\
(0.101)\end{array}$ & $\begin{array}{l}0.291^{* * *} \\
(0.096)\end{array}$ \\
\hline Socially responsible investor & $\begin{array}{l}1.727^{* * *} \\
(0.220)\end{array}$ & $\begin{array}{l}1.742^{* * *} \\
(0.220)\end{array}$ & $\begin{array}{l}1.694^{* * *} \\
(0.215)\end{array}$ \\
\hline First number of funds & $\begin{array}{l}1.057^{* * * *} \\
(0.016)\end{array}$ & $\begin{array}{l}1.058^{* * *} \\
(0.016)\end{array}$ & $\begin{array}{l}1.059^{* * *} \\
(0.016)\end{array}$ \\
\hline $\mathrm{N}$ & 255447 & 250347 & 245285 \\
\hline
\end{tabular}

${ }^{* * *} 1 \%$ significance, ${ }^{* *} 5 \%$ significance, ${ }^{*} 10 \%$ significance 


\subsection{Risk preferences and trading frequency}

In the previous sections, we investigated the closure of the brokerage account, which is a rather drastic decision for investors. In this section, we test for the effect of risk preferences on the frequency with which investors trade mutual funds.

Figure 2 presents the average yearly number of mutual fund purchases for investors with different risk profiles. We restrict the figure to risk profile two to six, because risk profile one and seven are for unadvised investors. The graph shows that purchase frequency increases with risk tolerance. This evidence is consistent with the documented positive correlation between risk preferences and trading frequency in common stocks (Dorn and Huberman, 2005). The figure also points out that men trade more than women for every risk profile. We ran unreported regressions with interaction effects between gender and risk tolerance and find that men trade more for every risk profile except for risk profile three. This finding is interesting in light of the gender effect identified for common stock trading (Barber and Odean, 2001).

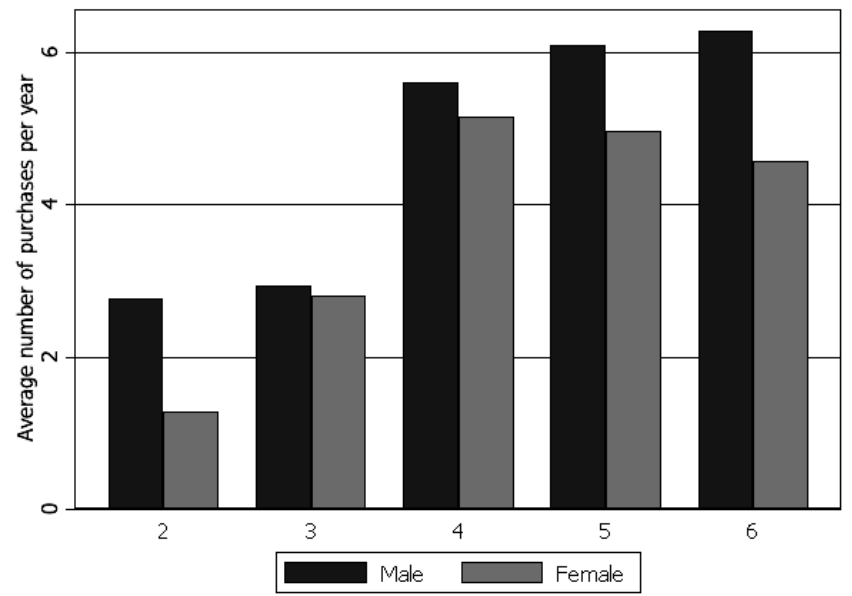

Figure 2 - Purchase frequency by male and female investors with different risk profiles This figure shows the average yearly number of mutual fund purchases for investors who joined the broker after January 2003, when the law on risk profiles was effective. A risk profile of two means very risk averse and six means very risk tolerant. Risk profile one and seven are special and are described in the appendix.

In the OLS regressions of Table 6 we use six dummies corresponding to the different risk profiles that allow for a non-linear effect of risk preferences on trading frequency. The baseline is investors who choose not to get advice on the level of risk in their portfolio (risk profile seven). The dependent variable in the first and third specification is the log of the number of purchases. The depend- 
ent variable in the second and fourth specification is the log of the number of fund sales.

Table 6 - Risk preferences and trading frequency

This table shows OLS regressions of the log of the average number of fund purchases or the log of the average number of fund sales on six dummies for different risk profiles. Risk profile seven is the baseline and corresponds to investors who choose not to get advice on the level of risk in their portfolio. All variables are defined in Table 1 and robust standard errors are in parentheses. Specification one and two are for investors who joined the broker since January 2003 when the law on risk profiles was effective and specification three and four are for investors who joined before January 2003.

\begin{tabular}{|c|c|c|c|c|c|c|}
\hline & $\begin{array}{c}\text { Log Number } \\
\text { of Purchases } \\
\text { (since Jan } \\
\text { 2003) }\end{array}$ & $\begin{array}{l}\text { Log Number } \\
\text { of Sales } \\
\text { (since Jan } \\
\text { 2003) }\end{array}$ & $\begin{array}{c}\text { Log Number } \\
\text { of Purchases } \\
\text { (before Jan } \\
\text { 2003) }\end{array}$ & $\begin{array}{l}\text { Log Number } \\
\text { of Sales } \\
\text { (before Jan } \\
2003 \text { ) }\end{array}$ & $\begin{array}{l}\text { Log Net pur- } \\
\text { chases minus } \\
\text { sales (before } \\
\text { Jan 2003) }\end{array}$ & $\begin{array}{l}\text { Log Net pur- } \\
\text { chases minus } \\
\text { sales (since } \\
\text { Jan 2003) }\end{array}$ \\
\hline & 1 & 2 & 3 & 4 & 5 & 6 \\
\hline $\begin{array}{l}\text { Risk } \\
\text { profile } 1\end{array}$ & $\begin{array}{c}0.237^{*} \\
(0.125)\end{array}$ & $\begin{array}{l}0.334^{* * * *} \\
(0.111)\end{array}$ & $\begin{array}{l}-0.264^{* * *} \\
(0.033)\end{array}$ & $\begin{array}{c}-0.179^{* * * *} \\
(0.034)\end{array}$ & $\begin{array}{l}0.085^{* * *} \\
(0.028)\end{array}$ & $\begin{array}{l}-0.097 \\
(0.102)\end{array}$ \\
\hline $\begin{array}{l}\text { Risk } \\
\text { profile } 2\end{array}$ & $\begin{array}{c}-0.128 \\
(0.083)\end{array}$ & $\begin{array}{l}-0.126 \\
(0.083)\end{array}$ & $\begin{array}{l}0.055^{* *} \\
(0.025)\end{array}$ & $\begin{array}{l}0.066^{* *} \\
(0.029)\end{array}$ & $\begin{array}{l}-0.011 \\
(0.022)\end{array}$ & $\begin{array}{c}-0.002 \\
(0.070)\end{array}$ \\
\hline $\begin{array}{l}\text { Risk } \\
\text { profile } 3\end{array}$ & $\begin{array}{l}0.196^{* * *} \\
(0.067)\end{array}$ & $\begin{array}{c}0.074 \\
(0.065)\end{array}$ & $\begin{array}{l}0.224^{* * *} \\
(0.019)\end{array}$ & $\begin{array}{l}0.223^{* * *} \\
(0.022)\end{array}$ & $\begin{array}{c}0.001 \\
(0.016)\end{array}$ & $\begin{array}{l}0.122^{* *} \\
(0.049)\end{array}$ \\
\hline $\begin{array}{l}\text { Risk } \\
\text { profile } 4\end{array}$ & $\begin{array}{l}0.892^{* * *} \\
(0.059)\end{array}$ & $\begin{array}{l}0.695^{* * * *} \\
(0.057)\end{array}$ & $\begin{array}{l}0.522^{* * *} \\
(0.019)\end{array}$ & $\begin{array}{l}0.451^{* * *} \\
(0.021)\end{array}$ & $\begin{array}{l}0.072^{* * *} \\
(0.014)\end{array}$ & $\begin{array}{l}0.197^{* * * *} \\
(0.038)\end{array}$ \\
\hline $\begin{array}{l}\text { Risk } \\
\text { profile } 5\end{array}$ & $\begin{array}{l}0.984^{* * *} \\
(0.055)\end{array}$ & $\begin{array}{l}0.702^{* * *} \\
(0.054)\end{array}$ & $\begin{array}{l}0.721^{* * *} \\
(0.020)\end{array}$ & $\begin{array}{l}0.594^{* * *} \\
(0.021)\end{array}$ & $\begin{array}{l}0.128^{* * *} \\
(0.014)\end{array}$ & $\begin{array}{l}0.281^{* * * *} \\
(0.036)\end{array}$ \\
\hline $\begin{array}{l}\text { Risk } \\
\text { profile } 6\end{array}$ & $\begin{array}{l}0.988^{* * *} \\
(0.069)\end{array}$ & $\begin{array}{l}0.566^{* * *} \\
(0.068)\end{array}$ & $\begin{array}{l}0.817^{\text {**** }} \\
(0.032)\end{array}$ & $\begin{array}{l}0.650^{* * *} \\
(0.034)\end{array}$ & $\begin{array}{l}0.167^{* * *} \\
(0.021)\end{array}$ & $\begin{array}{l}0.422^{* * *} \\
(0.045)\end{array}$ \\
\hline $\begin{array}{l}\text { Gender } \\
\text { (male) }\end{array}$ & $\begin{array}{l}0.302^{* * *} \\
(0.041)\end{array}$ & $\begin{array}{l}0.124^{* * *} \\
(0.040)\end{array}$ & $\begin{array}{l}0.304^{* * *} \\
(0.013)\end{array}$ & $\begin{array}{l}0.252^{* * *} \\
(0.015)\end{array}$ & $\begin{array}{l}0.052^{* * *} \\
(0.011)\end{array}$ & $\begin{array}{l}0.179^{* * *} \\
(0.029)\end{array}$ \\
\hline Age $18-30$ & $\begin{array}{c}0.000 \\
(0.080)\end{array}$ & $\begin{array}{c}-0.235^{* * *} \\
(0.078)\end{array}$ & $\begin{array}{l}0.278^{* * * *} \\
(0.026)\end{array}$ & $\begin{array}{l}0.125^{* * *} \\
(0.030)\end{array}$ & $\begin{array}{l}0.153^{* * *} \\
(0.023)\end{array}$ & $\begin{array}{l}0.235^{* * * *} \\
(0.053)\end{array}$ \\
\hline Age $31-50$ & $\begin{array}{l}-0.139^{* *} \\
(0.062)\end{array}$ & $\begin{array}{c}-0.226^{* * *} \\
(0.061)\end{array}$ & $\begin{array}{l}0.264^{* * *} \\
(0.022)\end{array}$ & $\begin{array}{l}0.137^{* * *} \\
(0.027)\end{array}$ & $\begin{array}{l}0.127^{* * *} \\
(0.020)\end{array}$ & $\begin{array}{l}0.087^{* *} \\
(0.042)\end{array}$ \\
\hline Age 51-65 & $\begin{array}{l}-0.115^{*} \\
(0.063)\end{array}$ & $\begin{array}{c}-0.091 \\
(0.062)\end{array}$ & $\begin{array}{l}0.276^{* * *} \\
(0.024)\end{array}$ & $\begin{array}{l}0.187^{* * *} \\
(0.029)\end{array}$ & $\begin{array}{l}0.089^{* * *} \\
(0.022)\end{array}$ & $\begin{array}{c}-0.024 \\
(0.043)\end{array}$ \\
\hline Wealth Q2 & $\begin{array}{l}-0.719^{* * *} \\
(0.071)\end{array}$ & $\begin{array}{c}-0.608^{* * *} \\
(0.069)\end{array}$ & $\begin{array}{c}-0.372^{* * *} \\
(0.022)\end{array}$ & $\begin{array}{c}-0.306^{* * * *} \\
(0.024)\end{array}$ & $\begin{array}{l}0.066^{* * *} \\
(0.016)\end{array}$ & $\begin{array}{l}-0.111^{* *} \\
(0.050)\end{array}$ \\
\hline Wealth Q3 & $\begin{array}{l}-0.812^{* * *} \\
(0.067)\end{array}$ & $\begin{array}{l}-0.527^{* * *} \\
(0.066)\end{array}$ & $\begin{array}{c}-0.436^{* * *} \\
(0.022)\end{array}$ & $\begin{array}{l}-0.235^{* * * *} \\
(0.024)\end{array}$ & $\begin{array}{l}0.202^{* * *} \\
(0.016)\end{array}$ & $\begin{array}{l}0.286^{\text {**** }} \\
(0.050)\end{array}$ \\
\hline Wealth Q4 & $\begin{array}{l}-0.871^{* * *} \\
(0.065)\end{array}$ & $\begin{array}{l}-0.518^{* * *} \\
(0.063)\end{array}$ & $\begin{array}{c}-0.499^{* * *} \\
(0.022)\end{array}$ & $\begin{array}{c}-0.148^{* * * *} \\
(0.024)\end{array}$ & $\begin{array}{l}0.352^{* * *} \\
(0.017)\end{array}$ & $\begin{array}{l}0.353^{* * *} \\
(0.046)\end{array}$ \\
\hline Wealth Q5 & $\begin{array}{l}-0.313^{* * *} \\
(0.057)\end{array}$ & $\begin{array}{c}0.008 \\
(0.057)\end{array}$ & $\begin{array}{c}-0.399^{* * *} \\
(0.023)\end{array}$ & $\begin{array}{l}0.075^{* * *} \\
(0.025)\end{array}$ & $\begin{array}{l}0.473^{* * *} \\
(0.017)\end{array}$ & $\begin{array}{l}0.321^{* * * *} \\
(0.038)\end{array}$ \\
\hline R squared & 0.159 & 0.102 & 0.107 & 0.057 & 0.044 & 0.075 \\
\hline $\mathrm{N}$ & 5151 & 5151 & 37085 & 37085 & 37085 & 5151 \\
\hline
\end{tabular}

*** $1 \%$ significance, ${ }^{* *} 5 \%$ significance, ${ }^{*} 10 \%$ significance 
The first two specifications describe investors who joined since January 2003. We find that risk tolerant investors trade significantly more than do risk averse investors. The most risk tolerant investors in risk profile six purchase $98.8 \%$ more than do investors who get no advice (baseline) and buy $60.7 \%$ more than do risk averse investors in risk profile one [(198.8\% - 123.7\%) / 123.7\%]. Specification (2) shows that risk tolerant investors also sell more mutual funds than do risk averse investors. These effects hold after controlling for variables like gender, age and wealth. The third and fourth specifications refer to investors who joined before January 2003. Again, there is a significant positive relation between risk preferences and trading frequency for both purchases and sales, which demonstrates the robustness of the findings.

The results on the control variables of the first specification in Table 6 are also important. Even after controlling for risk preferences, men execute 30.2\% more fund purchases than do women. The effect size is very close to that found by Barber and Odean (2001) for trading in common stocks. Our finding implies that the effect of gender on trading is not purely driven by a difference in the risk preferences of men and women. It is interesting that for sales, men only have a $12.3 \%$ higher frequency. That is, gender has a different effect on purchase frequency than it has on sales frequency. To test the effect of wealth on trading frequency, we create quintiles based on the level of wealth. Again, the baseline is the quintile with the lowest wealth. We find that investors in the lowest wealth quintile purchase the largest number of funds. This result is interesting in light of the findings of Campbell (2006) who shows that low-wealth investors are often unsophisticated.

Specification five and six test for the effect of risk preferences and gender on net purchases. The dependent variable is the average number of yearly fund purchases minus the average number of yearly fund sales. Consistent with the results for specifications one to four, we find that risk tolerance and being male are positively related to net purchases. Specification six is for investors who joined since January 2003. It shows for instance that risk tolerant investors in risk profile six have net purchases that are $42.2 \%$ higher than the net purchases for investors in the baseline with risk profile seven (unadvised). We document substantially higher net purchases for men than for women, with an effect size of $17.9 \%(\mathrm{p}=0.000)$.

\section{Conclusion}

This chapter documents statistical patterns in individual investor trading in mutual funds. The trading patterns we observe closely resemble those of common stocks. This finding has important implications for understanding individual investor behavior. We show that men trade substantially more than do women and risk tolerant investors trade more than do risk averse investors. 
Even though the trading pattern for common stocks and mutual funds is similar, the incentives for mutual fund families are different from those of discount brokers. The mutual fund broker in this chapter does not charge loads and therefore does not profit from a high trading volume, which is the major source of revenue for discount brokers. The mutual fund family mainly gets its revenue from the annual management fees paid by investors.

We find that risk preferences are systematically related to account closure probabilities. This suggests that several groups of investors significantly mismatch their portfolio against their risk preferences. As a result, they close their brokerage accounts early. Higher portfolio returns impact investor survival positively, but this effect is much smaller than that of risk preferences. We document that spill-over effects from fund holdings to the fund family level can result from investor preferences. This shows that spill-over effects to the family level are not only the result of the performance of individual funds (Nanda, Wang and Zheng, 2004), but also of factors such as risk preferences, social preferences and a preference for local funds.

Our evidence emphasizes the role of the mutual fund broker in the relationship to its customers and stresses the advantages of helping investors to match their portfolio to risk preferences. Mutual fund brokers can do this in several ways. First, the broker in this study developed an on-line tool to track the risk of an investor's portfolio and to give advice on the match to the risk preferences of the investor. Second, brokers can provide an appropriate range of products for investors with different risk appetites. This way, mutual fund brokers can keep investors satisfied and, at the same time, generate long-term revenue. 


\section{Appendix A - Questionnaire Investment Profile}

With this questionnaire it is possible to determine the investment profile for one account. In case you hold multiple accounts, fill out multiple questionnaires. Account number | | | | | | | | | | | | | | |

\section{Account holder}

Initial(s) and surname

Address

Zip code and city

Country

Phone number during the day phone during the evening

E-mail

\section{Determine your investment profile}

Broker $x$ determines the investment profile for each separate account. In case an account is shared by two persons, the profile will hold for both individuals. We will use this profile as a starting point for our advisory services. We make a distinction between seven investment profiles (I - VII). For profile II till VI we are able to provide advisory services. Profile I refers to a pure savings account for investors who are not willing to incur any risk on their deposits. Profile VII refers to investors that determine the composition of their investment portfolio based on their own insights. I choose:

口 $100 \%$ principal protection, because I do not want to allow the principal* to decrease at any point in time (investment profile I). This includes savings.

Investment based on own insights (investment profile VII).

\section{*The principal is your deposit minus possible one-time initial costs.}

Note: For these profiles it is not possible to receive any advice. In case you recognize yourself as belonging either to profile I or VII, you do not have to fill out the questionnaire, but you can indicate your choice directly.

\section{Investment objective}

The starting point for each account is the investment objective (why do you want to generate wealth?)

What is your primary objective for holding this account? (One option possible)

$\square$ (As supplement to) your pension

Early retirement

$\square$ (Grand)children

- Home ownership

$\square$ Unforeseen expenditures

$\square$ General income growth

Do you pursue multiple objectives? We advise you to link each objective to one account. 


\section{Questionnaire investment profile}

\section{Horizon}

1. Within what time-span do you want to achieve your investment objective?

0 : _ Within 2 years

10: _ Within 2 to 3 years

20: _ Within 4 to 5 years

30: _ Within 6 to 9 years

40: _ Within 10 years or later

Financial liabilities, income and assets (savings, investments, real estate minus debt).

2. Complete: My current income derived from wage and/or benefits is:

0: _ Not sufficient to cover my fixed liabilities and basic needs. My assets should generate additional revenue (yield)

10: _ Sufficient to cover my fixed liabilities and basic needs.

\section{Assets}

3. With which part of your total asset base (including those at other parties) do you invest in stock and bonds? With total asset base we refer to the sum of savings, investments and the value of your own house, minus debt (including mortgage debt)

0: _ More than $70 \%$

5: _ Between $30 \%$ and $70 \%$

10: _ Less than $30 \%$

\section{Income stability}

4. Complete: During my investment horizon I expect my income to:

2: _ Remain the same

1: _ Increase

0: _ Decrease

1: _ Fluctuate

\section{Risk attitude}

5. What is your reaction to a strong decrease in your asset base of your previously chosen investment objective?

0: _ I will sleep badly and will be worried

5: _ I will regret it, but I will trust that the end result will be positive

10: _ I am aware of the risks and I accept the consequences. 


\section{Experience}

6. Have you previously invested in financial instruments such as mutual funds and individual stocks?

2: _ Yes, actively

1: _ Yes, but not actively

$0: \quad$ No

\section{Occupation}

7. Do you professionally have to deal with (or had to deal with) trading in financial instruments?

2: _ Yes

0: _ No

\section{Education}

8. Did you complete an education in which you gained knowledge about financial instruments?

2: _ Yes

0: _ No

Now that you answered the questions, you can determine your investment profile based on the answer key.

Fill out your investment profile here: ....... 


\section{Questionnaire investment profile}

To conclude, we would like to ask you two questions in order to develop an understanding about how you would like to continue your investments.

\section{Investment style}

Your investment style indicates to what extent you would like to be involved with your portfolio and determines the type of product that we advise you. Indicate which style suits you best.

I consider a yearly critical look on my portfolio sufficient.

I do follow the stock market developments, but I consider a quarterly check of my positions sufficient.

I follow the market developments closely and I am therefore involved with my portfolio on a monthly basis.

Do you want to invest in a portfolio smaller than $€ 10.000$ ? We would like to advise you to opt for one of our mixed-funds. In that case you are insured against sufficient spread, without need to hold diverse funds.

I would like to invest in mixed-funds 
Appendix B - Determining an investor's risk profile based on the answers

Answer sheet to determine the investment profile of an individual

Step 1 What is the score for question 1 (horizon?)

Step 2 Determine the total score for question 2, 3 and 5

Fill out the score for question 2

(financial liabilities, income and assets)

Fill out the score for question 3 (assets)

Fill out the score for question 5 (risk attitude)

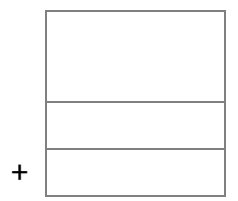

Sum up to derive your total score

Step 3 Determine the total score for question $4,6,7$ and 8

Fill out the score for question 4 (income stability)

Fill out the score for question 6 (experience)

Fill out the score for question 7 (occupation)

Fill out the score for question 8 (education)

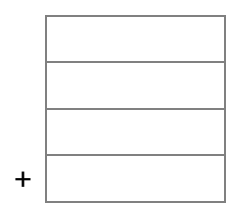


Step 4 Determine which table you should use based on the score from step 3.

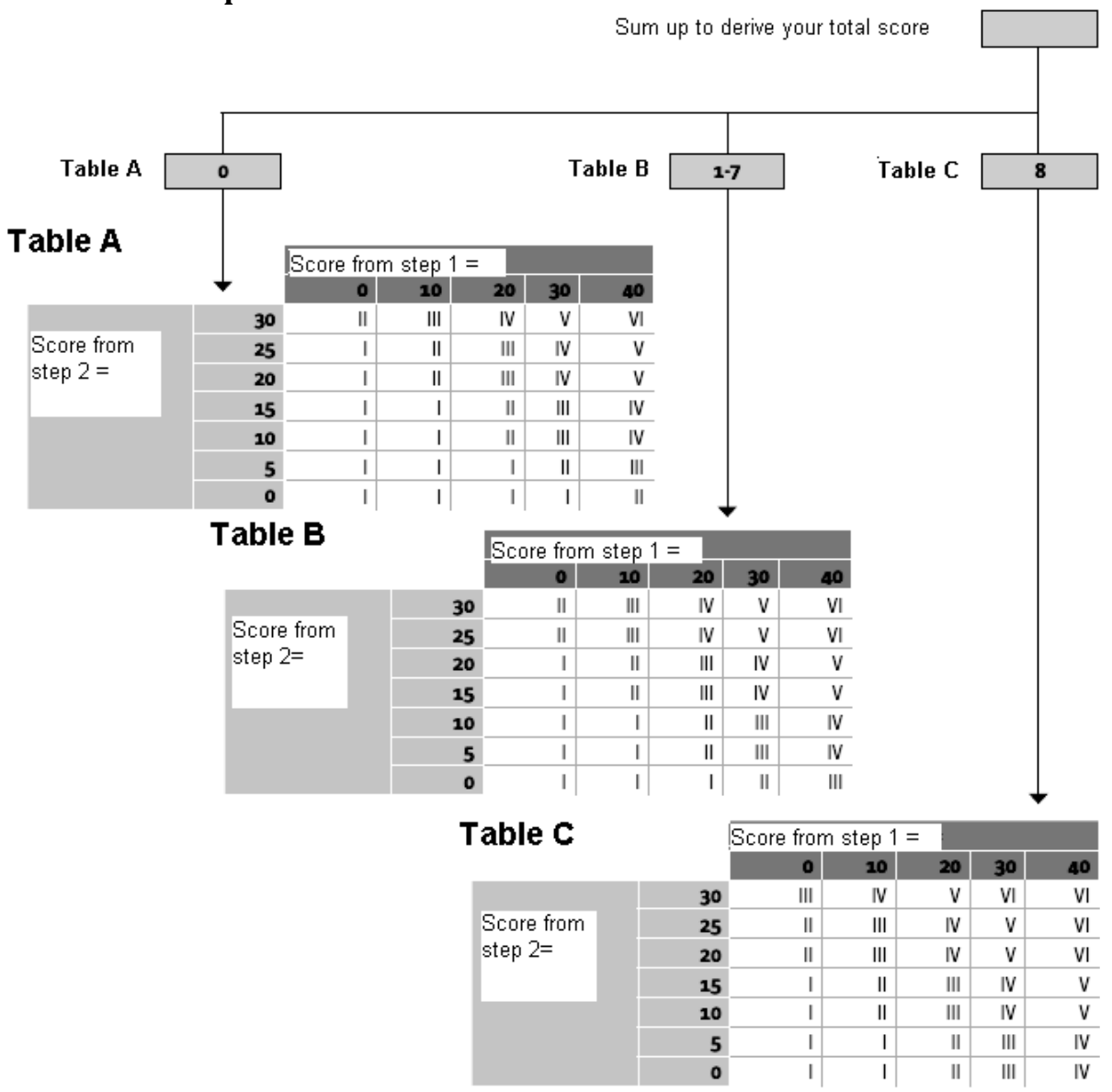


Answer sheet to determine investment profile of an individual

Overview investment profiles:

\begin{tabular}{lll}
\hline $\begin{array}{l}\text { Investement } \\
\text { profile }\end{array}$ & $\begin{array}{l}\text { Expected } \\
\text { return }\end{array}$ & $\begin{array}{l}\text { Possible } \\
\text { loss** }\end{array}$ \\
\hline I* & $3 \%$ & $0 \%$ \\
II & $4 \%$ & $-3 \%$ \\
III & $5 \%$ & $-10 \%$ \\
IV & $6 \%$ & $-15 \%$ \\
V & $7 \%$ & $-25 \%$ \\
VI & $8 \%$ & $-35 \%$ \\
VII & - & $-100 \%$ \\
\hline
\end{tabular}

* No advising possible

** Expected return and possible loss on a 12-monthly basis with $95 \%$ probability

Step 5 Your investment profile (the result of step 4) is:

You can keep this answer sheet for your own administration. 


\section{Appendix C - Recommendation for portfolio risk based on risk profiles}

\section{Investing according to your principles}

Good investment advice is custom-made. It is important that your investments match your principles, requirements and preferences. At Broker x your principles form the basis of your personal investment profile. This describes the purpose of your investment, how much risk you are able and willing to take, and for which period you plan to invest. The expected return that you are pursuing and your investment style also follow from your investment profile. We combine this with our expertise to develop an investment portfolio that suits you best.

\section{Seven investment profiles}

Broker $\mathrm{x}$ distinguishes between seven investment profiles. Investment profile I corresponds to investors that are not willing to accept any risk on their investments. Profiles II to IV run from low-risk to high-risk. Most investors recognize themselves in one of these five profiles (see the back of this form). Investment profile VII suits investors that invest at their own discretion and that want to keep an eye on the risk level themselves. Contrary to other investment profiles, investors with this investment profile do not receive advice from Broker $\mathrm{x}$.

\section{Your investment profile}

You can determine your investment profile online or by means of the questionnaire attached to this brochure. By answering the questions you will find yourself an investment profile that suits you and your investment objective best. Possibly, you pursue more than one objective. For example, you want to invest for your retirement and at the same time wish to set money aside for your own home. If your risk attitude differs between the objectives, we advise you to take one separate account for each objective.

\section{Your investment style}

An important part of your personal investment profile concerns your investment style, which determines in what funds you should invest. At Broker x we make a distinction between the following investment styles. 


\section{Moderately active}

You do look into your investment portfolio more than once a year. Our advice for the equity part of your portfolio is to invest in global mutual funds. This will create a strong base and you have little to worry about.

\section{Active}

You do follow the stock market developments on a regular basis and you check the position of your investments on a quarterly basis. We advise you to invest the equity part of your portfolio in regional funds. This allows you to profit from regional opportunities and developments that are easy to follow on a quarterly basis.

\section{Very active}

You do follow the market developments closely and are busy with your investments on a monthly basis. We advise you to invest the equity part of your portfolio in regional and trend funds. In case you prefer to invest in single stocks, we will advise you on selecting the best stocks in various investment sectors.

\section{Your investment profile}

\section{Optimal risk and return}

You invest for the returns, without being prepared to take more risk than you consider being acceptable. At any point in time you can check online whether your portfolio is not too risky. Log in to www.Broker x.nl and select the account that you wish to check. On the next screen, select the 'risk button' and you will see the result immediately. As your personal circumstances may change, it is advisable to control your investment profile critically at least once a year.

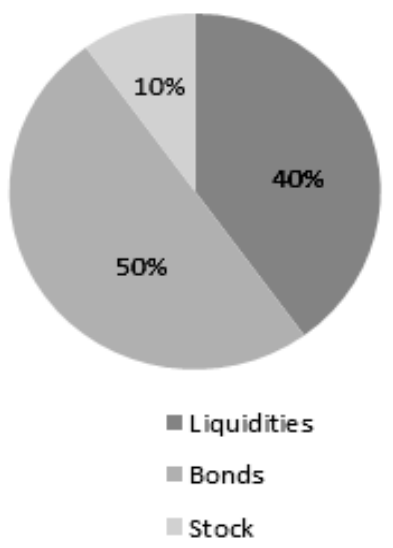

\section{Investment profile II: Highly Defensive}

This profile corresponds to an expected average yearly return of $4 \%$ in the long run. In the short term, the return ranges from $-3 \%$ to $18 \% *$. The portfolio that belongs to this profile consists mainly of cash and bonds. The risk and return of this portfolio are modest and only slightly higher compared to a situation in which you would only save. 

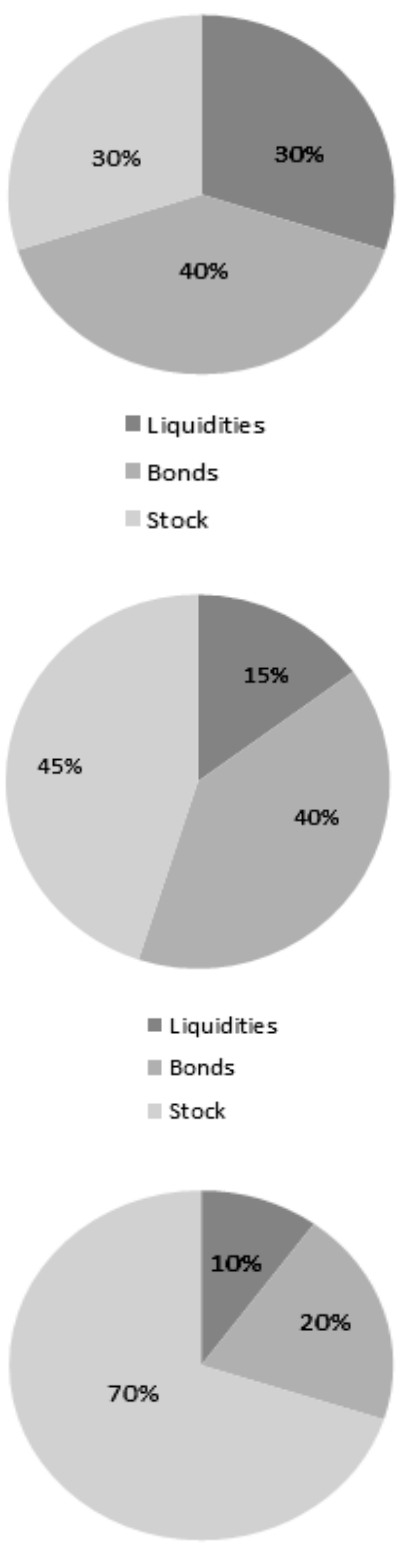

- Liquidities

Bonds

intock

\section{Investment profile III: Defensive}

This profile corresponds to an expected average yearly return of $5 \%$ in the long run. In the short term, the return ranges from $-10 \%$ to $26 \%$ *. Part of your assets will be invested in equities, but the majority is invested in a secure base consisting of bonds and cash. In order to achieve higher returns, you are willing to take a bit of risk.

\section{Investment profile IV: Neutral}

This profile corresponds to an expected average yearly return of $6 \%$ in to long run. In the short term, the return ranges from $-15 \%$ to $33 \% *$. Balance is the key word of this portfolio. You wish a higher return than can be delivered by a savings account and you are willing to bear more risk in order to achieve this. In the corresponding portfolio, your assets are distributed over various investment classes in a balanced manner.

\section{Investment profile V: Offensive}

This profile corresponds to an expected average yearly return of $7 \%$ in the long run. In the shortterm, the return ranges from $-25 \%$ to $45 \% *$. You have a clear perspective on investing. You consider a temporary price fall unfortunate but inevitable, as you simply want to achieve a higher return. You will not avoid risk, but you will not go for the extremes either. 


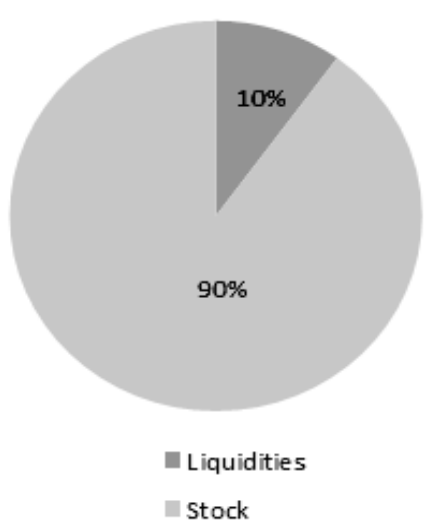

\section{Investment profile VI: Very Offensive}

This profile corresponds to an expected average yearly return of $8 \%$ in the long run. In the shortterm, the return ranges from $-35 \%$ to $57 \% *$. A high return is your objective and you are willing to bear high risks for that. Probably you are investing for the longer term, which limits the impact of stock price fluctuations. Your profile suits a portfolio that consists primarily of equity. * On a 12 -montly basis with $95 \%$ probability. 



\section{Chapter 3 \\ Strategic and Intrinsic Pro-Social Behavior of Individual Investors ${ }^{11}$}

\section{Introduction}

Pro-social behavior is important in daily life. There is solid evidence that people do not only maximize personal wealth, but also behave pro-socially in taking others well-being into account (e.g. Andreoni (1995), Berg, Dickhaut and McCabe (1995), Ledyard (1995), Glaeser et al. (2000), Egas and Riedl (2008), Fischbacher and Gächter (2010)). However, there is a debate whether observed pro-social behavior is based on intrinsic pro-social preferences or whether people behave pro-socially for strategic reasons in the hope and expectation that it increases their own immediate or future well-being (Batson et al. (1997), Levitt and List (2007), Gneezy et al. (2012)). In particular, as pointed out by Sobel (2005), pro-social behavior can be both strategic (instrumental) and intrinsic (non-strategic). Strategic pro-social behavior is motivated by self-serving factors such as signaling (Glazer and Konrad, 1996) and reputation gains (List, 2006). Intrinsic pro-social behavior, in contrast, does not provide such personal benefits, but is motivated by factors such as intrinsic reciprocity (Rabin, 1993) and inequality aversion (Fehr and Schmidt (1999), Bolton and Ockenfels (2000)).

By only observing behavior in the field, it is difficult to disentangle strategic from intrinsic pro-social behavior. For example, an individual that buys a hybrid car, which is perceived as an ecologically responsible consumption choice, may be intrinsically motivated and truly cares about the environment. However, he can also buy the car for strategic reasons, as tax benefits, a better mileage or reputation benefits. Asymmetric information allows a car owner to signal social responsibility to others, even if the true reason for buying the car is self-serving.

Another example where it is difficult to tell apart strategic and intrinsic prosocial behavior is an investment in socially responsible (SRI) mutual funds. Such

\footnotetext{
${ }^{11}$ This chapter is based on Riedl, Arno and Paul Smeets, 2012, Strategic and Intrinsic Pro-Social Behavior of Individual Investors, working paper.
} 
funds do, for instance, not hold shares of companies engaged in the production of weapons and select companies that have a good reputation regarding environmental policies, human rights, etc. (Social Investment Forum (2010), EUROSIF (2010)). Because of this investment policy, SRI can be perceived as having a public goods component. Therefore, intrinsic pro-social investors may buy these funds because they intrinsically care about the environment or about human rights. However, investors may also have strategic reasons and own socially responsible funds because of tax benefits or for signaling pro-sociality. Signaling is possible via, for instance, the use of debit and credit cards that display a symbol signaling that one is a client of a socially responsible bank.

In this chapter, we aim at disentangling strategic and intrinsic pro-social types of socially responsible investors. This is challenging, because many individuals might have a mix between intrinsic and strategic motivations. However, we classify individuals as intrinsic or strategic types based on their most important motivation for investing socially responsible. Intrinsic pro-social types invest primarily in SRI mutual funds for truly pro-social reasons and strategic prosocial types predominantly hold SRI funds for financial reasons like tax benefits or signaling. We hypothesize that intrinsic socially responsible investors also behave more pro-socially in other domains, especially in domains where signaling of pro-sociality is difficult or impossible. We consider the domains of charity donations, voluntary work, organ donor registrations and conduct a contextfree trust game and public goods experiment.

An important question in economics and social psychology is whether people behave consistently pro-social across different domains. Overall, the literature suggests that pro-social behavior is partly stable across domains. However, it is still not clear under what conditions pro-social behavior is more or less consistent. Previous studies find some factors that determine the degree of consistency in pro-social behavior. For example, Cesarini et al. (2011) show that preferences for giving are in part genetically determined. Therefore, individuals might behave consistently pro-socially because of their genes. Gneezy et al. (2012) argue that consistency in pro-social behavior is determined by the initial costs of this behavior. If the costs of behaving pro-socially are initially high, then the self-perception of individuals changes so that they feel a desire to behave consistently pro-social in the future. If the initial costs of pro-social behavior are low, people do not feel the need to behave consistently.

We argue that consistency in pro-social behavior is impacted by the strategic benefits offered by different domains of pro-social behavior. If signaling and reputation building are equally difficult in two domains, then we expect behavior to be more consistent among these domains than it would be if one domain clearly offers more signaling benefits than the other. For instance, we expect a relatively high correlation between anonymous donations to charity via internet and anonymous on-line purchases of socially responsible mutual funds. How- 
ever, we expect a lower correlation between the donations to charity (few signaling benefits) and voluntary work (many signaling benefits).

We have access to administrative individual investor data from a large mutual fund company in the Netherlands, which comprise more than 100,000 individual investors. The mutual fund company offers both a large variety of socially responsible and conventional mutual funds. Investors are personally responsible for their decisions by buying funds directly on-line without the interference of an intermediary. We use this database to identify socially responsible investors and conventional investors, which rules out potential problems with self-reported pro-social behavior in that domain.

In addition, we conduct a survey and artefactual field experiments (Harrison and List, 2004) with a subset of these investors and link the administrative data to the survey responses and behavior in a fully incentivized trust game experiment. We use survey questions to define strategic and intrinsic responsible investors and relate it to behavior in the trust game as well as to survey questions designed to elicit pro-social behavior in different domains. A common problem with survey responses is that individuals might provide socially desirable answers. Because we use the survey to distinguish between strategic and intrinsic pro-social investor types, we might underestimate the number of strategic prosocial types. Hence, we likely underestimate the difference in behavior between types in fully anonymous situations as the trust game experiment.

We find support for our main hypothesis that intrinsic socially responsible investors also behave more pro-socially in other domains than strategic SR investors and conventional investors do. This effect is particularly pronounced in the domain of donations to charity in which signaling is difficult. Intrinsic socially responsible investors donate $68 \%$ more money to charity than conventional investors donate and $72 \%$ more than strategic investors donate. Intrinsic SR investors also do significantly more voluntary work and are more often registered as an organ donor than conventional and strategic SR investors, but this difference is smaller because of signaling benefits in these domains.

To rule out signaling and reputation effects, we conduct an anonymous oneshot trust game. We find that about $90 \%$ of the individual investors sends back a positive amount as a second-mover, which suggests a large degree of intrinsic pro-social behavior among investors. In fact, the level of trustworthiness we observe among investors closely resembles that documented in previous studies that report on intrinsic pro-social behavior among students and other subject pools (e.g. Fehr and List (2004), Egas and Riedl (2008), Fischbacher and Gächter (2010), Falk, Meier and Zehnder (2011)). However, there is also substantial heterogeneity in the degree of intrinsic pro-social behavior in the trust game. Investors who indicate to invest socially responsible for an intrinsic reason behave more pro-socially than do other types of investors. Furthermore, investors who invest socially responsible for a strategic reason are substantially less 
trustworthy in the trust game than conventional investors and intrinsic SR investors are.

This finding illustrates that distinguishing between strategically and intrinsically motivated pro-social behavior is important for the interpretation of (un)observed correlations between pro-social behavior in artefactual field experiments and pro-social behavior in the field. Intrinsic pro-social behavior in the experiment should be correlated with intrinsic pro-social behavior in the field. However, there is less reason to expect that strategically pro-social types, who hold socially responsible mutual funds for tax benefits or reputational reasons, will behave more pro-socially in an experiment that rules out such benefits.

There is a lively discussion on the usefulness of laboratory experiments in explaining field behavior (Levitt and List (2007), Falk and Heckmann (2009)). Some studies show that there is a relation between behavior in artefactual field experiments and behavior in the field (Karlan (2005), Baran, Sapienza and Zingales (2010), Fehr and Leibbrandt (2011)). Other studies find that there is no such relation (List, 2006). By conducting an artefactual field experiment in a controlled environment, where we can rule out reputation effects. We show that without distinguishing between strategic and intrinsic pro-social behavior, studies likely underestimate the relation between pro-social behavior in the field and in artefactual field experiments.

Some other studies also report results on the link between pro-social behavior in the field and in experiments. For instance, Karlan (2005) conducts experiments with microfinance borrowers in Peru, and Fehr and Leibbrandt (2011) ran experiments with fishermen around a lake in northeastern Brazil. Our research differs from these studies in at least two important ways. First, we conduct experiments with financial investors in an industrialized country in the Northern hemisphere. Second, the social distance among our investors is likely much larger than among participants in these other studies. It is likely that the Peruvian microfinance borrowers know each other, just like the fishermen living around the same lake are socially close. Such closeness can bias the observation of intrinsic pro-social behavior, because subjects may care about their reputation (Hagen and Hammerstein, 2006). For instance, Glaeser et al. (2000) show that larger social distance decreases trustworthiness in a trust game and other studies show that in a social network generosity decreases with distance (Leider et al. 2009, Goeree et al. 2010, D'Exelle and Riedl 2010). In a similar vein, Goette, Meier and Huffman (2006) find that pro-social behavior is more common with in-group members than with out-group members. We conduct anonymous on-line experiments with investors across the whole of the Netherlands, which substantially increases social distance.

List (2006) also investigates strategic and intrinsic pro-social behavior in the lab and in the field. However, he does not directly link the decisions in the experiments to field behavior. Rather, sports card traders participate in gift exchange experiments in the lab with and without context. In addition, he runs 
gift exchange field experiments with these traders. He finds that trustworthy field behavior is primarily driven by reputation, but he does not test for the consistency in pro-social behavior across various domains.

Benz and Meier (2008) find a relation between student donation behavior in the lab and in the field. They compare the same context (donations) in a lab and field setting. In contrast, we relate context-free (intrinsic pro-social behavior) experiments to context-rich field behavior in different domains (with potential strategic motivations). In this respect, it is interesting that we find that intrinsic socially responsible investors donate substantially more to charity, do more voluntary work and are more likely to be registered as an organ donor, but do not find such an effect for strategic socially responsible investors.

This chapter is organized as follows. Section 2 presents the administrative investor data and the survey and experimental design. Section 3 derives the main hypothesis, section 4 presents the empirical results and we conclude in section 5 .

\section{Administrative investor data and experimental design}

In this section, we first describe the administrative investor data, secondly the design of the artefactual field experiment and finally the survey design.

We have access to administrative individual investor data from the largest mutual fund company in the Netherlands, covering the period January 1992 June 2010. A mutual fund company is one provider of a collection of mutual funds, like Vanguard, Fidelity and iShares in the United States. The mutual fund company in our study offers a wide range of investment funds, including equity funds, bond funds and mixed funds. Within each of these categories the company offers a list of funds like global funds, sector funds and socially responsible funds ${ }^{12}$. We observe in the administrative data which investors hold a socially responsible mutual fund and which do not. We define a socially responsible investor as an individual that holds at least one socially responsible mutual fund.

In contrast to conventional mutual funds, which only have a private earnings component (financial returns), socially responsible mutual funds can be perceived as also having a public good component. Socially responsible funds focus on broader societal issues by, for example, investing in companies that take care of human rights, employee relations, environmental protection, etc. (Social Investment Forum (2010), Bauer and Smeets (2012)). In the Netherlands socially responsible investing is a widespread phenomenon, as $18 \%$ of all private investors holds a socially responsible mutual fund (Millward Brown, 2011). Also in the rest of Europe and the United States, socially responsible in-

\footnotetext{
${ }^{12}$ For more information on the administrative investor data, see Bauer, Smeets and Wolk (2012)
} 
vestment is a growing industry (Social Investment Forum (2010), EUROIF (2010)).

In the administrative data set, there are 3,382 socially responsible investors, which were all invited to participate in the survey and the experiment. In addition, we randomly selected 38,305 investors from the approximately 145,000 remaining accounts in our database ${ }^{13}$. All selected investors received an email that contained a link to the on-line survey in spring 2011. In total, 2,957 investors completed the on-line survey. The response rate is $8 \%$ for conventional investors and $12 \%$ for socially responsible investors.

The investors that participated in the survey answered general questions and took part in three artefactual field experiments. For every investor, we measure risk preferences and time preferences (the latter are not reported in this chapter). We randomized the order of these two experiments, so that about half of the investors first completed the risk preference task and the other half first got the time preference task. In addition, each investor was randomly assigned either to the public goods game or to the trust game. We informed investors that at the end of the survey, it would be randomly determined (with a chance of one out of ten) whether they get paid the earnings from the experiment or not ${ }^{14}$. Those who were selected for payment got one of the three experiments (risk, time or social) paid out at random. We paid investors via bank transfer at the first working day after they completed the survey and payments were guaranteed by Maastricht University. We used a unique identification number to link the choices in the experiments and responses to the survey to our administrative data. The abstract identification number ensures the anonymity of the participants, of which we informed participating investors at the beginning of the survey.

The introduction to the on-line survey explained the general procedure, including an explanation about the earnings. In the first part of the survey, we asked about general investment issues like the assets held, the number of investment accounts held and investment goals. In this first part, investors also participated in the risk (and time) preferences elicitation experiment. The public goods and trust game are conducted afterwards and appear somewhere in the middle part of the survey. We asked all survey items regarding socially responsible investing and social behavior after the public goods experiment or the

\footnotetext{
${ }^{13}$ We excluded investors that were no longer holding the account at the time we conducted the experiments. We also did not invite investors that never placed a single trade and that were younger than 18 years.

${ }^{14}$ One could be concerned with the fact that only one in every ten participants gets the earnings of the experiments paid out. For instance, this might affect the level of risk aversion in the risk preference lottery. However, we are not so much interested in the level of preferences, but rather in the crosssectional differences between individuals. Moreover, Dohmen et al. (2011) validate the risk preference lottery used in this chapter, by using a dataset in which also only a fraction of the participants got the earnings paid out.
} 
trust game. Subjects were aware that there were three experiments in total, but they did not know what the experiments were about until they actually participated in them.

The main analyses in this chapter are based on the second mover behavior in the trust game. We also have data on the behavior of first movers in the trust game, but do not report on this here for brevity and because it is rather a measure of trust and not of pro-social behavior per se. The total number of subjects that participated as a second-mover in the trust game is about 600 .

\subsection{Artefactual field experiment - the trust game}

To measure intrinsic pro-social behavior, we use a variant of the trust game introduced by Berg, Dickhaut and McCabe (1995). Both the first mover and the second mover are endowed with 50 euro. The first mover decides on the amount he or she wants to send to the second mover, which can be any multiple of 5 euro, including zero and 50. The amount sent is tripled and the second mover decides how much of the received money to return to the first mover. Hence, the earnings of the first mover are 50 euro minus the amount sent plus the amount returned by the second mover. The earnings of the second mover are 50 euro plus triple the amount sent by the first mover minus the money sent back. Before the experiment starts, we first asked investors a couple of comprehension questions that were correctly answered by $89.5 \%$ of the investors ${ }^{15}$.

To minimize reputation effects, the trust game was played only once, and investors were informed that they and the other participants in the experiment would remain anonymous during and after the experiment.

We use the strategy method (Selten, 1967) for second movers, which means that the second mover decides how much to send back, for each of the 11 possible amounts sent by the first mover - ranging from 0 euro to 50 euro. We randomly match each second mover to a first mover and only the amount actually sent by the first mover determines the earnings. We use the strategy method because of practical reasons and in order to get a more comprehensive measure of the behavior of these investors. This method is also used by Falk and Zehnder (2007), Baran, Sapienza and Zingales (2010) and Falk, Meier and Zehnder (2011).

Second movers in the trust game are randomly assigned to one of the two conditions. In one condition, they are matched to a first mover who is a randomly chosen individual investor who participates in the survey and the experiment. In the other condition, a second mover is randomly matched to a first mover who is a socially responsible investor who participates in the survey and the experiment. We inform subjects in the introduction to the experiment whether

\footnotetext{
${ }^{15}$ We run our main analysis with all investors and confirm in unreported regressions that the results stay the same when excluding investors who answered incorrectly to at least one question after three trials.
} 
they are matched to a randomly chosen individual investor or to a randomly chosen socially responsible investor. Subjects are not made aware that there are two different conditions. In the analyses, we control for the treatment condition of investors.

\subsection{Measuring risk preferences}

We measure risk preferences with incentivized multiple price list lotteries, similar to Holt and Laury (2002) and Dohmen et al. (2011). Investors faced 20 different decision situations and for each situation they decided between receiving a specific sure amount and a lottery with a 50\% chance of winning 300 euro and a $50 \%$ chance of winning nothing. The choices presented to investors in the experiment are identical to Dohmen et al. (2011) and can be found in Table A.1 in the appendix. The sure amount was minimally 0 euro and maximally 190 euro and increased in steps of 10 euro from one to the next decision situation. It is determined randomly which of the 20 decisions is relevant for the earnings.

The choices made by individuals in each of the 20 decision situations, allow us to estimate their risk preferences. We investigate the point at which individuals switch between the gamble and the certain choice. A risk neutral individual will switch at a sure amount of 150 euro, which is the expected value of the gamble. Therefore, a risk-averse individual will switch at an amount below and a risk seeking individual at an amount above 150 euro.

\subsection{Survey questions}

In the first part of the survey, we asked investors about general investment issues. This part includes questions about their investment portfolio and risk tolerance. We asked all questions regarding socially responsible investing and pro-social behavior after the trust game experiment.

\subsection{Distinguishing strategic and intrinsic socially responsible investors}

To distinguish between strategic and intrinsic socially responsible investors, we asked socially responsible investors the following question (answer frequency in last column): 
What is the most important reason for you to hold socially responsible mutual funds (one answer possible)?

\begin{tabular}{llc}
\hline Intrinsic Reasons & Social Investment & $36.6 \%$ \\
& Environment & $23.0 \%$ \\
& Long-term character of SRI & $11.9 \%$ \\
\hline Strategic (Financial) Reasons & Tax advantages & $6.6 \%$ \\
& Higher expected return & $5.5 \%$ \\
& Better risk-return trade-off & $5.5 \%$ \\
& Diversification benefits & $4.7 \%$ \\
\hline Not Classified & Other reason; being ... & $1.7 \%$ \\
& I don't know & $0.6 \%$ \\
& I don't want to tell & $0.6 \%$ \\
\hline
\end{tabular}

To classify socially responsible investors as strategic or intrinsic, we first exclude all individuals who answer 'other', 'I don't know', 'I don't want to tell' and only focus on the remaining investors. We classify $26.4 \%$ of the remaining socially responsible investors as strategic, because they indicate to hold SRI mutual funds for getting a tax advantage, a higher expected return, a better riskreturn trade-off or diversification benefits. The other $73.6 \%$ of the socially responsible investors are classified as intrinsic, because they indicate the 'environment', 'social involvement' or 'because of the long term character of SRI' as the main reason for holding a socially responsible mutual fund.

There is a potential concern regarding a social desirability bias by distinguishing between strategic and intrinsic pro-social behavior based on a selfreported survey question. We cannot fully exclude the possibility that some investors give a socially desirable answer, but we are confident in our measure for two reasons. First, the administrative investor data allow us to check whether an investor holds a socially responsible mutual fund with or without tax advantages. We expect that strategic socially responsible investors are more likely to hold a fund with tax benefits. Indeed, we observe that $43.1 \%$ of the investors who hold a SRI fund with tax benefits indicate a strategic reason, but only $23.8 \%$ of the investors who hold a SRI fund without tax benefits provide a strategic reason. Second, we will show that investors who indicate that they invest socially responsible for an intrinsic reason also behave more pro-socially in the incentivized trust game.

Still, one could argue that strategic pro-social investors will actually not tell so in the survey. Their signaling benefits might disappear if they communicate in the survey that they are a strategic pro-social type instead of an intrinsic prosocial type. We are confident that this does not invalidate our results, because, first, survey participants are assured that the survey answers are treated confidentially and anonymously. Second, we likely underestimate the prevalence of strategic pro-social behavior if actually strategic pro-social investors indeed 
answer in a perceived socially desirable way. These investors would then be wrongly classified as intrinsic. The noise this creates in our measure should reduce any correlation between our survey measure of intrinsically pro-social behavior and behavior in the trust game. Hence, we would underestimate any correlation between our survey measures and pro-social behavior in the incentivized artefactual field experiment.

\subsection{Measuring pro-social behavior in different field contexts}

In addition to socially responsible investments as a measure of pro-social behavior in the administrative data, we collect self-reported pro-social field behavior in other contexts. Specifically, investors indicated whether they are registered as an organ donor, how often they do voluntary work and how much they annually donate to charities. We asked the following questions:

How much does your family donate to charity annually?

- _euro

- Idon't know

- I don't want to tell

Are you registered as an organ donor?

- Yes

- No

- I don't know

- I don't want to tell

How often do you do voluntary work? Choose the answer that most closely matches your personal situation.

- Once every week or more often

- Several times per month

- Several times per year

- Once per year

- Less often

- Never

- I don't want to tell

For the question on donations to charity and voluntary work, we excluded investors who answered "I don't know", or "I don't want to tell". We measured donations to charity as the amount that investors fill out in the open answer box. We created a dummy for voluntary work that has a value of 1 if the investor 
does voluntary work at least several times per month and 0 otherwise. We classified someone as organ donor if he or she answered "yes" and classified him or her as not registered if he or she answered "no", "I don't know", or "I don't want to tell". For robustness, we excluded investors in the latter two categories in unreported analysis and this gives similar results ${ }^{16}$.

At the end of the survey, we collected a large variety of demographic information including income, wealth, number of children and marital status. The complete questionnaire is available upon request.

\section{Hypotheses}

There is a large body of evidence indicating that individuals behave both prosocially in experiments and in the field. Sobel (2005) distinguishes between strategic and intrinsic pro-social behavior. Strategic pro-social behavior is motivated by factors such as signaling and reputation while intrinsic pro-social behavior does not provide these personal benefits, but is motivated by factors such as intrinsic reciprocity (Rabin, 1993) and inequality aversion (Fehr and Schmidt (1999), Bolton and Ockenfels (2000)).

An advantage of controlled experiments is that researchers can systematically allow and disallow for strategic benefits from pro-social behavior. In oneshot anonymous trust games, public goods games or dictator games, there are no strategic benefits to behaving pro-socially. Yet, even without strategic benefits, a majority of subjects behave pro-socially in these experiments (e.g. Andreoni (1995), Berg, Dickhaut and McCabe (1995), Ledyard (1995), Glaeser et al. (2000), Sobel (2005), Egas and Riedl (2008), Fischbacher and Gächter (2010)).

There are a few studies that distinguish between strategic and intrinsic prosocial behavior in laboratory experiments with students (Gächter and Falk (2002), Cabral, Ozbay and Schotter (2011), Dreber, Fudenberg and Rand (2011), Reuben and Suetens (2011)). These papers introduce multiple rounds over which subjects build a reputation, which can give them strategic benefits in future rounds. Together, these papers suggest that pro-social behavior in repeated games is both driven by strategic and intrinsic considerations. Pro-social behavior in the field can also be strategic and intrinsic. For instance, people can do voluntary work because of altruistic (intrinsic) reasons or because of signaling to others that they are a cooperative type (strategic benefits). List (2006) shows that reputation can indeed play an important role in the field.

The distinction between strategic and intrinsic pro-social behavior predicts differences in the correlation between pro-social behavior in the artefactual

\footnotetext{
${ }^{16}$ For the overall sample, $1.7 \%$ indicates that they do not know whether they are registered as an organ donor and $4.2 \%$ do not want to tell. For voluntary work, $2 \%$ indicate they do not want to tell. $14.8 \%$ of investors do not know how much they donate to charity and $9.5 \%$ do not want to tell.
} 
field experiments and the behavior in the field for different investor types. In particular, we expect a correlation between intrinsic pro-social behavior in the experiments and intrinsic pro-social behavior in the field. For example, a truly altruistic individual is expected to behave pro-socially in the trust game and donate to a charity for altruistic reasons. However, an individual that behaves strategically pro-social in the field is not more likely to behave pro-socially in an anonymous one-shot experiment than someone who does not behave strategically pro-social in the field. For instance, someone who does voluntary work to signal his or her pro-sociality to others does not have such signaling possibilities in the anonymous one-shot trust game. We therefore hypothesize that, in comparison to other investors, intrinsic socially responsible investors behave most pro-socially in the trust game and also behave more pro-socially in other domains in the field.

\section{Results}

\subsection{Variable definitions and summary statistics}

Table 1 presents the summary statistics of our sample of individual investors. With a share of $87.3 \%$ most participants are men, the average age is 57 years and $51.3 \%$ of investors has a university degree. These investor characteristics closely resemble those of individual investors at two explicitly socially responsible banks in the Netherlands (Bauer and Smeets, 2012). This suggests that in terms of observable characteristics, there is not much difference between the clientele of a mainstream broker (this study) and specifically socially responsible banks. Yet, the difference between the clientele can be in the unobservable characteristics.

The administrative data show that $19.8 \%$ of the investors in the sample owns at least one socially responsible mutual fund and these investors are therefore classified as being socially responsible investors. We use the survey responses to further classify these investors as either strategic socially responsible or intrinsic socially responsible. There are $14.6 \%$ intrinsic socially responsible investors and $5.2 \%$ strategic socially responsible investors ${ }^{17}$. About two thirds of all participating investors is matched to a randomly selected investor in the trust game or public goods game and the remaining one third is matched to a randomly selected socially responsible investor.

\footnotetext{
${ }^{17} 73.7 \%$ of the socially responsible investors gives an intrinsic reason to hold SRI funds. Therefore, $73.7 \%$ of $19.8 \%$ socially responsible investors gives $14.6 \%$ intrinsic socially responsible investors.
} 


\section{Table 1 - Summary statistics}

This table presents the summary statistics of our sample. 'No of Kids' is a variable representing the number of kids of the individual. 'Strategic SRI' is a dummy that has a value of one if the investor holds a socially responsible mutual fund in the administrative data and the investor indicates to have a strategic reason. 'Intrinsic SRI' is a dummy that has a value of one if the investor holds a socially responsible mutual fund for an intrinsic reason. 'Matched to SR Investor' has a value of one if the investor is matched to randomly selected socially responsible investors in the trust game or public goods game and zero if the subject is matched to randomly selected investors. 'Risk preferences' corresponds to the switch amount that determines the level of risk aversion in the risk preference lottery, measured in euro. Low wealth refers to liquid wealth (excluding real estate) of less than 75,000 euro, median wealth is between 75,000 and 250,000 euro and high wealth is above 250,000 . Low income is below 60,000 per year, medium income between 60,000 and 100,000 euro and high income is above 100,000 euro per year.

\begin{tabular}{lcccccc}
\hline & $\mathrm{N}$ & Mean & Median & S.D & Min & Max \\
\hline Male & 1349 & 0.87 & 1 & 0.33 & 0 & 1 \\
Age & 1333 & 56.96 & 56 & 10.82 & 24 & 91 \\
University Degree & 1254 & 0.51 & 1 & 0.50 & 0 & 1 \\
Married & 1254 & 0.70 & 1 & 0.46 & 0 & 1 \\
No of Kids & 1254 & 1.75 & 2 & 1.27 & 0 & 5 \\
Intrinsic SRI & 1140 & 0.15 & 0 & 0.35 & 0 & 1 \\
Strategic SRI & 1140 & 0.05 & 0 & 0.22 & 0 & 1 \\
Matched to SR Investor & 1351 & 0.31 & 0 & 0.46 & 0 & 1 \\
Risk Preferences & 1351 & 113.87 & 110 & 40.16 & 0 & 200 \\
Low Wealth & 1248 & 0.27 & 0 & 0.44 & 0 & 1 \\
Medium Wealth & 1248 & 0.33 & 0 & 0.47 & 0 & 1 \\
High Wealth & 1248 & 0.24 & 0 & 0.42 & 0 & 1 \\
Untold Wealth & 1248 & 0.16 & 0 & 0.39 & 0 & 1 \\
Low Income & 1248 & 0.30 & 0 & 0.46 & 0 & 1 \\
Medium Income & 1248 & 0.32 & 0 & 0.47 & 0 & 1 \\
High Income & 1248 & 0.21 & 0 & 0.41 & 0 & 1 \\
Untold Income & 1248 & 0.16 & 0 & 0.37 & 0 & 1 \\
\hline
\end{tabular}

Risk preferences correspond to the switch amount that determines the level of risk aversion in the risk preference lottery, measured in euro ${ }^{18}$. Table 1 shows that the average investor switches at 113.87 euro (S.D. $=40.16$ ) indicating that the average investor is risk averse. (The risk neutral switching point is at 150 euro.) This result is in line with findings in other studies (Barsky et al. (1997), Holt and Laury (2002), Dohmen et al. (2011)) who also find that individuals are risk averse in similar experiments. Similar to those studies we also find prominent number effects particularly at 100 euro and at the risk neutral switching point of 150 euro. In addition, we observe a large variation in risk tolerance.

\footnotetext{
${ }^{18}$ About $5 \%$ of the investors have multiple switch points in the risk preference task. We take the first switching point as their level of risk aversion.
} 
Income and wealth are self-reported amounts and we merged some categories to get about equally sized groups for low, medium and high income and wealth, respectively ${ }^{19}$. Of all investors, $16.4 \%$ indicate that they do not want to tell their income and $16.1 \%$ do not report their wealth. In our analyses we control for missing income and wealth. Low wealth refers to liquid wealth (excluding real estate) of less than 75,000 euro, median wealth is between 75,000 and 250,000 euro and high wealth is above 250,000 euro. Low income is below 60,000 euro per year before taxes, medium income between 60,000 and 100,000 euro and high income is above 100,000 euro per year.

To test whether investors perceive socially responsible mutual funds as products with a public goods component, we asked all respondents two questions. First, we asked investors to rate their agreement to the statement "I believe that socially responsible investing contributes to a better society." Investors believe that they positively contribute to a better world by holding socially responsible mutual funds (5.0 on a 1-7 scale) and thus create a positive externality. Second, we asked investors about their beliefs on the returns of SRI mutual funds compared to conventional mutual funds. About $60 \%$ of the investors expects a lower return on SRI mutual funds compared to conventional mutual funds. Most socially responsible investors therefore in expectation get lower investment returns than conventional investors do. In other words, most SR investors pay a price for contributing to a public good through socially responsible investments.

\subsection{Intrinsic pro-social behavior of investors}

Do individual investors behave intrinsically pro-social? Figure 1 depicts the behavior of investors in the trust game in the basic condition, in which investors are matched to a randomly selected participating investor. The figure shows the amounts returned by the second mover for a maximum transfer by the first mover of 50 euro. On average, investors return 74.57 euro (S.D. $=34.90$ ) to the first mover, which is about $50 \%$ of what they have received. Hence, on average investors behave trustworthy, which indicates intrinsic pro-social behavior. First movers on average earn a return of almost 50\% (24.57 euro) on sending their endowment of 50 euro to the second person. In fact, the most common back-transfer is 100 euro, which corresponds to an equal split of total earnings.

The level of trustworthiness found among investors is similar to (and sometimes even slightly higher than) that found among other subject pools (Glaeser et al. (2000), Fehr and List (2004), Baran, Sapienza and Zingales (2010), Falk,

\footnotetext{
${ }^{19}$ We also have a proxy for wealth in the investor database, which is the account size in euro. However, we believe that it is better to use the self-reported measure of wealth, because this covers wealth at all investment accounts and not only the wealth in the account of this mutual fund company. The proxy for wealth from the administrative data is not significantly related to behavior in the trust game.
} 
Meier and Zehnder (2011)). This is interesting, because at the outset it is not clear that investors behave intrinsically pro-social to the same extent as university students or participants recruited from other subject pools. After all, investors tend to be experienced financial decision makers, which could potentially make them behave more like homo economicus.
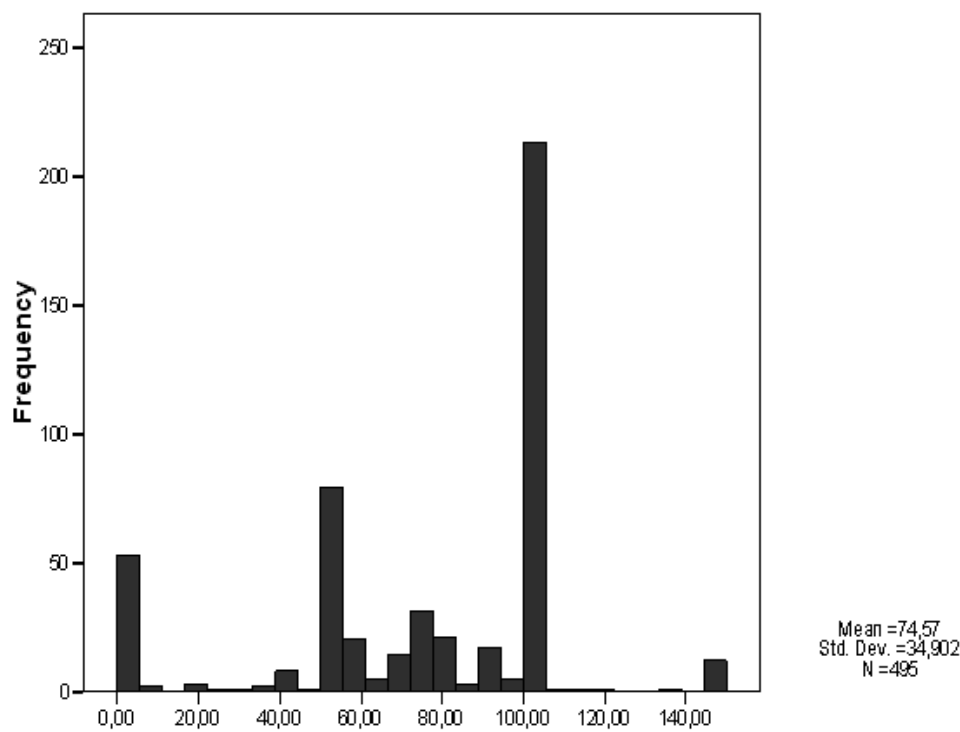

Figure 1 - Intrinsic pro-social behavior in the trust game

This figure presents the distribution of the level of trustworthiness of investors in the basic condition, which means that they are matched to a randomly selected investor at the same broker. Trustworthiness is measured by the amount send back by the second mover in the trust game (strategy method) for a maximum transfer of 50 euro by the first mover.

\subsection{Behavior of strategic and intrinsic SR investors in different field contexts}

We have established that a majority of individual investors behave intrinsically pro-social in an artefactual field experiment. In this section, we turn to selfreported pro-social behavior in the field. In the experiment, participating investors are required to make a choice about the amount they send back to the first mover. However, in the field, individuals make an active decision whether or not to behave pro-socially by, for instance, donating to charity or doing voluntary work. If they do not make a choice, they do not behave pro-socially. Therefore, preferences are revealed differently in the field than they are in the experiment (see e.g. Beshears et al., 2008).

Specifically, this section tests our hypothesis that intrinsic socially responsible investors also behave more pro-socially in other contexts in the field. We focus on three domains of pro-social field behavior: donations to charity, organ 
donor registrations and voluntary work. We consider three types of investors: conventional investors, investors who hold socially responsible mutual funds for a strategic (financial) reason and investors who hold socially responsible mutual funds for an intrinsic reason. These three groups have been created based on the survey question as explained above.

Figure 2 shows that investors who hold socially responsible mutual funds for an intrinsic reason also behave more pro-socially in the other three domains, which supports our main hypothesis.

Concerning organ donor registrations, $59 \%$ of intrinsic socially responsible investors is registered, which is significantly higher than the $44 \%$ for strategic socially responsible investors ( $p=0.024$, Mann-Whitney) and higher than $49 \%$ for conventional investors ( $\mathrm{p}=0.005$, Mann-Whitney). As a comparison, $48 \%$ of the population in the Netherlands is registered as an organ donor ${ }^{20}$ (Ministerie van Volksgezondheid, 2011). Our results show that conventional investors almost have the same rate of organ donor registrations as the average person in the Netherlands, but that intrinsic socially responsible investors are significantly more likely to be registered. The difference between strategic and conventional investors is not statistically significant.

Voluntary work is done at least once per month by $51 \%$ of intrinsic socially responsible investors, which is significantly higher than the $42 \%$ among conventional investors ( $\mathrm{p}=0.007$, Mann-Whitney). Of the strategic socially responsible investors $43 \%$ does voluntary work, but this is not statistically different from the other two groups (probably because of a lack of power due to the small sample size of strategic socially responsible investors).

Intrinsic socially responsible investors on average donate 1,319 euro to charity annually, which is substantially more than the 783 euro of conventional investors ( $\mathrm{p}=0.000$, Mann-Whitney) and the 769 euro $^{21}$ for strategic socially responsible investors ( $\mathrm{p}=0.092$, Mann-Whitney). The difference in donations between intrinsic socially responsible investors and the other two groups is large, because intrinsic pro-social types donate $68 \%$ more than conventional investors and $72 \%$ more than strategic pro-social types donate.

This evidence that intrinsic socially responsible investors are also more likely to behave pro-socially in other domains suggests that pro-social behavior is at least partly stable across domains. We show that the difference between intrinsic pro-social types and the other two types is the largest for donations to charity. This is important, because donations to charity arguably give fewer opportunities for signaling and reputation building than does voluntary work and organ

\footnotetext{
${ }^{20}$ Unfortunately, there is no data available on the organ donor registration spilt into demographic categories, so that we can match the sample characteristics. It is the case, that in the Netherlands overall more women than men are registered as an organ donor.

${ }^{21}$ The average household in the Netherlands donated 308 euro in the year 2007 (Central Bureau of Statistics (CBS) of the Netherlands). However, these numbers cannot be readily compared, because investors are generally wealthier than non-investors are. We do not have more detailed data.
} 
donor registrations. The largest amount of charitable donations are made via bank transfers that are anonymous and charitable door-to-door fund raising typically represent only small amounts of a couple of euro.

In contrast to charitable donations via bank transfer, voluntary work is clearly visible to others and therefore gives signaling benefits. Strategic prosocial investor types might care about these signaling benefits more than intrinsic pro-social types. Similarly, there are signaling benefits when being registered as an organ donor. From anecdotal evidence, people often tell others that they are registered as an organ donor at parties or other social events. In contrast, one rarely hears: "I just donated 500 euro to charity yesterday."
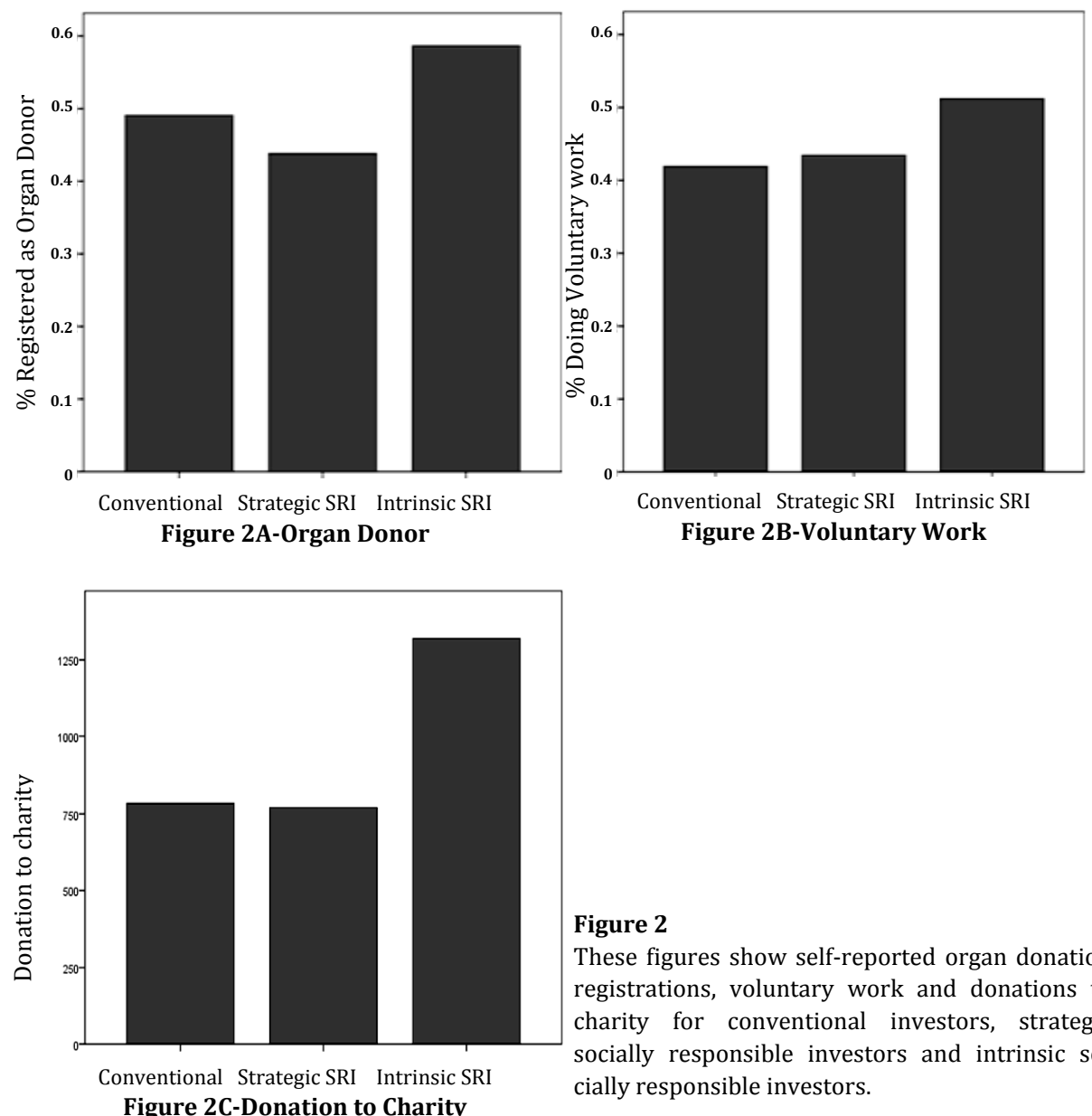

Figure 2

These figures show self-reported organ donation registrations, voluntary work and donations to charity for conventional investors, strategic socially responsible investors and intrinsic socially responsible investors. 


\subsection{Intrinsic pro-social behavior in a context-free trust game}

We have shown that intrinsic socially responsible investors also behave more pro-socially in other field contexts, in particular in domains where signaling is difficult. In this section, we explicitly rule out signaling and test whether intrinsic socially responsible investors behave more pro-socially in an anonymous one-shot trust game.

In the OLS regressions we run, the dependent variable is the amount sent back given the first mover has sent 50 euro. Although, this does not fully exploit the strategy method, it is arguable the best measure of intrinsic pro-social behavior, because the stakes are the highest (Baran, Sapienza and Zingales, 2010) ${ }^{22}$. We again distinguish between the three types of investors defined above: conventional investors, strategic socially responsible investors and intrinsic socially responsible investors. We use a dummy variable to identify intrinsic SRI, which takes on value 1 if the investor holds a socially responsible mutual fund and indicates to have an intrinsic reason, 0 otherwise. Strategic SRI is identified with a dummy variable taking on value 1 if the investor holds a socially responsible mutual fund and indicates to have an intrinsic reason.

We control for the condition in which investors participated by the dummy variable 'matched to SR investor', which takes value 1 if the subject is matched to a randomly selected socially responsible investor in the trust game and 0 otherwise.

Table 2 presents results of OLS regressions. The first specification shows that intrinsic socially responsible investors behave significantly more prosocially in the trust game than do conventional investors, which supports our main hypothesis. This type of investor sends back 7.72 euro extra $(p=0.023)^{23}$. The economic effect is quite large, because the average back transfer is 74.57 euro. Interestingly, strategic socially responsible investors are significantly less pro-social in the anonymous trust game by sending back 9.27 euro less than do conventional investors $(\mathrm{p}=0.085)$.

In the second specification, we add control variables. The effect of intrinsic socially responsible investors remains both statistically and economically unaltered, with a back transfer of 7.73 euro $(\mathrm{p}=0.025)$ more than conventional investors. The statistical significance of the strategic SRI dummy vanishes, but the economic effect remains.

Interestingly, second movers in the trust game reciprocate less to trusting behavior of socially responsible investors than to randomly selected investors, which is indicated by the significantly negative coefficient of the dummy variable "Matched to SR Investor". This effect could be due to in-group and out-group effects, which mean that individuals tend to behave more pro-socially to members similar to themselves (Goette, Meier and Huffman, 2006).

\footnotetext{
${ }^{22}$ We report on the results exploiting all choices in Table $\mathrm{A} 2$ in the appendix

${ }^{23}$ Recall that our main hypothesis is a one sided test, so we use one-sided p-values.
} 
Some of the results on the control variables in the second specification of Table 2 are worth noting. We find that risk preferences are related to intrinsic prosocial behavior. An investor with a ten euro higher switch amount in the risk preference experiment sends back 1.12 euro more. So, a risk neutral investor (switch point at 150) sends back 5.60 euro more to the first mover than does a risk-averse investor who switches at 100 euro. This is interesting, because it points to a yet unobserved correlation between risk preferences and social preferences.

Table 2 - Trust game behavior of strategic and intrinsic socially responsible investors This table presents OLS regressions in which the dependent variable is the amount that the second mover sends back in the trust game for a maximum transfer by the first mover of 50 euro. The independent variables are defined in Table 1. Standard errors are in parentheses.

\begin{tabular}{|c|c|c|}
\hline & (1) & (2) \\
\hline \multirow[t]{2}{*}{ Constant } & $76.790^{* * *}$ & $74.108^{* * *}$ \\
\hline & {$[1.761]$} & [10.649] \\
\hline \multirow[t]{2}{*}{ Intrinsic SRI } & $7.718^{* *}$ & $7.726^{* *}$ \\
\hline & [3.876] & [3.933] \\
\hline \multirow[t]{2}{*}{ Strategic SRI } & $-9.270^{*}$ & -7.992 \\
\hline & [6.742] & [6.885] \\
\hline \multirow[t]{2}{*}{ Matched to SR Investor } & -4.849 & $-5.717^{*}$ \\
\hline & [2.951] & {$[3.052]$} \\
\hline \multirow[t]{2}{*}{ Risk Preferences } & - & $0.112^{* * *}$ \\
\hline & & {$[0.035]$} \\
\hline \multirow[t]{2}{*}{ University } & - & 3.954 \\
\hline & & [2.976] \\
\hline \multirow[t]{2}{*}{ Male } & - & -3.031 \\
\hline & & {$[4.251]$} \\
\hline \multirow[t]{2}{*}{ Married } & - & -2.073 \\
\hline & & {$[3.461]$} \\
\hline \multirow[t]{2}{*}{ Low Income } & - & 3.761 \\
\hline & & [3.707] \\
\hline \multirow[t]{2}{*}{ High Income } & - & -1.535 \\
\hline & & {$[4.011]$} \\
\hline \multirow[t]{2}{*}{ Untold Income } & - & 3.874 \\
\hline & & [6.339] \\
\hline \multirow[t]{2}{*}{ Low Wealth } & - & 1.787 \\
\hline & & {$[3.702]$} \\
\hline \multirow[t]{2}{*}{ High Wealth } & - & -5.775 \\
\hline & & [3.925] \\
\hline \multirow[t]{2}{*}{ Untold Wealth } & - & -4.553 \\
\hline & & [6.290] \\
\hline \multirow[t]{2}{*}{ Age } & - & -0.233 \\
\hline & & [0.149] \\
\hline \multirow[t]{2}{*}{ Kids } & - & 1.992 \\
\hline & & {$[1.244]$} \\
\hline$R^{2}$ & 0.015 & 0.054 \\
\hline n obs. & 616 & 594 \\
\hline
\end{tabular}

*** $1 \%{ }^{* *} 5 \%{ }^{*} 10 \%$ significance level

We use one-sided p-values for strategic and intrinsic socially responsible investors, because we derive specific hypotheses for their behavior. 
The variation in income and wealth is large in our sample compared to many other studies. Interestingly, we find that income and wealth are unrelated to intrinsic pro-social behavior in the trust game. Neither are investors who do not report their income or wealth more or less pro-social than those who do report them. We also find that none of the other control variables have explanatory power for pro-social behavior in the trust game. This is consistent with previous research which shows that demographic variables can only explain a very small part of the variation in intrinsic pro-social behavior in the trust game (Glaeser et al. (2000), Falk and Zehnder (2007), Baran, Sapienza and Zingales (2010)).

In Table 3, we exploit the strategy method and run OLS regressions for back transfers for first mover transfers of 50, 40, 30, 20 and 10 euro. We find that our main effects on strategic and intrinsic behavior hold for back transfers corresponding to large transfers by the first mover. However, for small transfers like ten euro, the effects are insignificant. This is in line with results reported in Baran, Sapienza and Zingales (2010) who also find that back transfers for large amounts correlate better to pro-social field behavior than back transfers at low amounts.

In this section we have shown that intrinsic pro-social behavior in the field is correlated to intrinsic pro-social behavior in an artefactual field experiment that rules out signaling and reputation effects. Individuals who behave strategically pro-social in the field are less pro-social when the strategic incentives are absent. If we were to ignore the distinction between strategic and intrinsic prosocial investors, the differences in behavior in the trust game of these two types of investors would cancel out and we would wrongly conclude that there is no correlation between pro-social behavior in the field and in the artefactual field experiment. 
Table 3 - Full strategy method trust game

This table presents OLS regressions in which the dependent variable in column (1) is the amount returned by the second mover in the trust game (using the strategy method) for a maximum transfer of 50 euro by the first mover. The dependent variable in column (2) is the amount returned for a transfer of 40 euro by the first mover and so on. The independent variables are defined in Table 1. Standard errors are in parentheses.

\begin{tabular}{|c|c|c|c|c|c|}
\hline & $€ 50$ & $€ 40$ & $€ 30$ & $€ 20$ & $€ 10$ \\
\hline Constant & $\begin{array}{l}74.108^{* * *} \\
{[10.649]}\end{array}$ & $\begin{array}{c}61.375^{* * *} \\
{[8.363]}\end{array}$ & $\begin{array}{c}47.633^{* * *} \\
{[6.263]}\end{array}$ & $\begin{array}{c}31.964^{* * *} \\
{[4.265]}\end{array}$ & $\begin{array}{c}15.946^{* * *} \\
{[2.277]}\end{array}$ \\
\hline Intrinsic SRI & $\begin{array}{l}7.726^{* *} \\
{[3.933]}\end{array}$ & $\begin{array}{l}5.707^{\text {** }} \\
{[3.089]}\end{array}$ & $\begin{array}{l}4.316^{* *} \\
{[2.313]}\end{array}$ & $\begin{array}{c}2.276^{*} \\
{[1.575]}\end{array}$ & $\begin{array}{c}0.679 \\
{[0.841]}\end{array}$ \\
\hline Strategic SRI & $\begin{array}{c}-7.992 \\
{[6.885]}\end{array}$ & $\begin{array}{c}-5.210 \\
{[5.407]}\end{array}$ & $\begin{array}{c}-3.572 \\
{[4.049]}\end{array}$ & $\begin{array}{c}-1.745 \\
{[2.757]}\end{array}$ & $\begin{array}{c}-0.218 \\
{[1.472]}\end{array}$ \\
\hline Matched to SR Investor & $\begin{array}{l}-5.717^{*} \\
{[3.052]}\end{array}$ & $\begin{array}{c}-5.705^{* *} \\
2.397\end{array}$ & $\begin{array}{c}-4.222 \\
{[1.795]}\end{array}$ & $\begin{array}{l}-2.460^{* *} \\
{[1.222]}\end{array}$ & $\begin{array}{l}-1.262^{*} \\
{[0.653]}\end{array}$ \\
\hline Risk Preferences & $\begin{array}{l}0.112^{* * *} \\
{[0.035]}\end{array}$ & $\begin{array}{l}0.081^{* * *} \\
{[0.028]}\end{array}$ & $\begin{array}{l}0.054^{* * *} \\
{[0.021]}\end{array}$ & $\begin{array}{l}0.033^{* *} \\
{[0.014]}\end{array}$ & $\begin{array}{c}0.011 \\
{[0.007]}\end{array}$ \\
\hline University & $\begin{array}{c}3.954 \\
{[2.976]}\end{array}$ & $\begin{array}{c}3.137 \\
{[2.337]}\end{array}$ & $\begin{array}{c}1.626 \\
{[1.750]}\end{array}$ & $\begin{array}{c}0.762 \\
{[1.192]}\end{array}$ & $\begin{array}{c}0.438 \\
{[0.636]}\end{array}$ \\
\hline Male & $\begin{array}{c}-3.031 \\
{[4.251]}\end{array}$ & $\begin{array}{c}-2.741 \\
{[3.339]}\end{array}$ & $\begin{array}{c}-2.239 \\
{[2.500]}\end{array}$ & $\begin{array}{c}-1.756 \\
{[1.702]}\end{array}$ & $\begin{array}{c}-0.929 \\
{[0.909]}\end{array}$ \\
\hline Married & $\begin{array}{c}-2.073 \\
{[3.461]}\end{array}$ & $\begin{array}{c}-1.598 \\
{[2.719]}\end{array}$ & $\begin{array}{c}-1.44 \\
{[2.036]}\end{array}$ & $\begin{array}{c}-0.603 \\
{[1.386]}\end{array}$ & $\begin{array}{c}-0.408 \\
{[0.74]}\end{array}$ \\
\hline Low Income & $\begin{array}{c}3.761 \\
{[3.707]}\end{array}$ & $\begin{array}{c}3.048 \\
{[2.911]}\end{array}$ & $\begin{array}{c}2.721 \\
{[2.180]}\end{array}$ & $\begin{array}{c}2.411 \\
{[1.485]}\end{array}$ & $\begin{array}{c}0.762 \\
{[0.793]}\end{array}$ \\
\hline High Income & $\begin{array}{c}-1.535 \\
{[4.011]}\end{array}$ & $\begin{array}{c}-1.174 \\
{[3.151]}\end{array}$ & $\begin{array}{c}-0.502 \\
{[2.359]}\end{array}$ & $\begin{array}{c}-0.566 \\
{[1.607]}\end{array}$ & $\begin{array}{c}-0.469 \\
{[0.858]}\end{array}$ \\
\hline Untold Income & $\begin{array}{c}3.874 \\
{[6.339]}\end{array}$ & $\begin{array}{c}3.227 \\
{[4.979]}\end{array}$ & $\begin{array}{c}2.25 \\
{[3.728]}\end{array}$ & $\begin{array}{c}1.818 \\
{[2.539]}\end{array}$ & $\begin{array}{c}0.578 \\
{[1.355]}\end{array}$ \\
\hline Low Wealth & $\begin{array}{c}1.787 \\
{[3.702]}\end{array}$ & $\begin{array}{c}1.785 \\
{[2.908]}\end{array}$ & $\begin{array}{c}1.235 \\
{[2.178]}\end{array}$ & $\begin{array}{c}0.731 \\
{[1.483]}\end{array}$ & $\begin{array}{c}0.375 \\
{[0.792]}\end{array}$ \\
\hline High Wealth & $\begin{array}{c}-5.775 \\
{[3.925]}\end{array}$ & $\begin{array}{l}-5.112^{*} \\
{[3.083]}\end{array}$ & $\begin{array}{l}-4.172^{*} \\
{[2.309]}\end{array}$ & $\begin{array}{l}-3.030^{*} \\
{[1.572]}\end{array}$ & $\begin{array}{c}-1.746^{* *} \\
{[0.839]}\end{array}$ \\
\hline Untold Wealth & $\begin{array}{c}-4.553 \\
{[6.290]}\end{array}$ & $\begin{array}{c}-4.252 \\
{[4.940]}\end{array}$ & $\begin{array}{c}-2.928 \\
{[3.700]}\end{array}$ & $\begin{array}{c}-2.354 \\
{[2.519]}\end{array}$ & $\begin{array}{c}-1.113 \\
{[1.345]}\end{array}$ \\
\hline Age & $\begin{array}{c}-0.233 \\
{[0.149]}\end{array}$ & $\begin{array}{l}-0.199^{*} \\
{[0.117]}\end{array}$ & $\begin{array}{l}-0.155^{*} \\
{[0.088]}\end{array}$ & $\begin{array}{c}-0.100^{*} \\
{[0.06]}\end{array}$ & $\begin{array}{c}-0.037 \\
{[0.032]}\end{array}$ \\
\hline Kids & $\begin{array}{c}1.992 \\
{[1.244]}\end{array}$ & $\begin{array}{c}1.482 \\
{[0.977]}\end{array}$ & $\begin{array}{c}1.094 \\
{[0.732]}\end{array}$ & $\begin{array}{c}0.728 \\
{[0.498]}\end{array}$ & $\begin{array}{c}0.446^{*} \\
{[0.266]}\end{array}$ \\
\hline$R^{2}$ & 0.054 & 0.056 & 0.055 & 0.049 & 0.036 \\
\hline n obs. & 594 & 594 & 594 & 594 & 594 \\
\hline
\end{tabular}

*** $1 \%{ }^{* *} 5 \% * 10 \%$ significance level

We use one-sided p-values for strategic and intrinsic socially responsible investors, because we derive specific hypotheses for their behavior. 


\subsection{Public goods game}

Our main measure of intrinsic pro-social behavior is the amount returned by the second mover in the anonymous one-shot trust game. To see whether pro-social behavior is also correlated with behavior in other social decision situations we randomly assigned half of the participating investors to a linear one-shot anonymous public goods game.

There are important differences between the decisions that the trustees make in the trust game and decisions of participants in the public goods game. In particular, participants in the public goods game face uncertainty about the behavior of others and consequently beliefs are likely to play an important role. For example, Fischbacher and Gächter (2010) find that most subjects are conditional cooperators, which means that they contribute more only if (they expect) others (to) contribute more.

\subsubsection{Measuring voluntary contributions}

To measure voluntary contribution behavior, we conducted a one-shot threeperson linear public goods experiment. We used a design that is very similar to Egas and Riedl (2008) and Fehr and Leibbrandt (2011). Each investor was endowed with 40 euro and could decide to contribute nothing, everything, or a part of this money to the public good. Contributions to the public good earned a $50 \%$ return to all three group members (i.e., the marginal per capita return (MPCR) was 0.5). Thus, the value of each euro contributed to the public good was increased to 1.5 euro and then equally divided among the subjects. The earnings of an individual investor were the sum of the euro kept (i.e. the euro not invested in the public good) plus the return from the public good.

We informed investors that they were randomly matched to two other participating individual investors, who would stay anonymous during and after the experiment. Investors also knew that they would stay anonymous themselves. To ensure that participants understood the game well, we asked them a couple of comprehension questions.

After investors made their choice about how much to contribute to the public good, we elicited investors' beliefs about the contributions of the other two group members. We use the interval scoring rule to elicit these beliefs (Schlag and Van der Weele, 2009). Investors gave a confidence interval on their expectations of the contributions of the other two group members. That is, they gave a range of the minimum and maximum expected contribution. If the prediction was right (i.e. is within the interval), investors could at maximum earn an extra 5 euro. The amount they earned decreased proportionally with the size of the interval. The advantages of the interval scoring rule are, first, that investors are incentivized for their predictions, second, that it delivers a measure for both their expectation and their confidence in this prediction and, third, that it is 
easier to understand and takes less time for subjects than other measures of beliefs, like the quadratic scoring rule.

Similar to the trust game, we have two conditions in the public goods game. In the basic condition, subjects were matched to two randomly selected conventional individual investors participating in the experiment. In the second condition, subjects were matched to two randomly selected socially responsible individual investors. We informed subjects about the condition they were in, but they were not aware of the existence of different conditions.

\subsubsection{Results public goods game}

Figure 3 shows the behavior of investors in the public goods game for the basic condition of random matching. Similar to the trust game, we also observe intrinsic pro-social behavior in the public goods game. On average, investors contribute 16.88 euro (S.D. $=14.05$ ) to the public good, which corresponds to $42 \%$ of their endowment. Moreover, $72 \%$ of the investors contributes a positive amount to the public good and only $28 \%$ is pure free-rider. This level of contributions is similar to that found in comparable studies (Ledyard (1995), Sobel (2005), Egas and Riedl (2008), Fischbacher and Gächter (2010)).

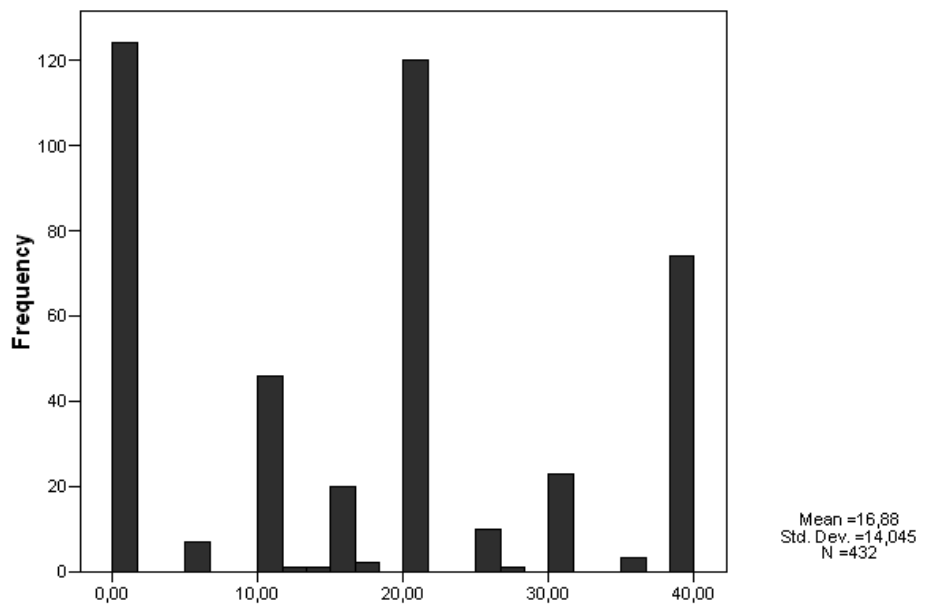

Figure 3 - Intrinsic pro-social behavior in the public goods game

This figure depicts the distribution of contributions to the one-shot public goods game of investors in the basic condition of random matching to two other individual investors at the broker. Investors are endowed with 40 euro, they are in a group of three and the marginal contribution rate is 0.5 .

According to their elicited beliefs, investors expect that the two other group members on average contribute 18.51 euro to the public good. Investors thus expect that others contribute slightly more than they do themselves (16.88 euro). Interestingly, investors are not very confident regarding their beliefs, as the average confidence range in beliefs is 12.81 euro. 
Table 4 presents OLS regressions for intrinsic behavior in the public goods game, similar to those for the trust game. The dependent variable is the euro amount contributed to the public good. Similar to the trust game, we used a dummy variable for strategic socially responsible investors and another dummy for intrinsic socially responsible investors. To control for the different experimental conditions, we used a dummy variable that takes on value 1 if the investor was matched to two randomly selected socially responsible investors and 0 otherwise.

The third specification with all control variables included shows that strategic socially responsible investors contribute 3.13 euro less to the public good than conventional investors $(\mathrm{p}=0.052)$ do. This effect is with $18.5 \%$ of the average contribution of 16.88 euro, economically significant. In contrast to the trust game, the coefficient on intrinsic socially responsible investor is insignificant, which implies that intrinsic SR investors are not more cooperative in the public goods game than conventional investors are.

It is worth noting that we do not find any statistically significant differences in beliefs of the three types of investors. All three types, conventional investors, strategic socially responsible investors and intrinsic socially responsible investors, believe that the other will contribute between 18 and 20 euro. This implies that regardless of the investor type, individuals have similar beliefs about the pro-social behavior of other investors.

We test for the effect of beliefs on contributions in the second and third specification of Table 4 . We take the midpoint of the elicited beliefs interval as a measure of her belief about the contribution of others. We find that beliefs are both statistically and economically highly significant predictors of contributions to the public good, which supports the idea of conditional cooperation. The third specification shows that investors who expect others to contribute one euro more, contribute 0.886 euro more themselves $(p=0.000)$. Hence, we find that (imperfect) conditional cooperation is not only present in laboratory experiments with students, but also in an artefactual field experiment with investors. Frey and Meier (2004) document conditional cooperation in a field experiment on charitable giving with students.

Consistent with the findings in the trust game, we again find that risk tolerance is positively related to intrinsic pro-social behavior. An investor, who has a 10 euro higher switch amount in the risk preference lottery, contributes 0.40 euro more to the public good. So, a risk neutral investor (with a switch point at 150 euro) contributes 2 euro more than a risk-averse investor does who switches at 100 euro in the risky lottery. This effect is $11.8 \%$ of the average contribution to the public good of 16.88 euro. 
Table 4 - Behavior in the public goods game by strategic and intrinsic socially responsible investors

This table presents OLS regressions in which the dependent variable is the amount that the investor contributes to the public good. The independent variables are defined in Table 1. Standard errors are in parentheses.

\begin{tabular}{|c|c|c|c|}
\hline & (1) & (2) & (3) \\
\hline Constant & $\begin{array}{c}19.638^{* * *} \\
{[0.770]}\end{array}$ & $\begin{array}{l}2.745^{* * *} \\
{[1.057]}\end{array}$ & $\begin{array}{l}8.236^{* *} \\
{[3.561]}\end{array}$ \\
\hline Intrinsic SRI & $\begin{array}{c}-1.097 \\
{[1.766]}\end{array}$ & $\begin{array}{c}0.101 \\
{[1.352]}\end{array}$ & $\begin{array}{c}-0.285 \\
{[1.373]}\end{array}$ \\
\hline Strategic SRI & $\begin{array}{l}-3.714^{*} \\
{[2.443]}\end{array}$ & $\begin{array}{c}-3.102^{* *} \\
{[1.868]}\end{array}$ & $\begin{array}{l}-3.134^{*} \\
{[1.925]}\end{array}$ \\
\hline Matched to SR Investor & $\begin{array}{c}0.859 \\
{[1.300]}\end{array}$ & $\begin{array}{r}-0.461 \\
{[.997]}\end{array}$ & $\begin{array}{c}-0.711 \\
{[1.011]}\end{array}$ \\
\hline Beliefs & - & $\begin{array}{l}0.890^{* * *} \\
{[.0461]}\end{array}$ & $\begin{array}{l}0.886^{* * *} \\
{[.0470]}\end{array}$ \\
\hline Risk Preferences & - & - & $\begin{array}{l}0.040^{* * *} \\
{[0.012]}\end{array}$ \\
\hline University & - & - & $\begin{array}{c}-0.567 \\
{[0.976]}\end{array}$ \\
\hline Male & - & - & $\begin{array}{c}1.025 \\
{[1.448]}\end{array}$ \\
\hline Married & - & - & $\begin{array}{c}-1.311 \\
{[1.195]}\end{array}$ \\
\hline Low Income & - & - & $\begin{array}{c}-1.921 \\
{[1.206]}\end{array}$ \\
\hline High Income & - & - & $\begin{array}{c}-0.671 \\
{[1.316]}\end{array}$ \\
\hline Untold Income & - & - & $\begin{array}{l}-4.816^{*} \\
{[2.473]}\end{array}$ \\
\hline Low Wealth & - & - & $\begin{array}{c}-1.812 \\
{[1.236]}\end{array}$ \\
\hline High Wealth & - & - & $\begin{array}{c}-0.803 \\
{[1.278]}\end{array}$ \\
\hline Untold Wealth & - & - & $\begin{array}{c}1.799 \\
{[2.452]}\end{array}$ \\
\hline Age & - & - & $\begin{array}{c}-0.133^{* * *} \\
{[0.05]}\end{array}$ \\
\hline Kids & - & - & $\begin{array}{c}-0.107 \\
{[0.432]}\end{array}$ \\
\hline$R^{2}$ & 0.006 & 0.420 & 0.451 \\
\hline n obs. & 523 & 523 & 508 \\
\hline
\end{tabular}

*** $1 \%{ }^{* *} 5 \% * 10 \%$ significance level

We use one-sided p-values for strategic and intrinsic socially responsible investors, because we derive specific hypotheses for their behavior. 
In addition, we find that older investors behave less pro-socially in the public goods game than younger investors do. This effect is in contrast to Egas and Riedl (2008) who find that older people contribute more in a similar three person public goods game. Since the average age in our sample is higher than in the sample of the mentioned study, this result suggests an inverse u-shape relation between age and pro-social behavior in the public goods.

\subsubsection{Contributors and free riders}

The previous section showed that strategic socially responsible investors contribute significantly less in the public goods game than conventional investors do. Fischbacher and Gächter (2010) distinguish between different types of subjects in public goods games, of which an important type is the pure free rider. In this section, we test whether strategic socially responsible investors are more likely to be pure free riders in the public goods game. In Table 5, we run binary logistic regressions in which the dependent variable is a dummy that has a value of 1 if the investor contributes a positive amount to the public good and 0 otherwise.

The third specification shows that strategic socially responsible investors are indeed significantly more likely to be a pure free rider. This finding strengthens the confidence in the survey measure that distinguishes strategic from intrinsic socially responsible investors, because the survey item is significantly related to free riding behavior in an incentivized anonymous experiment.

Specification (3) also shows that beliefs are positively related to contributing to the public good. This implies that beliefs do not only impact the amount investors contribute to the public good, but also the decision of whether to contribute at all. We also find that risk preferences are positively related to the decision to contribute. Interestingly, age does not impact the choice to contribute, but it does influence the amount contributed (as was shown in Table 4). 
Table 5 - Binary logit regressions for positive contributions in the public goods game

This table presents binary logistic regressions in which the dependent variable is a dummy that has a value of one if the investor contributes a positive amount in the public goods game and has a zero if the investor contributed nothing. The independent variables are defined in Table 1. Standard errors are in parentheses.

\begin{tabular}{|c|c|c|c|}
\hline & (1) & (2) & (3) \\
\hline Constant & $\begin{array}{l}1.111^{* * * *} \\
{[0.130]}\end{array}$ & $\begin{array}{c}-1.005^{* * *} \\
{[0.252]}\end{array}$ & $\begin{array}{c}-0.241 \\
{[0.927]}\end{array}$ \\
\hline Intrinsic SRI & $\begin{array}{c}-0.180 \\
{[0.295]}\end{array}$ & $\begin{array}{c}-0.076 \\
{[0.332]}\end{array}$ & $\begin{array}{l}-0.118 \\
{[0.352]}\end{array}$ \\
\hline Strategic SRI & $\begin{array}{c}-0.812^{* *} \\
{[0.367]}\end{array}$ & $\begin{array}{l}-0.910^{* *} \\
{[0.434]}\end{array}$ & $\begin{array}{c}-1.047^{* *} \\
{[0.463]}\end{array}$ \\
\hline Matched to SR Investor & $\begin{array}{c}0.200 \\
{[0.224]}\end{array}$ & $\begin{array}{c}0.020 \\
{[0.256]}\end{array}$ & $\begin{array}{c}0.014 \\
{[0.272]}\end{array}$ \\
\hline Beliefs & - & $\begin{array}{c}0.13^{* * *} \\
{[0.014]}\end{array}$ & $\begin{array}{l}0.141^{* * *} \\
{[0.016]}\end{array}$ \\
\hline Risk Preferences & - & - & $\begin{array}{l}0.010^{* *} \\
{[0.003]}\end{array}$ \\
\hline University & - & - & $\begin{array}{c}0.022 \\
{[0.255]}\end{array}$ \\
\hline Male & - & - & $\begin{array}{c}-0.032 \\
{[0.392]}\end{array}$ \\
\hline Married & - & - & $\begin{array}{l}-0.557^{*} \\
{[0.314]}\end{array}$ \\
\hline Low Income & - & - & $\begin{array}{l}-0.596^{*} \\
{[0.313]}\end{array}$ \\
\hline High Income & - & - & $\begin{array}{c}0.003 \\
{[0.354]}\end{array}$ \\
\hline Untold Income & - & - & $\begin{array}{c}-0.694 \\
{[0.636]}\end{array}$ \\
\hline Low Wealth & - & - & $\begin{array}{c}0.007 \\
{[0.334]}\end{array}$ \\
\hline High Wealth & - & - & $\begin{array}{l}-0.350 \\
{[0.326]}\end{array}$ \\
\hline Untold Wealth & - & - & $\begin{array}{c}0.418 \\
{[0.634]}\end{array}$ \\
\hline Age & - & - & $\begin{array}{c}-0.022 \\
{[0.014]}\end{array}$ \\
\hline Kids & - & - & $\begin{array}{c}-0.023 \\
{[0.111]}\end{array}$ \\
\hline pseudo $\mathrm{R}^{2}$ & 0.01 & 0.205 & 0.241 \\
\hline n obs. & 523 & 523 & 508 \\
\hline
\end{tabular}

${ }^{* * *} 1 \%{ }^{* *} 5 \%{ }^{*} 10 \%$ significance level 


\subsubsection{Discussion of differences in behavior in the trust game and the public goods game}

We have shown that strategic socially responsible investors behave less prosocially in both the trust game and public goods game. Intrinsic socially responsible investors behave more pro-socially than do conventional investors in the trust game, but they are equally cooperative in the public goods game.

Previous research also finds that the correlation between field behavior and behavior in the trust game is different than the correlation between field behavior and the public goods game. Karlan (2005) finds that pro-social behavior in the field (the repayment of a microfinance loan) is related to trustworthiness in the trust game, but not to behavior in the public goods game. Baran, Sapienza and Zingales (2010) do find a relation between second-player trust game behavior and donations to a charitable fund, but there is no correlation between behavior in an 8-person prisoner's dilemma game (similar to a public goods game) and donations to charity. They find an insignificantly negative coefficient.

There can be several reasons for this difference between the results for the trust game and public goods game. First, the trust game might just be better in measuring pro-social behavior. Second, it could be that trustworthiness is more related to pro-social behavior in the field than to conditional cooperation.

The difference between the results for the public goods and trust game can be seen in a broader discussion on the stability of personality traits and behavioral consistency across decision situations. In the psychology literature there is evidence that personality traits tend to have some stable components, but also vary depending on the context (for an overview see Ross and Nisbett, 1991). Pro-social behavior can therefore also be context dependent and this could drive the differences between the public goods and trust game.

Economists have also addressed the issue of stability in pro-social behavior. For instance, Benz and Meier (2008) show that the correlation among pro-social behaviors in different contexts is at maximum between 0.3 and 0.4. Blanco, Engelmann and Normann (2011) find that pro-social behavior across a dictator game, ultimatum game, sequential prisoner's dilemma game and public goods game only has a very low correlation at the individual level. Van den Assem, Dolder and Thaler (2012) analyze cooperative behavior in a high stakes TV show and find evidence for reciprocity, but not for conditional cooperation among the same subjects.

For both the behavior in the trust game and public goods game, we find a correlation with risk preferences. It is easier to explain our finding that risk preferences are related to pro-social behavior in the public goods game than to explain the relation we find between risk preferences and trustworthiness. In the public goods game, subjects are uncertain about the contributions of others and might therefore be risk averse about their own contributions. A risk tolerant investor is more likely to take the risk of investing into the public good than 
a risk-averse investor is. The observed correlation between risk preferences and trustworthiness is to be explored by future research.

\section{Conclusion}

We combine administrative investor data, artefactual field experiments and a survey and find that intrinsic socially responsible investors also behave more pro-socially in other domains. These domains comprise donations to charity, voluntary work and organ donor registrations. Our evidence suggests that intrinsic pro-social types behave (partly) consistently pro-social across various domains. Intrinsic pro-social types behave particularly more pro-socially than other types in domains where signaling is difficult.

Intrinsic socially responsible investors also behave more pro-socially in an anonymous one-shot trust game that rules out reputation by design. In contrast, strategic socially responsible investors are significantly less pro-social in the trust game than conventional investors are. This suggests that studies that ignore the distinction between strategic and intrinsic pro-social behavior underestimate the correlation between experiments and field behavior. The evidence we find contributes to the discussion on the usefulness of experiments to study pro-social behavior (Levitt and List (2007), Falk and Heckmann (2009)). Our evidence shows that linking highly controlled artefactual field experiments to field behavior can provide important insights in the motivations behind prosocial behavior in the field.

Our findings also have important consequences for practice. First, banks and mutual funds can benefit from distinguishing between strategic and intrinsic pro-social behavior in their marketing. They can use the fact that many investors hold socially responsible mutual funds for reputation reasons. There is anecdotal evidence of one Dutch socially responsible bank that provides debit and credit cards which display a large whale with which one can signal to others that one is a client of the socially responsible bank. In addition, banks can organize social events to support charity, where socially responsible investors can bring friends. Second, the Dutch government decided in 2011 that the tax benefits that exist on certain types of socially responsible mutual funds will be reduced from a maximum of $2.5 \%$ to $1.2 \%$. Investors who hold socially responsible mutual funds for strategic reasons will be more likely to sell these funds than investors who hold them for intrinsic reasons. 


\section{Appendix}

Table A1 - Design of the risk preference experiment

\begin{tabular}{|c|c|c|}
\hline & Safe $\mathrm{p}$ & ottery \\
\hline 1 & $€ 0 \mathrm{f}$ & or $50 \mathrm{p}$ \\
\hline 2 & & inning $€ 300$ and 50 percent chance of getting $€ 0$ \\
\hline & $€ 20$ & or 50 percent chance of winning $€ 300$ and 50 percent chance of getting $€ 0$ \\
\hline & $€$ & or 5 \\
\hline 5 & $€ 40$ & chance of winning $€ 300$ and 50 perc \\
\hline 6 & $€ 50 \mathrm{f}$ & or 50 percent chance of winning $€ 300$ and 50 percent chance of getting $€ 0$ \\
\hline 7 & $€ 6$ & $g € 300$ and 5 \\
\hline 3 & $€ 70 \mathrm{f}$ & ance of winning $€ 300$ and 50 percent \\
\hline 9 & $€ 80 \mathrm{f}$ & inning $€ 300$ and 50 \\
\hline 10 & $€ 90 \mathrm{f}$ & or 50 percent chance of winning $€ 300$ and 50 percen \\
\hline 11 & $€ 100$ & or 50 percent chance of winning $€ 300$ and 50 percent chance of $g$ \\
\hline 12 & $€ 110$ for sure & or 50 percent chance of winning $€ 300$ and 50 percent chance of getting $€ 0$ \\
\hline 13 & $€ 120$ & chance of winning $€ 300$ and 50 percent chance of $\xi$ \\
\hline 14 & $€ 130$ & or $50 \mathrm{pe}$ \\
\hline 15 & $€ 1$ & or 50 percent chance of winning $€ 300$ and 50 percent \\
\hline 16 & $€ 15$ & or 50 percent chance of winning $€ 300$ and 50 percent chance of getting $€ 0$ \\
\hline 17 & $€ 160$ for sure & or 50 percent chance of winning $€ 300$ and 50 percent chance of getting $€ 0$ \\
\hline 18 & $€ 170$ for sure & or 50 percent chance of winning $€ 300$ and 50 percent chance of getting $€ 0$ \\
\hline 19 & $€ 1$ & or 50 perc \\
\hline 20 & re & f 300 and 50 \\
\hline
\end{tabular}

Source: Dohmen et al. (2011) 


\section{Chapter 4 \\ Social Preferences and Investor Loyalty $^{24}$}

\section{Introduction}

Social preferences can have an important impact on investment decisions ${ }^{25}$. For instance, Hong and Kostovetsky (2011) show that mutual fund managers who donate to the Democratic Party select stocks that score higher on social responsibility than the stocks selected by fund managers that support the Republicans. In previous research, there is mixed evidence on the impact of corporate social responsibility (CSR) on the financial performance of companies. For instance, Hong and Kacperczyk (2009) find that sin stocks have outperformed, because many investors shun away from stocks that do not fit their social values. On the other hand, Edmans (2010) finds that companies with good employee relations outperform other companies. Derwall et al. (2005) document that companies with high scores on eco-efficiency outperform companies with low ecoefficiency. These studies use aggregate-level data.

In this chapter, we investigate at the individual investor level how social preferences influence investor loyalty towards banks that offer in-house socially responsible mutual funds. Investor loyalty can arise if investors perceive a good match between their personal values and the values of the bank. We combine experimental and survey data on individual investor choices for mutual funds. These data show that there is substantial heterogeneity in social preferences, even within the clientele of a socially responsible bank. This heterogeneity can result in different levels of investor loyalty.

We find that investors with strong social preferences are more loyal to their bank by using three alternative proxies for investor loyalty. First, we regress the share of the investment portfolio held at the socially responsible bank on our measure for social preferences. We document an economically and statistically

\footnotetext{
${ }^{24}$ This chapter is based on Bauer, Rob and Paul Smeets, 2012, Social Preferences and Investor Loyalty, working paper.

${ }^{25}$ See for instance, Statman (2004), Bollen (2007), Guiso, Sapienza and Zingales (2008), Hong and Kacperczyk (2009), SIF (2010), EUROSIF (2010), Kaustia and Torstila (2011) and Hong and Kostovetsky (2011).
} 
significant positive relation. Second, we find that investors with strong social preferences hold a smaller number of investment and savings accounts at competitive banks or brokers.

Next, we test whether the increase in investor loyalty resulting from social preferences has an impact on bank revenue. This is not clear ex ante for two main reasons. First, there is inconsistent evidence in previous research on the relation between social preferences and investor loyalty. Bollen (2007) finds that investors are more likely to keep bad performing socially responsible mutual funds than to keep bad performing conventional mutual funds, by using aggregate fund-flow data. In contrast, Bauer, Smeets and Wolk (2012) find that socially responsible investors are substantially more likely to leave a mainstream broker of mutual funds, by using individual-level transaction data. A second reason for the non-obvious link between social preferences and bank revenue is that investors with strong social preferences might hold a large share of their portfolio at the socially responsible bank, but hold a small portfolio in absolute sense and generate little revenue for the bank. For example, we find that risk preferences are negatively related to the portfolio share invested at the bank, but they are unrelated to bank revenue. The reason is that risk tolerant investors compensate the lower portfolio share by a larger portfolio in absolute sense.

We measure bank revenue by the management fees that an investor pays for the in-house mutual funds offered by the bank. We regress the revenue generated by an investor on social preferences and find a significant, positive relation. An investor with a one standard deviation increase in social preferences generates $37.5 \%$ extra revenue for the bank per year. It is possible that investors with strong social preferences have worse investment knowledge, are more risk averse and more likely to be female. If this were the case, then the effect of social preferences on investor loyalty could for instance simply reflect that investors have limited knowledge about outside investment opportunities. We show that our results are robust to a large number of control variables, including investment knowledge, risk aversion, wealth and gender.

The link between social preferences and investor loyalty is likely the result of a match between the personal values of an investor and the values of a socially responsible bank. In traditional models of portfolio choice, investors only care about risk and return. However, there is a large body of experimental evidence that individuals also behave pro-socially by giving up financial wealth to increase the utility of others (for a review, see Sobel (2005)). Moreover, Riedl and Smeets (2012) show that a majority of investors behaves intrinsically prosocially in incentivized experiments with individuals at a mainstream mutual fund broker. Social preferences also have been playing an important role evolutionary (Henrich et al., 2001) and there are also several theories in economics that explicitly incorporate social preferences (e.g. Rabin (1993), Fehr and Schmidt (1999), Bolton and Ockenfels (2000)). In fact, social preferences are 
easily observable in daily life, because many people donate to charity, help others and buy fair trade products. Given the importance of social preferences, it follows logically that a group of individual investors also considers the social responsibility of banks and mutual funds. Socially responsible investing is widespread in the U.S. (SIF, 2010) and in Europe (EUROSIF, 2010).

The match between the social values of investors and the values of the bank can result in social identification with the bank. Individuals often identify with a group or company that shares their personal values (e.g. Tajfel and Turner (1979), Akerlof and Kranton (2000, 2005)). Companies like Apple and Harley Davidson have many customers that strongly identify themselves with their brand. If an investor with strong social preferences identifies herself more with a socially responsible bank, then the prediction is that she will be more loyal to the bank. The banks in this study create a feeling of social identification by their marketing and communication efforts. For instance, they have debit and credit cards that display a whale and signal social responsibility. They also publish a monthly magazine that shows the social impact of their socially responsible banking.

Social identification can affect investor loyalty in two ways. First, social identification can give a direct utility gain to the investor, because she gets a good feeling from investing at a socially responsible bank that fits her values. Consequently, she invests a large fraction of her wealth at the socially responsible bank and stays for a long period. Similarly, Cohen (2009) finds that employees are loyal to their employer by holding a significant fraction of their portfolio in employer stock, because they identify with the company in which they work. Second, social identification can create positive affect that alters the subjective probability estimates of an investor. For example, Kuhnen and Knutson (2011) conduct experiments and show that positive affect influences financial risk taking and subjective probability estimates. Consequently, investors with strong social preferences might have higher expectations of the returns on SRI funds and become more loyal than investors with weaker social preferences.

In contrast to the positive effect of social preferences on investor loyalty documented in this chapter, Bauer, Smeets and Wolk (2012) find that socially responsible investors at a mainstream broker are more likely to close their brokerage account. The contrasting findings could arise from different levels of social identification with the socially responsible banks than with the mainstream mutual fund broker. It might be easier for investors with strong social preferences to identify with a socially responsible bank than to identify with a mainstream supplier that offers many other funds besides SRI funds.

We elicit social preferences by a conjoint analysis (Wilcox (2003), Hair et al. (2006)). In this quasi-experimental set-up, investors rate different mutual funds on their attractiveness. The mutual funds in the experiment differ in past returns, risk and fees. Most importantly, the mutual funds are either of a socially responsible or conventional nature. We extract social preferences by measuring 
the extent to which each investor in the experiment has a preference for socially responsible over conventional mutual funds. We use a conjoint analysis, because it is challenging to measure social preferences with actual investor trading in socially responsible and conventional mutual funds. The different mutual fund attributes - past returns, risk, fees and social responsibility - are often correlated. An investor who buys a SRI fund with high past performance could then wrongly be classified as having strong social preferences, but she actually chases past performance. In our experimental design, we use mutual funds of which the attributes are orthogonal to each other, which helps to isolate the effect of a preference for the social responsibility attribute.

This chapter is organized as follows. First, we present the experimental design and explain how we measure investor loyalty. Second, we present the empirical results and then conclude.

\section{Measuring investor loyalty and social preferences}

\subsection{Socially responsible investments and research design}

We collected experimental and survey data on the clientele of two socially responsible banks that offer in-house SRI mutual funds in the Netherlands and thereby also act as a mutual fund family. The two banks in this study offer the most comprehensive range of SRI mutual funds in Europe, including green funds and microfinance funds, which can be found in Table A1 in the appendix. The SRI mutual funds offered by the two banks are comparable to SRI funds offered in the U.S, of which examples are listed in Table A2. The two banks in this study are socially responsible banks that are fully dedicated to offer in-house SRI mutual funds and have no conventional (non-SRI) mutual funds. Therefore, investors with strong social preferences can identify themselves with the banks and develop loyalty.

The Netherlands offers two main advantages for the study at hand. First, socially responsible investments are widespread in the Netherlands: $18 \%$ of the investors holds a socially responsible mutual fund (Millward Brown, 2011). As a comparison, only $7 \%$ of Dutch investors holds index trackers. Second, the two socially responsible banks in this study are the market leaders in their segment and already exist for many years. This allows us to investigate loyalty by analyzing for how long investors have already been investing at the banks.

In total, the two banks had about 650,000 clients in July 2009. We dropped all clients that hold no investment products, but only hold a savings account and excluded all investors that are younger than 18 years, because their accounts are managed by their parents. From the remaining clients, we randomly selected 10,000 investors at the first bank and 8,500 investors at the second bank. The selected investors received an e-mail with a request to participate in re- 
search on investment decisions. We purposely did not mention that the research is about socially responsible investing. The e-mail contained a link that provides access to the online survey, which includes the conjoint analysis and some general questions. The survey consists of three sections that occurred in the following order: general investment issues, the conjoint analysis and socially responsible investments. The full survey - including the conjoint analysis - took participants about 20-25 minutes to complete. The survey was sent out in July 2009 and completed by 3,187 individuals, which implies a response rate of $17 \%$.

\subsection{Measuring investor loyalty and control variables}

Table 1 presents the measures we use for all variables. We measure investor loyalty with three survey items. First, we ask investors what percentage of their investment portfolio is invested at the bank in this study. Next, we ask how many investment accounts they have at other banks or brokers. Third, investors indicate how many savings accounts they have at different banks or brokers.

Table 1 - Variable overview

This table defines all variables used in the chapter.

\begin{tabular}{|c|c|}
\hline Variable & Description \\
\hline Social preferences & $\begin{array}{l}\text { The extent to which investors prefer socially responsible mutual } \\
\text { funds over conventional mutual funds, measured with a conjoint } \\
\text { analysis }\end{array}$ \\
\hline $\begin{array}{l}\text { Percentage invested at the } \\
\text { bank }\end{array}$ & $\begin{array}{l}\text { "What percentage of your portfolio is invested at bank x?" } \\
\text { - Less than } 25 \% \\
\text { - } 26-50 \% \\
\text { - } 51-75 \% \\
\text { - } 76-99 \% \\
\text { - } 100 \% \\
\text { - I don't want to tell }\end{array}$ \\
\hline $\begin{array}{l}\text { Number of investment ac- } \\
\text { counts }\end{array}$ & $\begin{array}{l}\text { "At how many different banks do you hold one or more investment } \\
\text { accounts?" } \\
\text { - One } \\
\text { - Two } \\
\text { - Three } \\
\text { - Four } \\
\text { - More than four } \\
\text { - I don't know } \\
\text { - I don't want to tell }\end{array}$ \\
\hline Number of savings accounts & $\begin{array}{l}\text { "At how many different banks do you hold one or more savings } \\
\text { accounts?" } \\
\text { - One } \\
\text { - Two } \\
\text { - Three } \\
\text { - Four } \\
\text { - More than four }\end{array}$ \\
\hline
\end{tabular}




\begin{tabular}{|c|c|}
\hline Variable & Description \\
\hline & $\begin{array}{l}\text { - I don't know } \\
\text { - I don't want to tell }\end{array}$ \\
\hline Total portfolio value & $\begin{array}{l}\text { We asked investors what percentage of their wealth is invested into } \\
\text { equity, bonds, cash and other. We multiply the percentage of equity } \\
\text { and bonds with their level of wealth to end up with their total port- } \\
\text { folio value. }\end{array}$ \\
\hline Amount invested at the bank & Percentage invested at the bank $\mathrm{x}$ total portfolio value \\
\hline Fees per year & $\begin{array}{l}\text { Average amount of mutual fund fees paid by investors to the bank. } \\
\text { We calculate this as } 1.5 \% \mathrm{x} \text { amount invested at the bank. We take } \\
1.5 \% \text { as the percentage of fees, because this is the average fee of the } \\
\text { funds in the menu of the banks. }\end{array}$ \\
\hline Total previous fees & $\begin{array}{l}\text { Average amount of mutual fund fees paid by investors during their } \\
\text { client relation with the bank. We assume that the fees remained } \\
\text { constant during the client relationship and calculate this variable as } \\
\text { fees per year x number of years investing socially responsible }\end{array}$ \\
\hline $\begin{array}{l}\text { Self-Rated investment } \\
\text { knowledge }\end{array}$ & $\begin{array}{l}\text { "How would you rate your investment knowledge?" } \\
\text { - Very poor } \\
\text { - Poor } \\
\text { - Average } \\
\text { - Good } \\
\text { - Very good }\end{array}$ \\
\hline Hold index trackers & $\begin{array}{l}\text { "Do you invest in index trackers?" } \\
\text { - Yes } \\
\text { - No } \\
\text { - I don't know }\end{array}$ \\
\hline Risk preferences & $\begin{array}{l}\text { "How would you describe your attitude towards risk in financial } \\
\text { matters?" (very risk averse 1-7 very risk tolerant) }\end{array}$ \\
\hline Low wealth & $€ 0-€ 49,999$ \\
\hline Median wealth & $€ 50,000-€ 124,999$ \\
\hline High wealth & More than $€ 125,000$ \\
\hline Low income & $€ 0-€ 49,999$ \\
\hline Median Income & $€ 50,000-€ 129,999$ \\
\hline High Income & More than $€ 130,000$ \\
\hline $\begin{array}{l}\text { Percentage invested in SRI } \\
\text { mutual funds }\end{array}$ & $\begin{array}{l}\text { "What percentage of wealth you hold in mutual funds is invested in } \\
\text { socially responsible mutual funds?" } \\
\text { - } 0 \% \\
\text { - } 1-10 \% \\
\text { - } 11-20 \% \\
\text { - } 21-40 \% \\
\text { - } 41-60 \% \\
\text { - } 61-80 \% \\
\text { - } 81-90 \% \\
\text { - } 91-100 \% \\
\text { - I don't know }\end{array}$ \\
\hline
\end{tabular}




\begin{tabular}{ll}
\hline Variable & Description \\
\hline Length of holding SRI mutual & How long do you already invest socially responsible? \\
funds & - Shorter than one year \\
& - 1-2 years \\
& - 3-5 years \\
& - 6-10 years \\
& - Longer than 10 years \\
& I don't know \\
\hline
\end{tabular}

As control variables, we use three proxies for investment knowledge. First, we measure subjective investment knowledge by asking investors to rate their level of investment knowledge from being very poor (1) to very good (5). There are potential problems with responses to survey items, but Dorn and Huberman (2005), Graham, Harvey and Huang (2009) and Van Rooij, Lusardi and Alessie (2011) show that this measure of self-reported investment knowledge is a good predictor of investor behavior. Moreover, Dorn and Huberman (2005) and Van Rooij, Lusardi and Alessie (2011) validate this survey question by demonstrating a significant correlation with an objective finance quiz. As a second proxy for investment knowledge, we use a dummy variable that indicates whether an investor has a university degree. Third, we use a dummy that has a value of one if the investor holds an index tracker, which is often seen as a smart investment strategy. Index trackers have lower fees than have actively managed mutual funds and they are also well diversified (Elton, Gruber and Busse (2004), Frazzini and Lamont (2008)). We elicit risk preferences by asking investors to rate their agreement to the following statement: "How would you describe your attitude towards risk in financial matters?" (very risk averse 1-7 very risk tolerant). This measure has been validated by Dorn and Huberman (2005) and Dohmen et al. (2011).

\subsection{Eliciting social preferences with a conjoint analysis}

We elicit social preferences with a conjoint analysis (Green and Rao (1971), Wilcox (2003), Hair et al. (2006)). Investors rate different fictitious mutual funds on their attractiveness on a 0-10 scale. The mutual funds in the conjoint analysis are either socially responsible or conventional mutual funds and they differ in past performance, risk and fees. In the experimental design, we orthogonalize the mutual fund attributes, so that past performance, risk, fees and are unrelated to each other. This is an advantage of a conjoint analysis above using trading data, where the different mutual fund attributes can be correlated.

To understand the way we elicit social preferences with the conjoint analysis, consider the following example. Suppose an investor consistently rates socially responsible mutual funds high and conventional funds low. She rates mutual funds with high and low risks identically and therefore focuses more on social responsibility than on risk. We assign this investor a high importance score for 
social responsibility and a low score for risk. We characterize the investor as having strong social preferences.

The introduction to the conjoint analysis in the survey states clearly that all mutual funds that appear are global equity mutual funds that hold stocks of companies in developed countries. Similar to Wilcox (2003), we instruct investors to rate equity mutual funds on their relative attractiveness as if they have already made their asset allocation. The order of the profiles presented to subjects is randomized to eliminate order and learning effects. We use four financial mutual fund attributes, similar to those of Wilcox (2003), and add an attribute indicating whether a fund is socially responsible or conventional. The financial attributes are: (1) returns of the fund over the last year, (2) average yearly returns over the last 10 years, (3) risk, (4) fees. Panel A of Table 2 provides a complete overview of the attributes and levels that are used in our conjoint analysis. We include short and long term past return attributes, because there is evidence that investors chase past returns (e.g. Sirri and Tufano (1998) and Frazzini and Lamont (2008)).

\section{Table 2 - Mutual fund attributes and levels used in the conjoint experiment}

Panel A shows the five mutual fund attributes presented to investors in the conjoint experiment. The levels that appear in the conjoint design are in line with levels for real mutual funds at the time we conducted the study (July 2009). Note that both past return attributes have negative return levels due to the financial crisis. The funds that show up in the experiment are a random combination of the levels shown in this table. Panel B shows an example of a mutual fund that appeared in the experiment.

Panel A

\begin{tabular}{lcccc}
\hline Mutual Funds Attributes & \multicolumn{4}{c}{ Levels } \\
\hline SRI (yes/no) & No Filters & Only & Only & Social and \\
(conventional) & Social & Environmental & Environmental \\
1 -Year Return & $-21 \%$ & $-28 \%$ & $-35 \%$ & - \\
10 -Year Return & $-4.2 \%$ & $-3.5 \%$ & $-2.8 \%$ & - \\
Risk & Low & High & - & - \\
Fees (TER) & $1 \%$ & $1.5 \%$ & $2 \%$ & - \\
\hline
\end{tabular}

Panel B

\begin{tabular}{|c|c|}
\hline Mutual Funds Attributes & Levels \\
\hline SRI (yes/no) & $\begin{array}{c}\text { Social and } \\
\text { Environmental }\end{array}$ \\
\hline 1-Year Return & $-35 \%$ \\
\hline 10-Year Return & $-4.2 \%$ \\
\hline Risk & High \\
\hline Fees (TER) & $1.5 \%$ \\
\hline
\end{tabular}


We use attribute levels that correspond closely to the real-life levels at the time we conducted the conjoint analysis (July 2009). Due to the financial crises, the returns over the last year and the average yearly return over the last 10 years are all negative. The attribute 'Risk' is represented by the levels 'low risk' or 'high risk.' These labels are nearly identical to real-life risk categorizations on websites like Morningstar. In addition, investors can click on an info-button that shows the construction of the risk categories to aid their understanding. The costs are represented by the yearly management fees. The Dutch regulator requires mutual funds to provide the total expense ratio in a transparent manner.

The social responsibility attribute has four levels that are in line with SRI funds offered in the market: the fund uses (1) only social screens, (2) only environmental screens, (3) both social and environmental screens, and (4) no screens (conventional mutual fund). We explain the screens to survey participants in the introduction to the conjoint analysis. Panel B of Table 2 shows an example of a mutual fund that was presented to the participants.

We estimate the preferences of investors for different mutual fund attributes with a simple equation:

$$
y_{j k}=\sum_{p=1}^{P} \sum_{l=1}^{L_{p}} x_{j k l p} \beta_{j l p}+\varepsilon_{j k}
$$

$y_{j k}$ is the preference of investor $j(j=1, \ldots$,$) for mutual fund k(k=1, \ldots, K) ; p(p$ $=1, \ldots, P$ ) is an index for mutual fund attributes with $P$ being their total number; $l\left(l=1, \ldots, L_{p}\right)$ is an index for attribute levels (e.g., $1 \%$ or $2 \%$ management fees) and $L_{p}$ is the number of levels defined for attribute $p ; x_{j k l p}$ is a dummy variable that takes a value of one when level $l$ of attribute $p$ holds in profile $k$ for $j$ and $x_{j k l p}=0$ otherwise; $\beta_{j l p}$ is the utility that investor $j$ attaches to level $l$ of attribute $p$, and we assume $\varepsilon_{j k}$ to be a normal independent and identically distributed (i.i.d.) error term with variance $o^{2}$.

To estimate the importance of each mutual fund attribute, we calculate the relative importance weight $\left(w_{i}\right)$ of each attribute. We do this by dividing the range in utility of one attribute by the sum of the ranges in utility for all attributes (Wilcox (2003), p. 649). For example, if $\bar{U}_{i j}$ is the estimated preference for the most desired level of attribute $j$ for $i$ and $\underline{U}_{i j}$ is the least desired level, then the importance weight of attribute $j$ relative to that of all other attributes $\mathrm{k} \in \mathrm{K}$ for investor $i$ can be calculated as:

$$
\text { Importance }_{i j}=\frac{\bar{U}_{i j}-\underline{U}_{i j}}{\sum_{\mathrm{k} \in \mathrm{K}} \bar{U}_{i k}-\underline{U}_{i k}}
$$




\section{Empirical results}

\subsection{Summary statistics and social preferences in the conjoint analysis}

The summary statistics are presented in Table 3. The total portfolio value of the average investor at bank one is 39,494 euro and 29,235 euro at bank two. The total portfolio value refers to investments in mutual funds, stocks and bonds held by the investor at the banks in this study and at other banks or brokers. The average amount invested at bank one is 14,994 euro, which corresponds to $35 \%$ of the total portfolio value that the individual holds at different banks and brokers. This indicates that the investment accounts held at the socially responsible bank make up a substantial share of investors' overall portfolio.

Individuals who want to invest socially responsible need not to restrict themselves to one bank, but can do so at both banks in this study and at several other banks and brokers. Investors on average hold two investment accounts at competing banks or brokers. We see in our data that $30 \%$ of the investors hold an investment account at both banks of this study. Investors indicate that of all the money in mutual funds they hold, 61\% and 63\% is invested in SRI mutual funds for bank one and two respectively. Clients of both banks have already been investing socially responsible for more than seven years on average.

The clientele of the socially responsible banks is well educated, because almost half of the investors have a university degree. Moreover, $25 \%$ holds index trackers at bank one and $16 \%$ at bank two, compared to $7 \%$ for the average investor in the Netherlands (Millward Brown, 2011). This suggests that socially responsible investors at least have the same level of financial literacy as conventional investors have. The clientele of the two socially responsible banks is similar in many ways, but mainly differs in portfolio value, which is significantly larger at bank one. The average age of investors and the gender composition closely resemble those of the clientele of a mainstream mutual fund broker in the Netherlands (cf. Bauer, Smeets and Wolk (2012)). 
Table 3 - Summary statistics for both banks

All variables are defined in Table 1.

\begin{tabular}{|c|c|c|c|c|}
\hline & \multicolumn{2}{|c|}{ Bank1 } & \multicolumn{2}{|c|}{ Bank2 } \\
\hline & Mean & $\mathrm{N}$ of $\mathrm{Obs}$ & Mean & $\mathrm{N}$ of Obs \\
\hline \multicolumn{5}{|l|}{ Demographics } \\
\hline Gender (Male) & $66 \%$ & 2028 & $72 \%$ & 1135 \\
\hline Age & 57.12 & 1971 & 54.22 & 1105 \\
\hline Low Wealth (€0-€49,999) & $38 \%$ & 1788 & $41 \%$ & 1028 \\
\hline Medium Wealth $(€ 50,000-€ 124,999)$ & $32 \%$ & 1788 & $33 \%$ & 1028 \\
\hline High Wealth (More than $€ 125,000$ ) & $31 \%$ & 1788 & $26 \%$ & 1028 \\
\hline Low Income (€0-€49,999) & $42 \%$ & 1794 & $39 \%$ & 1039 \\
\hline Medium Income (€50,000-€129,999) & $52 \%$ & 1794 & $54 \%$ & 1039 \\
\hline High Income (More than $€ 130,000$ ) & $6 \%$ & 1794 & $7 \%$ & 1039 \\
\hline Porfolio value (€) & 39,494 & 1254 & 29,235 & 772 \\
\hline Risk Prefernces (1-7) & 3.52 & 2044 & 3.69 & 1143 \\
\hline Married & $57 \%$ & 2009 & $58 \%$ & 1128 \\
\hline No. of Kids at Home & 0.47 & 2044 & 0.61 & 1143 \\
\hline \multicolumn{5}{|l|}{ Investment Knowledge } \\
\hline Self-Rated Investment Knowledge (1-5) & 2.64 & 2044 & 2.70 & 1143 \\
\hline University & $49 \%$ & 2027 & $46 \%$ & 1132 \\
\hline Hold Index Trackers & $25 \%$ & 1115 & $16 \%$ & 705 \\
\hline \multicolumn{5}{|l|}{ Socially Responsible Investing } \\
\hline Percentage SRI Funds & $61 \%$ & 1795 & $63 \%$ & 1075 \\
\hline Years Investing in SRI Funds & 7.41 & 1776 & 7.87 & 1058 \\
\hline \multicolumn{5}{|l|}{ Investor loyalty } \\
\hline Percentage at the bank & $35 \%$ & 1333 & - & - \\
\hline No. of Investments Accounts & 2.02 & 2036 & 1.98 & 1143 \\
\hline No of Savings Account & 2.78 & 2039 & 2.77 & 1143 \\
\hline Amount Invested at the bank (€) & 14,994 & 927 & - & - \\
\hline Fees Per Year $(€)$ & 225 & 927 & - & - \\
\hline Total Previous Fees (€) & 2,081 & 922 & - & - \\
\hline
\end{tabular}

To elicit social preferences, we run OLS regressions as in equation (1) for the conjoint analysis for the two banks separately. In the regressions, the dependent variable is the individual attractiveness rating of the mutual funds in the conjoint analysis. To minimize the influence of a different usage of response scales by individuals, we standardize the dependent variable to have a mean of zero and a standard deviation of one (Hair et al. (2006)). The independent variables comprise the five attributes that appear in the conjoint analysis. The variable SRI (yes/no) is a dummy variable that takes on the value of one if the fund either has an environmental screen, a social screen, or both and takes on a value of zero if it is a conventional mutual fund. The variables of the one-year return, 
ten-year return, and fees can take on three values depending on whether they have a low, medium, or high level in the respective profile, and the variable risk has two values: low and high. Column (1) of Table 4 provides the results of the standard regression model for the first bank, where the regression coefficients have been transformed into importance scores according to equation (2). The table presents the importance scores for each mutual fund attribute, for the average investor at the bank.

Table 4 - Social preferences and the preferences for other mutual fund attributes

This table shows the preferences of the average investor for the five different mutual fund attributes in the conjoint analysis for both banks. A higher percentage means that the attribute is more important to the investor. The importance weight on SRI (yes / no) is our central measure for social preferences and indicates the extent to which an investor has a preference for socially responsible (SRI) mutual funds over conventional mutual funds. The importance scores are estimated with OLS regressions like in equation (1) and coefficients are transformed into importance scores according to equation (2). Standard deviations are in parantheses.

\begin{tabular}{lcc}
\hline & Bank 1 & Bank 2 \\
\hline Sutual Fund Attributes & & $\mathbf{5 1 . 3 \%}$ \\
& $50.3 \%$ & $(21.6 \%)$ \\
1-year Return & $(21.7 \%)$ & $11.9 \%$ \\
& $12.3 \%$ & $(9.8 \%)$ \\
10-year Return & $(9.7 \%)$ & $10.3 \%$ \\
& $10.6 \%$ & $(10.3 \%)$ \\
Risk & $(10.7 \%)$ & $2.6 \%$ \\
& $3.0 \%$ & $(6.6 \%)$ \\
Fees & $(6.3 \%)$ & $24 \%$ \\
& $23.9 \%$ & $(12.8 \%)$ \\
Adjusted R & $(13.5 \%)$ & $3.5 \%$ \\
\hline
\end{tabular}

In general, investors at the first bank have a high importance score of $50.3 \%$ for the social responsibility attribute of mutual funds. The standard deviation of $21.7 \%$ is relatively large, which indicates substantial heterogeneity in social preferences. The importance score on the social responsibility attribute is our central measure for social preferences in the chapter and it is unique for each investor. Investors at the second bank have nearly identical preferences as investors at the first bank, which is interesting because the two banks are independent organizations. This points into the direction that the explicit focus of the banks on socially responsible investing attracts a similar clientele.

Investors have a relatively high importance weight for management fees. For bank one, this weight is $23.9 \%$, compared to $12.3 \%$ for one-year returns, $10.6 \%$ for ten-year returns and $3 \%$ for the risk classification relative to the investment category. Again, this suggests that socially responsible investors have at minimum equal investment knowledge as conventional investors, because it is generally found that investors pay relatively little attention to management 
fees (e.g. Elton, Gruber and Busse (2004), Choi, Laibson and Madrian (2010)). The low importance weight for risk might seem surprising. ${ }^{26}$ Yet, recall that the risk attribute measures the risk of a particular mutual fund relative to other mutual funds in the same investment category. A risk-averse investor might care more about risk at the asset allocation level than about the relative risk within the category of global equity mutual funds. Wilcox (2003) also finds that investors attach the least importance to the risk attribute.

We test the internal validity of the conjoint analysis by an out-of-sample Kendall's tau test (see Hair et al. (2006)). This test uses the individual importance weights to predict the ranking of six hold-out profiles that are also rated by each investor. These hold-out profiles are similar to the 16 mutual funds used to estimate the importance weights, but they differ in the attribute levels and are not used for the estimation of the importance weights. We find that the estimated importance weights can predict the rankings of the six hold-out profiles $(\mathrm{p}=0.001)$, which implies that the conjoint analysis in internally valid. In section 3.3 , we also test the external validity of our conjoint analysis and show that it has predictive power for the cross-sectional fund holdings of investors.

\subsection{Social preferences and investor loyalty}

We hypothesized that social preferences are positively related to investor loyalty. We use three measures for investor loyalty: (1) the share of the portfolio invested at the bank of interest, (2) the number of investment accounts held at competing banks and (3) the number of savings accounts held at competing banks. We expect that investors with stronger social preferences hold fewer investment and savings accounts at competing banks and invest a larger share of their portfolio at the bank of interest. We also test the effect of social preferences on the revenue generated for the bank. The regressions of the number of investment accounts and savings accounts at competitors are based on data for both banks. The regressions on the percentage invested at the bank and bank revenue are only available for the first bank.

Table 5 presents OLS regressions of the three different measures of investor loyalty on social preferences and control variables. In column (1), the dependent variable is the percentage of the portfolio invested at the bank of interest. We have transformed the categorical survey responses into a continuous measure, because this is easier to interpret. We assign a value of $37.5 \%$ to an investor who indicates that she holds between $25 \%$ and $50 \%$ of the investment portfolio at the bank. We also ran ordered probit regressions with a categorical variable that yield similar results.

\footnotetext{
${ }^{26}$ In the pre-test of the conjoint analysis, we had already found that investors attach little importance to the risk attribute. Therefore, we made the risk classification salient by using the levels "low" and "high" risk. Yet, even then investors still attached little importance to the risk attribute.
} 
Table 5 - Social preferences and investor loyalty

This table reports OLS regressions for three different measures of investor loyalty that are defined in Table 1. Specification four and five focus on the revenue generated for the bank in terms of the management fees that investors pay for holding in-house mutual funds. We elicit social preferences with a conjoint analysis. The control variables that are suppressed comprise gender, age, marital status, number of kids living at home, wealth and income dummies. The regressions on the number of investment and savings accounts held at competitors comprise the data of both banks and the other specifications are only for bank one, because the data is not available for bank two.

\begin{tabular}{lccccc}
\hline & $\begin{array}{c}(1) \\
\text { Percentage at } \\
\text { the bank }\end{array}$ & $\begin{array}{c}\text { No of Invest- } \\
\text { ments Accounts }\end{array}$ & $\begin{array}{c}\text { No of Savings } \\
\text { Accounts }\end{array}$ & $\begin{array}{c}\text { Fees per } \\
\text { Year }\end{array}$ & $\begin{array}{c}\text { Total Previous } \\
\text { Fees }\end{array}$ \\
\hline Social Preferences & $25.924^{* * *}$ & $-0.223^{*}$ & $-0.811^{* * *}$ & $388.467^{* * *}$ & $4070.381^{* * *}$ \\
& {$[5.062]$} & {$[-1.759]$} & {$[-4.455]$} & {$[4.499]$} & {$[3.995]$} \\
Investment knowledge & & & & & \\
Self-Rated Knowledge & -0.213 & $0.131^{* * *}$ & $0.104^{*}$ & -21.253 & 23.205 \\
& {$[-0.126]$} & {$[3.336]$} & {$[1.833]$} & {$[-0.716]$} & {$[0.066]$} \\
University & -2.404 & 0.017 & -0.096 & $63.628^{*}$ & $1022.198^{* *}$ \\
& {$[-1.075]$} & {$[0.326]$} & {$[-1.248]$} & {$[1.704]$} & {$[2.316]$} \\
Hold Index Trackers & -0.303 & $0.218^{* * *}$ & $0.186^{* *}$ & -19.316 & -240.509 \\
& {$[-0.119]$} & {$[3.381]$} & {$[1.997]$} & {$[-0.469]$} & {$[-0.494]$} \\
Risk Preferences & $-3.367^{* * *}$ & $0.088^{* * *}$ & $-0.062^{* *}$ & -6.252 & -9.377 \\
& {$[-3.782]$} & {$[4.153]$} & {$[-2.027]$} & {$[-0.425]$} & {$[-0.054]$} \\
Controls & Yes & Yes & Yes & Yes & Yes \\
$R^{2}$ & 0.156 & 0.126 & 0.138 & 0.208 & 0.156 \\
n obs. & 493 & 1021 & 1021 & 426 & 424 \\
\hline
\end{tabular}

${ }^{* * *} 1 \%{ }^{* *} 5 \% * 10 \%$ significance level

T-stats in parentheses

The variable 'social preferences' represents the effect of a 100\% increase in the importance attached to the social responsibility attribute in the conjoint analysis. An investor with 10\% stronger social preference invests $2.59 \%$ more at the bank of this study. Given that individuals on average invest $35.32 \%$ at the bank (see Table 2), this corresponds to an increase of 7.33\% (2.59 / $35.32 \times 100 \%$ ). Column (2) and (3) of Table 5 present regressions of the number of investment accounts and savings accounts on social preferences. Consistent with our hypothesis, we find that investors with stronger social preferences hold a smaller number of investment and savings accounts at competitors. However, the economic effect is smaller than it is for the measure of the percentage invested at the bank.

We find that risk tolerance is negatively related to our measures of investor loyalty. An increase in the risk preference variable means that investors are more risk tolerant. Investors who rate their risk tolerance one point higher on a 1-7 scale invest $3.37 \%$ of their portfolio less at the socially responsible bank. Risk averse investors might feel comfortable by investing most of their money at one bank with which they are familiar. We are not aware of previous research 
that shows a correlation between risk preferences and investor loyalty. The three proxies for investment knowledge have little effect on investor loyalty. As expected, investors who hold index trackers hold more investment accounts at competitors, because the banks in this study do not offer index trackers. For reasons of conciseness, we do not report the coefficients of all control variables. The controls comprise gender, age, income, wealth, number of kids living at home and marital status and they are defined in Table 1.

It is important that social preferences remain significant after control variables like investment knowledge and risk aversion. This shows that more loyal socially responsible investors are not simply dumb or very risk averse. This finding complements the work on investor loyalty of Bollen (2007) and Cohen (2009) who do not control for investment knowledge and risk aversion.

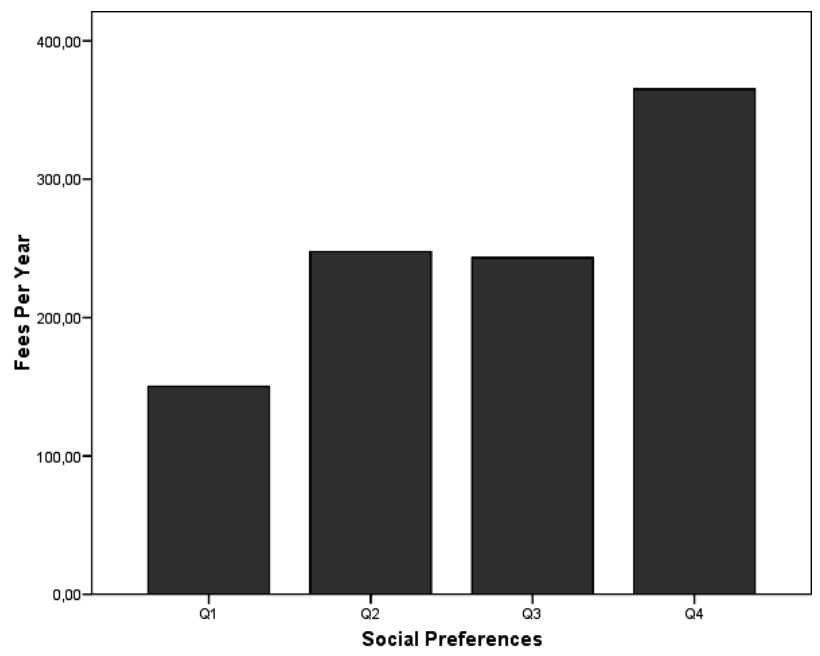

Figure 1 - Social preferences and bank revenue

This figure illustrates how social preferences are related to the fees an investor pays to the first bank for holding their in-house mutual funds. These fees are the major source of revenue for the bank. We measure social preferences with a conjoint analysis and spilt our data into quartiles based on the strength of the social preferences of an investor. Fees are measured in euro and the euro / dollar exchange rate was about 1.45 / 1 at the time of our study (July 2009).

Does the increase in investor loyalty because of social preferences also result in extra bank revenue? Figure 1 shows that investors with stronger social preferences indeed generate more revenue for the bank. We test this in a multivariate setting in the fourth specification of Table 5. Because the bank also acts as a mutual fund family by offering its own funds, the bank gets revenue from the yearly fees paid on the mutual funds. Table A1 shows that the typical mutual fund offered by the banks has management fees of $1.5 \%$ per year. We therefore calculate the average yearly revenue as the amount the individual invests at the 
bank times $1.5 \%$. The use of $1.5 \%$ average management fees only serves as an illustrative purpose and does not affect our main findings. We can interpret the coefficients in such a way that we illustrate the effect of a one standard deviation increase in social preferences on the percentage increase in fees paid per year. What ultimately matters is the amount the individual invests at the bank. If we would take $3 \%$ of management fees instead of $1.5 \%$, then all numbers would just double, but the relative difference between investors with strong and weak social preferences would remain the same.

We find that an investor who has $10 \%$ stronger social preferences generates 38.85 euro extra fees per year. The average investor pays 225 euro in fees per year (Table 3). Therefore the effect of 38.85 euro corresponds to $17.3 \%$ of the average fees paid, which is economically relevant. An investor with a one standard deviation increase in social preferences pays $37.5 \%$ more fees per year ${ }^{27}$. This is the net effect of social preferences on fees paid, after controlling for investment knowledge, risk preferences and other controls. We also look the total fees investors have generated for the bank so far. Because we have crosssectional data, we have to rely on the assumption that the fees and the amount invested at the bank have remained constant. We proxy for the years invested at the bank by the number of years the investor has been investing in socially responsible mutual funds. We find in column (5) that social preferences are also positively related to the total revenue generated by investors. Investors with $10 \%$ stronger social preferences have paid 407.04 euro more fees during their stay with the bank.

We discussed that risk tolerance is positively related to the number of investment accounts held at competitors and negatively related to the share invested at the socially responsible bank. However, we also find that risk tolerance has no impact on bank revenue. Risk tolerant investors hold a smaller share of their portfolio at the socially responsible bank, but have a larger portfolio in absolute sense. This compensates for the lower share invested.

\subsection{Reasons of motives for investors to hold investment accounts at competing banks}

To get additional insights in the relation between social preferences and investor loyalty, we asked investors: "What is the most important reason why you also invest outside of bank $\mathrm{x}$ ?" Respondents could choose the following answer options: investment products, offered fees, services, diversification and other. We split investors into two groups depending on whether they have above or below median social preferences.

\footnotetext{
${ }^{27}$ The effect of an one percentage increase in the importance score of social preferences is $1.73 \%$, namely $3.885 / 225$. Table 4 shows that the standard deviation of the social preference importance score is $21.7 \%$. The effect is therefore $1.73 \% \times 21.7=37.5 \%$.
} 


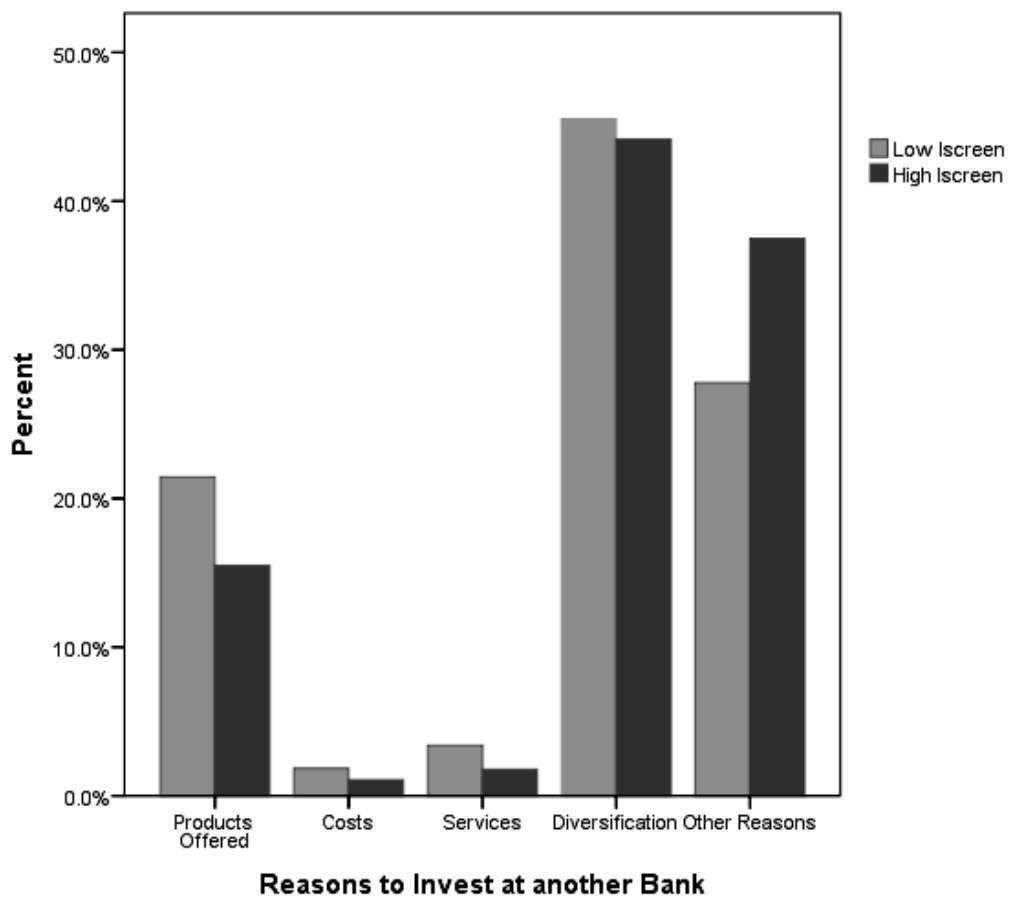

Figure 2 - Social preferences and reasons to invest at another bank

This figure spilt investors into half depending on whether they have above or below median social preferences. We asked investors for their most important reason to hold an investment account at another bank and investors could choose from the answer categories in the figure.

Figure 2 shows that the most important reasons for investors to hold an account at a competitor are diversification and other reasons ${ }^{28}$. The graph illustrates that investors with above median social preferences are less likely to hold an account at competitors because of products offered, services and fees and are more likely to give another reason. We scanned the open answers, which show that many investors indicate they already had an existing investment account at a conventional bank before they opened an account at the socially responsible bank. Many of these investors indicate they do not want to fully close the old account, but still hold their highest wealth in the account of the socially responsible bank. In particular in recent years, the two socially responsible banks have been growing in popularity.

\footnotetext{
${ }^{28}$ Investors could provide these other reasons in an open answer box.
} 


\subsection{Social preferences in the experiment and in the field}

We test the external validity by investigating whether investors who have stronger social preferences in the conjoint experiment, behave more prosocially in the field. We use two measures for pro-social field behavior. First, we ask investors what percentage of their portfolio is invested in socially responsible mutual funds. This percentage can differ from the percentage invested at the socially responsible bank in this study, because individuals can also invest socially responsible at other banks or brokers. We expect that investors with stronger social preferences in the experiment invest a larger share of their portfolio in SRI funds. The second measure of pro-social field behavior is the length of time the investor already holds SRI mutual funds. We expect that investors with strong social preferences entered the market for SRI products early, but investors with weaker social preferences waited to observe the returns on SRI funds before joining.

The first specification in Table 6 regresses the percentage of mutual funds in an investor's portfolio on the estimated importance of social preferences in the conjoint experiment and control variables. Column (1) shows that investors with stronger social preferences in the experiment hold a significantly larger share of their portfolio in socially responsible mutual funds ${ }^{29} \quad(t=12.195$, $\mathrm{p}=0.000$ ). A $10 \%$ increase in social preferences results in a $5.46 \%$ increase in the percentage of SRI funds in the portfolio of the investor. The second specification shows that investors with stronger social preferences in the conjoint experiment, have been holding SRI mutual funds for a significantly longer period $(\mathrm{t}=5.011, \mathrm{p}=0.000)$. If social preferences are $10 \%$ higher, then the investor has been holding SRI funds for 0.368 extra years. Recall that investors on average have been investing in SRI funds for 7.41 years. The relation between social preferences in the experiment and in the field holds after controlling for many confounding factors such as investment knowledge, risk aversion and gender.

\footnotetext{
${ }^{29}$ We have transformed the categorical survey responses into a continuous measure by taking the midpoint of the interval. So, if an investor indicated that she invests between $10 \%$ and $20 \%$ in SRI funds, then we take $15 \%$ for the measure. This way, it is easier to interpret the coefficients. Ordered probit regressions - not reported here - yield similar results. We use the same transformation for the years investing in SRI funds.
} 
Table 6 - Social preferences in the experiment and in the field

This table presents OLS regressions of the percentage of SRI funds from the total mutual fund holdings of the investor and the number of years the investor has been investing in SRI funds. We test the external validity of the conjoint analysis by relating it to pro-social behavior in the field. Social preferences have been measured with a conjoint analysis. The remaining variables are defined in Table 1 . We run the regressions for the data of both banks jointly.

\begin{tabular}{|c|c|c|}
\hline & $\begin{array}{c}\text { (1) } \\
\text { Percentage SRI Funds }\end{array}$ & $\begin{array}{c}(2) \\
\text { Years Investing in SRI Funds }\end{array}$ \\
\hline Social Preferences & $\begin{array}{l}54.649^{* * *} \\
{[12.195]}\end{array}$ & $\begin{array}{c}3.68^{* * *} \\
{[5.011]}\end{array}$ \\
\hline \multicolumn{3}{|c|}{ Proxies for Investment knowledge } \\
\hline Self-rated knowledge & $\begin{array}{c}-0.488 \\
{[-0.349]}\end{array}$ & $\begin{array}{l}0.495^{* *} \\
{[2.147]}\end{array}$ \\
\hline University & $\begin{array}{c}2.555 \\
{[1.348]}\end{array}$ & $\begin{array}{c}0.333 \\
{[1.071]}\end{array}$ \\
\hline Hold Index Trackers & $\begin{array}{l}-9.982^{* * * *} \\
{[-4.369]}\end{array}$ & $\begin{array}{c}-0.09 \\
{[-0.24]}\end{array}$ \\
\hline Risk Preferences & $\begin{array}{l}-2.913^{* * *} \\
{[-3.897]}\end{array}$ & $\begin{array}{c}0.05 \\
{[0.404]}\end{array}$ \\
\hline Gender (Male) & $\begin{array}{l}-3.978^{*} \\
{[-1.754]}\end{array}$ & $\begin{array}{l}-0.911^{* *} \\
{[-2.447]}\end{array}$ \\
\hline Age & $\begin{array}{l}-0.193^{* *} \\
{[-2.049]}\end{array}$ & $\begin{array}{l}0.068^{* * *} \\
{[4.419]}\end{array}$ \\
\hline Married & $\begin{array}{c}-0.19 \\
{[-0.089]}\end{array}$ & $\begin{array}{c}-0.523 \\
{[-1.493]}\end{array}$ \\
\hline No of Kids at Home & $\begin{array}{c}0.392 \\
{[0.345]}\end{array}$ & $\begin{array}{c}0.217 \\
{[1.159]}\end{array}$ \\
\hline Medium Wealth & $\begin{array}{l}-3.779 \\
{[-1.578]}\end{array}$ & $\begin{array}{l}1.11^{* * *} \\
{[2.822]}\end{array}$ \\
\hline High Wealth & $\begin{array}{l}-7.124^{* * * *} \\
{[-2.933]}\end{array}$ & $\begin{array}{l}1.282^{* * *} \\
{[3.217]}\end{array}$ \\
\hline Medium Income & $\begin{array}{c}1.43 \\
{[0.676]}\end{array}$ & $\begin{array}{c}-0.392 \\
{[-1.129]}\end{array}$ \\
\hline High Income & $\begin{array}{c}-1.623 \\
{[-0.449]}\end{array}$ & $\begin{array}{c}-0.669 \\
{[-1.129]}\end{array}$ \\
\hline$R^{2}$ & 0.229 & 0.074 \\
\hline n obs. & 1003 & 995 \\
\hline
\end{tabular}

*** $1 \% * * 5 \% * 10 \%$ significance level

T-stats in parentheses

Further, we find that risk tolerant investors hold a smaller percentage of their portfolio in SRI mutual funds. This is consistent with the negative relation we found between risk tolerance and the percentage invested at the socially responsible bank. Investment knowledge is positively associated with the years individuals have been investing in SRI funds. It is likely that the investment experience makes these individuals more knowledgeable. Investors who hold 
index trackers invest a smaller percentage of their portfolio in SRI mutual funds, which is probably why most SRI funds are active funds and not index trackers.

Men invest about 4\% less in SRI funds than do women, which implies that men behave somewhat less pro-socially than women behave in the domain of investments. Many previous studies also find that men behave less pro-socially than do women in other choice domains (Eckel and Grossman (1998), List (2004), Croson and Gneezy (2009), Van den Assem, Dolder and Thaler (2012)). Our results also demonstrate that an investor who is ten years older, holds $1.9 \%$ less of his mutual fund investments in SRI funds, which suggests that older investors behave less pro-socially than do younger ones. This is in line with Riedl and Smeets (2012) who find that older investors behave less pro-socially in an incentivized public goods experiment with individuals at a mainstream mutual fund broker. The typical investor is quite old compared to the average person in the Netherlands. Studies that focus on a sample consisting of younger people generally find that older people behave more pro-socially (List (2004), Egas and Riedl (2008)). Together, the evidence from the papers points into the direction that there is a curve linear relation between age and pro-social behavior. As individuals mature, they first increase their level of pro-social behavior up to a certain age and then start behaving more selfish.

\section{Conclusion}

Using data from two Dutch banks that offer socially responsible mutual funds and savings accounts, we show that social preferences are positively related to investor loyalty. Investors with strong social preferences also generate substantially more bank revenue. These results hold for three different proxies for loyalty and after controlling for investment knowledge, risk aversion and other confounding factors.

Investor loyalty is important for banks, because there are fixed costs associated with attracting new investors, which include marketing costs and administrative expenses. In addition, a loyal client base results in stable cash flows for the bank. A provider of in-house mutual funds (the banks in this study) has different incentives than discount brokers have, Discount brokers prefer a high trading volume among their investors, because their main revenue comes from transaction costs. In contrast, the major source of revenue for a mutual fund provider is the yearly management fee paid by investors. This means that mutual fund providers prefer investors that hold funds for a long period.

In contrast to social preferences, we find that risk tolerance is negatively correlated with investor loyalty. Risk tolerant investors have a larger number of investment accounts and savings accounts at competitors and hold a smaller share of their total portfolio at the socially responsible banks. However, there is no significant effect of risk preferences on the bank revenue. Risk tolerant in- 
vestors have a larger portfolio in absolute terms, which makes up for the lower share invested at the socially responsible banks. Future research could investigate whether the relation between risk preferences and investor loyalty also holds for conventional banks and mutual fund providers. 


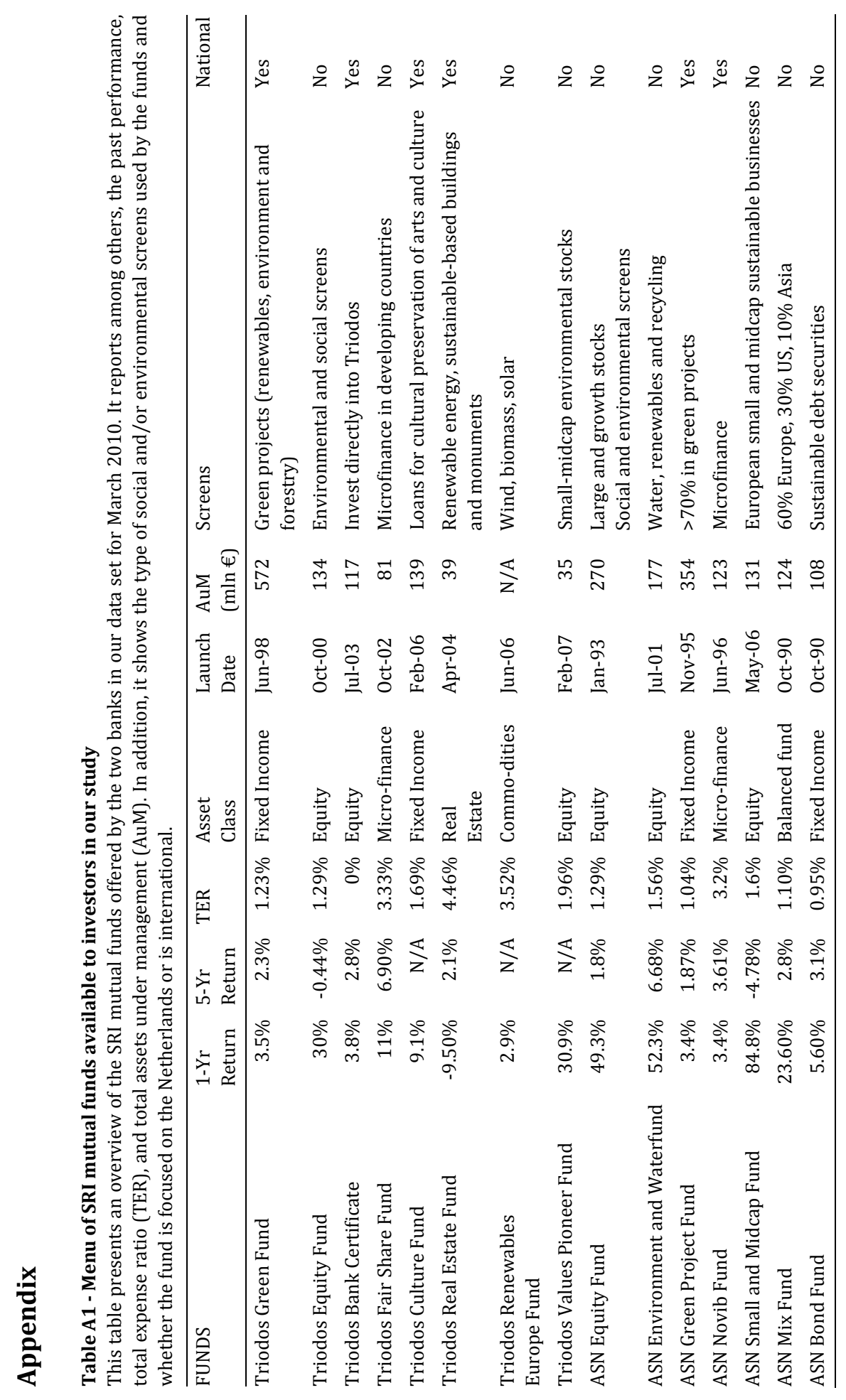




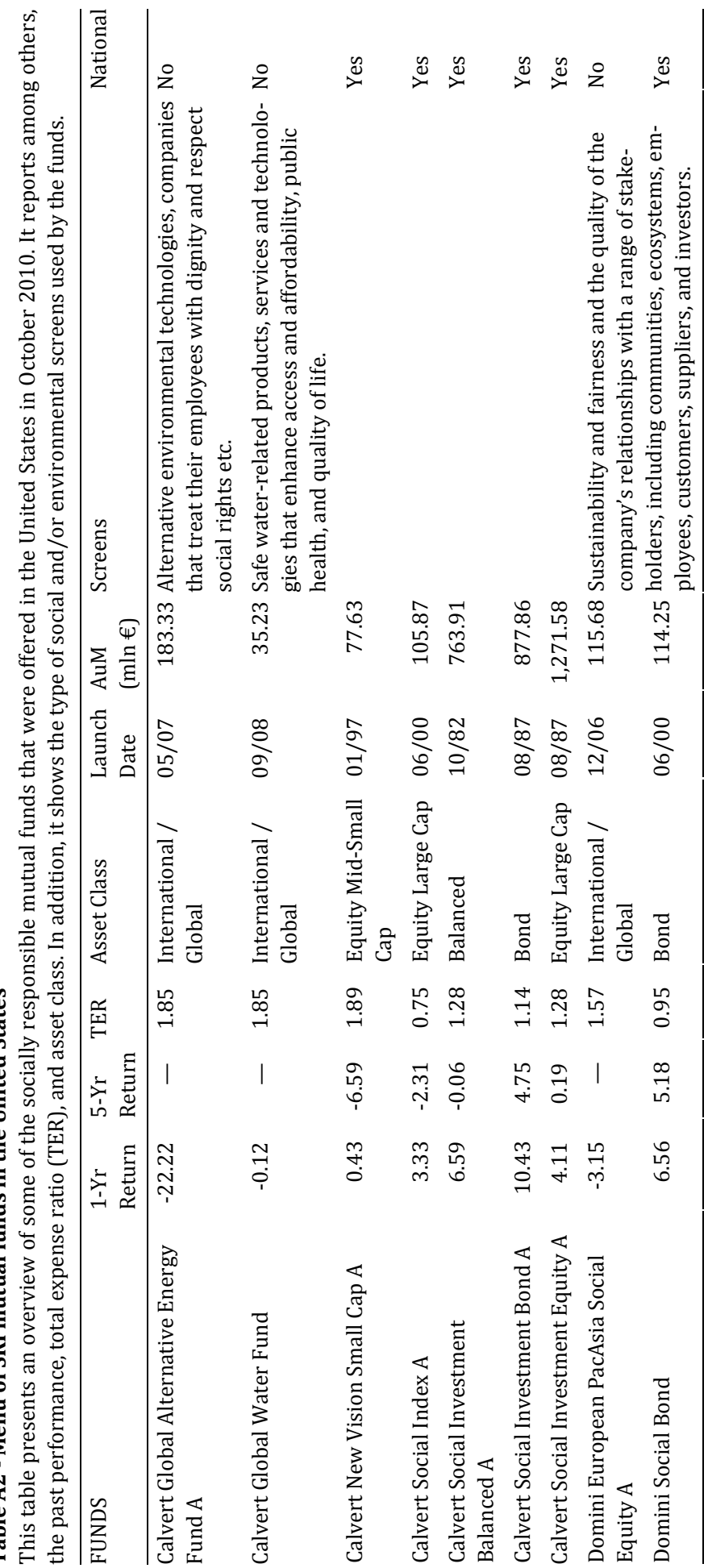




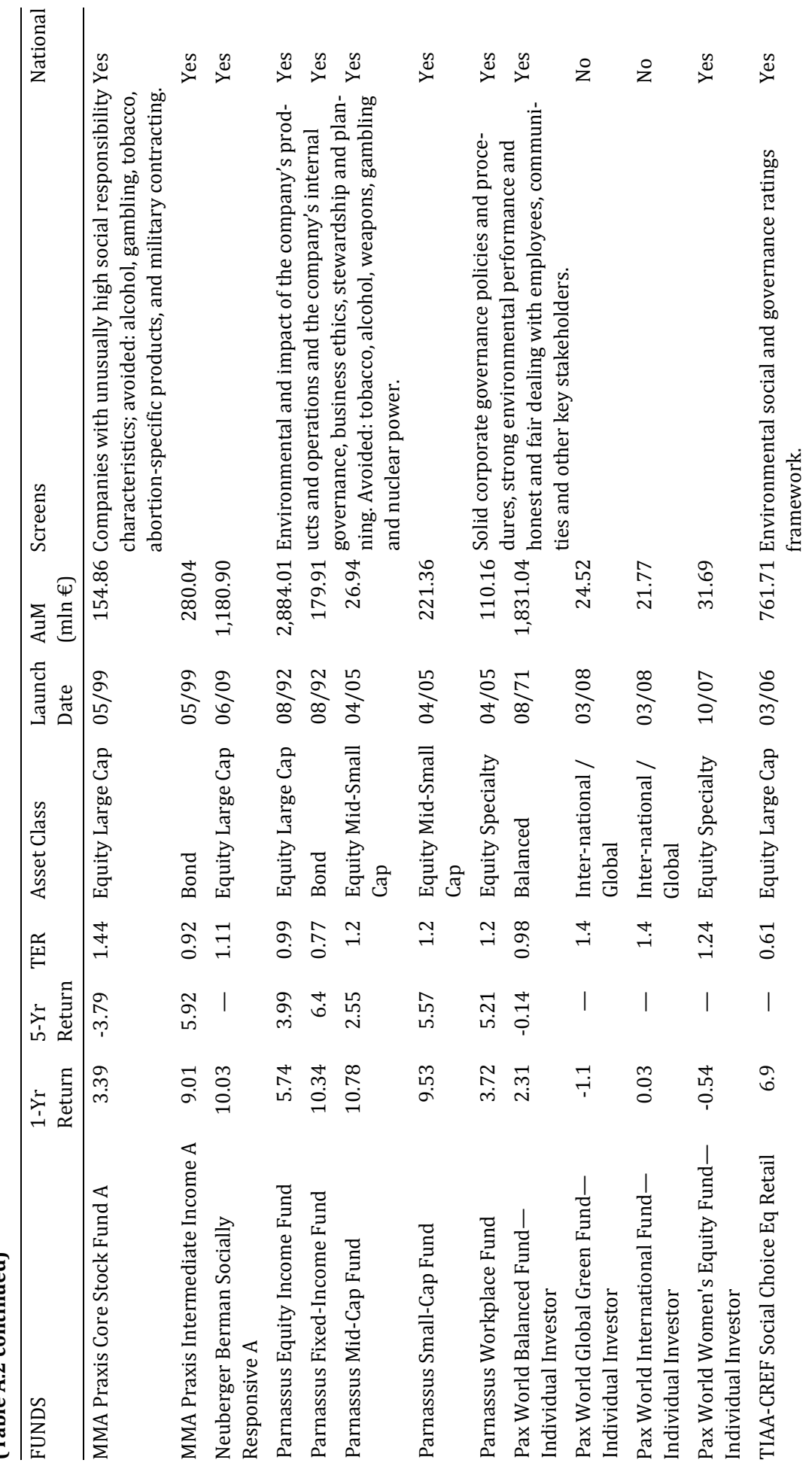




\section{Chapter 5 \\ Summary}

This dissertation investigates how risk preferences and social preferences drive investment decisions of individuals. I combine three different datasets, from two different Dutch socially responsible banks and from a Dutch mainstream provider of mutual funds that offers both conventional and socially responsible mutual funds. Furthermore, I make use of different research methods: field experiments, surveys and individual investor transaction data. The main advantage of the investor trading data is that they represent revealed choices of more than 100,000 individual investors from January 1992 to June 2010. The experimental and survey data allow me to get more detailed insights into the beliefs of investors and to elicit their preferences.

Chapter 2 focuses on risk preferences by analyzing the individual investor trading data of the mainstream mutual fund broker. The chapter shows that highly risk averse and highly risk tolerant investors are more likely to close their brokerage account than investors with an intermediate level of risk tolerance are. This suggests that several groups of investors mismatch their portfolio choices to risk preferences. This is surprising for two reasons. First, individuals can choose from a broad fund menu that ranges from risk free investment products to mutual funds with high risk and a potential for high returns. Second, the mutual fund broker offers on-line advice on the level of portfolio risk that matches an individual's risk profile. I show that the portfolios of these highly risk averse and highly risk tolerant investors deviate most from the on-line advice.

Chapter 2 also documents that risk tolerance is positively related to the frequency with which individuals trade mutual funds. That is, risk tolerant investors trade substantially more than risk averse investors trade. After controlling for risk preferences, men trade about one third more than women do. I am the first to show that risk tolerance and gender drive the frequency with which individuals trade mutual funds in the same way as they drive the trading frequency of single stocks (Barber and Odean (2001), Dorn and Huberman (2005)).

In addition to risk preferences, social preferences and having a preference for a local fund (Holland fund) is also related to the probability that an individual keeps her brokerage account. These results hold after controlling for factors 
such as portfolio returns, gender, age and wealth. Investors who ever held the local fund are substantially more likely to keep their account. Because I explicitly control for portfolio returns, the effect of holding the local fund is more likely to be of a psychological nature than of a financial nature (e.g. superior information on local companies). In contrast to the effect of holding a local fund, investors who ever held a socially responsible (SRI) mutual fund are more likely to close their account at the mainstream broker. This is interesting, because I show in Chapter 4 that the effect of social preferences on investor loyalty is positive for two socially responsible banks.

Chapter 3 is also based on data from the mainstream mutual fund broker. In this chapter, I link the investor trading data to fully incentivized field experiments and to a survey. I show that intrinsic socially responsible investors also donate more to charity, are more likely to do voluntary work and to be registered as an organ donor. This suggests that pro-social behavior is at least partly stable across different domains. However, in some domains the difference in pro-sociality between intrinsic SR investors and other types is larger than the difference in pro-sociality in other domains. Intrinsic SR investors donate 68\% more money to charity than conventional investors do, but are only $21 \%$ more likely to do voluntary work. This finding is consistent with my hypothesis that intrinsic SR investors behave particularly more pro-socially than other investor types in domains with few opportunities for signaling and reputation building. Donations to charity are mostly made by anonymous bank transfers and therefore provide fewer signaling opportunities than voluntary work does. The chapter also documents that intrinsic SR investors behave significantly more prosocial as a second mover in an incentivized anonymous one-shot trust game.

There is no difference between conventional investors and strategic SR investors in the degree of pro-social behavior in the field (donations to charity, voluntary work and organ donor registrations). However, strategic SR investors behave significantly less pro-social in the incentivized trust game that rules out signaling and reputation effects by design. This provides further evidence that the consistency of pro-social behavior across domains is influenced by the opportunities for strategic benefits of a domain.

Chapter 4 uses experimental and survey data from two Dutch socially responsible banks that offer in-house SRI mutual funds and savings accounts. The chapter shows that even within the clientele of a socially responsible bank, there is substantial heterogeneity in social preferences. Investors with stronger social preferences are more loyal to a socially responsible bank and generate substantially more bank revenue. An investor with an one standard deviation increase in social preferences generates $37.5 \%$ more bank revenue per year. These results hold after controlling for factors such as risk preferences, investment knowledge, gender, age and wealth.

Chapter 4 illustrates that banks and mutual fund brokers can benefit from attracting investors with strong social preferences. However, Chapter 2 shows 
that socially responsible investors at a mainstream broker are more likely to close their brokerage account than conventional investors are. It is likely that this difference is driven by the different nature of the banks and broker. The socially responsible banks exclusively offer SRI mutual funds, but the mainstream broker offers both SRI funds and a wide variety of other mutual funds. It might be easier for investors with strong social preferences to identify with a socially responsible bank than with a mainstream broker that offers some socially responsible mutual funds. On the other hand, investors with a preference for local funds stay significantly longer at the mainstream broker, which suggests that they can identify well with the broker.

Overall, my evidence emphasizes the role of the mutual fund broker and banks in the relationship to their customers and stresses the advantages of helping investors to match their portfolio to their individual preferences. Mutual fund brokers can do this in several ways. This way, mutual fund brokers and banks can keep investors satisfied and, at the same time, generate long-term revenue. 



\section{Samenvatting (Summary in Dutch)}

In maart 2011 switchten circa 1.000 Nederlanders van de ING Bank naar de ASN Bank en Triodos Bank, twee duurzame banken (De Ondernemer, 2011). In dezelfde maand verdubbelde het aantal nieuw geopende rekeningen bij ASN Bank en verdrievoudigde dit bij Triodos Bank. Een voor de hand liggende reden was dat de ING Bank haar raad van bestuur hoge bonussen bleef uitkeren, hoewel het in oktober 2008 een miljarden steun van de Nederlandse overheid had gekregen. Indirect financierde de belastingbetaler dus de bonussen. De klanten die switchten naar een duurzame bank vonden de bonussen onethisch. Hoewel 1.000 klanten in feite niet veel lijkt, gaven deze mensen wel een duidelijk signaal af door te stemmen met hun voeten, hetgeen de nodige media aandacht opleverde. Als gevolg van de slechte publiciteit besloten alle leden van de raad van bestuur van ING om hun bonus terug te betalen. Dit illustreert dat het belangrijk is de wensen van klanten serieus te nemen. Zo is er in dit voorbeeld een duidelijke discrepantie tussen de sociale normen van de klanten en die van ING. Bij ASN en Triodos Bank voelden deze klanten zich waarschijnlijk beter thuis.

Dit is een vrij extreem voorbeeld van hoe sociale voorkeuren financiële beslissingen beïnvloeden. Mijn proefschrift laat echter zien dat sociale voorkeuren regelmatig beleggingsbeslissingen bepalen en dat sociale voorkeuren samenhangen met de loyaliteit van beleggers aan hun bank. Sociale voorkeuren uiten zich bijvoorbeeld in het feit dat in Nederland een op de zes beleggers al een duurzaam beleggingsfonds bezit (Millward Brown, 2011). Duurzaam beleggen groeit ook sterk in de rest van Europa (EUROSIF, 2010) en in de Verenigde Staten (SIF, 2010).

Hoofdstuk 4 gebruikt een vragenlijst en experimentele data om het gedrag te analyseren van individuele beleggers bij twee duurzame banken in Nederland: ASN Bank en Triodos Bank. Dit hoofdstuk laat zien dat beleggers die een sterke voorkeur hebben voor duurzame beleggingsfondsen loyaler zijn aan hun bank en ook meer omzet genereren voor de bank. Hoofdstuk 2 laat echter zien dat duurzame beleggers eerder weggaan als klant bij een grote Nederlandse aanbieder van zowel duurzame als gewone beleggingsfondsen (Robeco). Het is dus belangrijk voor banken en aanbieders van beleggingsfondsen om goed na te denken over de vraag of men duurzame fondsen moet aanbieden. Indien een 
bank besluit dit te doen, is het belangrijk deze duurzame fondsen op de juiste manier in de markt te zetten. Hoofdstuk 2 en 4 gaan hier verder op in.

Hoofdstuk 2 en 3 gebruiken transactiedata van meer dan 100.000 particuliere beleggers bij Robeco. Ik heb deze beleggers gevolgd over de periode van januari 1992 tot juni 2010. De data omvatten onder andere de dagelijkse transacties van elke belegger, de behaalde rendementen, de risicoprofielen en demografische gegevens. Ik koppel de transactiedata op individueel niveau aan een vragenlijst en aan keuze-experimenten. In de experimenten krijgen beleggers echt geld betaald op basis van de keuzes die zij maken. Beleggers kunnen tot 300 euro verdienen en krijgen het verdiende bedrag op hun bankrekening overgemaakt op de eerstvolgende werkdag.

Van elke deelnemer aan de keuze-experimenten meet ik hoe sociaal hij of zij zich gedraagt. Ik doe dit aan de hand van een 'trust game' en focus op het gedrag van de ontvanger. Heel beknopt komt dit op het volgende neer: een belegger krijgt de keuze om 200 euro voor zichzelf te houden of een deel af te staan aan een andere deelnemer aan het experiment. Belangrijk is hierbij dat alle deelnemers zowel tijdens als na het experiment anoniem zijn en het experiment slechts eenmalig wordt gedaan. Hierdoor is er geen strategisch voordeel te behalen door een deel van het geld naar de ander te sturen. Ik kan zo dus innerlijk sociaal gedrag meten. Uit het experiment blijkt dat maar liefst $90 \%$ van de beleggers een positief bedrag naar de andere deelnemer terugstuurt. Het is zelfs zo dat een grote groep beleggers 100 euro naar de ander stuurt en het totaal bedrag van 200 euro dus eerlijk deelt. Dit toont aan dat een ruime meerderheid van de beleggers zich innerlijk sociaal gedraagt, zelfs als dit geen enkel eigen belang dient.

Hoofdstuk 3 laat zien dat er grofweg twee types duurzame beleggers te onderscheiden zijn: innerlijk gemotiveerde duurzame beleggers en strategisch gemotiveerde duurzame beleggers. Innerlijk gemotiveerde duurzame beleggers handelen sociaal omdat zij hier van binnenuit van overtuigd zijn, maar strategisch gemotiveerden gedragen zich alleen sociaal als het hen zelf goed uitkomt. Strategische voordelen van sociaal gedrag zijn bijvoorbeeld het opbouwen van een goede reputatie en het profiteren van belastingvoordeel dat geldt op bepaalde duurzame fondsen.

Een belangrijke vraag in de sociale psychologie en gedragseconomie is of mensen zich consequent sociaal gedragen. In andere woorden, gedraagt een sociaal verantwoorde (duurzame) belegger zich ook sociaal op andere gebieden dan beleggen? Doet een duurzame belegger vaker vrijwilligerswerk dan een gewone belegger? Doneert een duurzame belegger meer aan goede doelen? Eerder onderzoek naar deze vraag geeft geen eenduidig antwoord. Het lijkt erop dat sociaal gedrag enigszins consistent is in verschillende contexten. Het is niet duidelijk onder welke omstandigheden sociaal gedrag in meer of mindere maten consistent is. Ik laat zien dat innerlijk sociale types zich consequenter prosociaal gedragen dan strategisch sociale mensen. In andere woorden, beleggers 
die duurzame fondsen kopen vanwege het sociale karakter of het milieu doneren meer aan goede doelen, doen vaker vrijwilligerswerk en zijn vaker geregistreerd als orgaandonor dan beleggers die duurzame fondsen strategisch kopen.

Hoofdstuk 2 laat zien dat sterk risicomijdende beleggers en sterk risico zoekende beleggers eerder weggaan als klant bij Robeco dan beleggers met een gemiddeld risicoprofiel. Risicomijdende beleggers volgen het online advies van Robeco niet altijd op en beleggen in risicovollere aandelenfondsen dan hun wordt geadviseerd. Dit suggereert dat enkele groepen beleggers hun portefeuillerisico niet goed afstemmen op hun daadwerkelijke risicovoorkeuren.

\section{Wat kun jij leren van dit proefschrift?}

Dit proefschrift laat zien dat een meerderheid van de beleggers zich sociaal gedraagt in een volledig anoniem experiment waarin mensen echt geld krijgen. Het is dus nog niet zo slecht gesteld met de samenleving als vaak gesuggereerd wordt in de media. Hoewel een meerderheid van de beleggers zich sociaal gedraagt in het experiment, heeft slechts een op de zes Nederlandse beleggers een duurzaam (sociaal verantwoord) beleggingsfonds (Millward Brown, 2011). Een mogelijke verklaring hiervoor is de volgende. Beleggers in het experiment moeten een keuze maken om zich sociaal te gedragen of dit juist niet te doen. Echter, in het veld betekent het niet maken van een keuze vaak dat iemand zich niet pro-sociaal gedraagt. Bijvoorbeeld, een klant van een gewone bank die geen actie onderneemt, wordt geen duurzame belegger. De vraag is echter of dit de optimale beslissing is. Beshears et al. (2008) laten zien dat mensen niet altijd beslissen op basis van hun daadwerkelijke voorkeuren. In het bijzonder als beslissingen complex zijn en mensen vanuit inertie (luiheid) handelen, kiezen zij vaak niet op basis van hun echte voorkeuren. Beleggingsfondsen zijn complex en keuzes worden in dit veld vaak gemaakt op basis van inertie. Het kan dus zijn dat beleggers met sterke sociale voorkeuren niet naar een duurzame bank overstappen vanwege luiheid of complexiteit.

Ben je gewoon te laks om te veranderen van bank? Mijn neef heeft toegegeven dat hij in ieder geval te laks is. Hij heeft me verteld dat hij zeker het geld in het experiment op een sociale wijze zou delen met een andere deelnemer, maar hij is niet geregistreerd als orgaan donor, doet geen vrijwilligerswerk en maakt bijna nooit geld over naar een goed doel. Ik was benieuwd naar de reden van dit op het eerste oog inconsistent gedrag en vroeg mijn neef naar de reden. Hij zei: "Ik ben over het algemeen te lui, maar jij dwingt me om een keuze te maken in het experiment."

Dit proefschrift stelt dat er twee types pro-sociale mensen zijn: innerlijk gemotiveerde sociale mensen en strategisch gemotiveerde. Strategisch sociale types gedragen zich minder consequent pro-sociaal dan innerlijk gemotiveerde sociale mensen. Het is interessant voor toekomstig onderzoek of dit optimaal is 
voor mensen. Wellicht kunnen strategische types profiteren als zij zich meer consequent pro-sociaal gedragen, omdat anderen hen dan sneller beschouwen als een sociaal persoon. Bijvoorbeeld, iemand die vrijwilligerswerk doet om strategische redenen, kan zich ook inschrijven als orgaan donor en dit rondvertellen op verjaardagen. Hierdoor krijgen anderen een nog socialer beeld van die persoon. Iemand kan er ook voor kiezen om een hybride auto te kopen om de identiteit als sociaal persoon nog verder te versterken.

In tegenstelling tot strategische types, gedragen innerlijk sociale mensen zich wellicht 'te' consequent pro-sociaal. Iemand die veel doneert aan goede doelen voelt zich wellicht ook verplicht om zich sociaal te gedragen in een andere context, omdat haar zelfbeeld dit voorschrijft (Benabou en Tirole, 2011). Innerlijk sociale types kunnen zichzelf de vraag stellen: "waar komt mijn voorkeur om geld te doneren vandaan; waarom doe ik vrijwilligerswerk en waarom koop ik groene producten? Wil ik echt altijd sociaal zijn, of gedraag ik me alleen zo om voor mezelf consequent over te komen?" Marketeers misbruiken de wens van mensen om zich consequent te gedragen. Een tijdje geleden, liep ik door Maastricht en werd ik aangesproken door een jonge dame van het Wereld Natuur Fonds. Zij vroeg me of ik van dieren houd. Op dit moment had ik in de gaten wat haar doel was. De meeste mensen zullen deze vraag met 'ja' beantwoorden. Immers, waarom zou je 'nee' zeggen tegen de leuke dame van het Wereld Natuur Fonds? Echter, dit is precies wat de marketeers willen. Als je antwoordt met 'ja', heeft de jonge dame de mogelijkheid om te profiteren van je wens consequent over te komen. Haar volgende zin is: "meneer, dat is zo aardig om te horen. Ik ben er zeker van dat u een kleine donatie wil geven aan het Wereld Natuur Fonds." Om aardig en consequent over te komen, zullen veel mensen hun beurs trekken en een geldbedrag doneren. Als de jonge dame je niet gevraagd had of je van dieren houdt, wilde je wellicht alleen aardig overkomen. Nu wil je aardig en consequent zijn.

Het proefschrift suggereert ook dat sommige beleggers hun portefeuillerisico niet goed afstemmen op hun risicovoorkeuren. Je kunt jezelf de vraag stellen of je beleggingsproducten goed genoeg begrijpt om het risico ervan goed af te stemmen op je eigen risicovoorkeuren. Als het antwoord 'nee' is, dan is het wellicht verstandig om professioneel advies van een onafhankelijk persoon in te schakelen. Vrienden zouden je ook beleggingsadvies kunnen geven, maar zij raden je misschien producten aan gebaseerd op hun eigen risicohouding. Onafhankelijke professionele adviseurs zijn vaak beter in staat om advies te geven op basis van jouw voorkeuren door expliciet te vragen naar jouw beleggingsdoelen, jouw beleggingshorizon en op een goede manier jouw risicohouding te meten. Robeco biedt gratis online advies aan. Soms ben je misschien geneigd om dit advies te negeren, maar wellicht krijg je hier later spijt van. Vooral risicomijdende beleggers nemen meer risico in hun beleggingen dan blijkt uit hun advies. Als je dus risicomijdend bent is het erg belangrijk om vast te houden aan een beleggingsstrategie die het risico beperkt. Vrienden vertellen vaak over de hoge 
rendementen die zij halen in de aandelenmarkt en dit kan jou overhalen om zelf ook extra risico te nemen. Echter, deze vrienden praten waarschijnlijk minder over hun grote verliezen in de aandelenmarkt.

\section{Wat kunnen banken en andere financiële instellingen leren van dit proefschrift?}

Beleggers met een sterke voorkeur voor duurzame fondsen zijn loyaler aan een duurzame bank dan beleggers met een minder sterke voorkeur voor duurzaamheid, zo kunnen we concluderen uit hoofdstuk 4. Deze loyalere beleggers genereren ook substantieel meer omzet voor de duurzame bank. Bovendien laat hoofdstuk 3 zien dat een meerderheid van de duurzame en van de gewone beleggers zich pro-sociaal gedraagt in een experiment en in het veld. Er zijn dus kansen voor banken en aanbieders van beleggingsfondsen om duurzame fondsen aan te bieden. Echter, voorzichtigheid is geboden met het aanbieden van duurzame fondsen. Immers, uit hoofdstuk 2 leren we dat 'mainstream' aanbieders hun duurzame klanten sneller lijken te verliezen dan hun overige klanten. Het lijkt dan ook voor 'mainstream' aanbieders niet de optimale strategie om een beperkt aantal duurzame fondsen aan hun assortiment toe te voegen. Mogelijk is het beter als de hele organisatie zich richt op corporate social responsibility (maatschappelijk verantwoord ondernemen). Een dergelijke koerswijziging betekent echter een fundamentele ingreep op de identiteit van de bank. Daarom moet de bank zich de vraag stellen of zij dit wil en zo ja, hoe zij dit beoogt te effectueren. Het is belangrijk dat beleggers zich kunnen identificeren met de bank, zodat zij loyaal blijven. Een betere mogelijkheid dan het aanbieden van duurzame producten binnen de hoofdorganisatie kan zijn om een apart dochterbedrijf op te richten dat zich specifiek op duurzaamheid richt. Dit gebeurt al in Nederland waar de ASN Bank een dochter organisatie is van de SNS Reaal groep.

De meeste beleggers gedragen zich pro-sociaal. Echter, hoofdstuk 4 laat ook zien dat er grote verschillen bestaan in de sociale voorkeuren van beleggers bij duurzame banken. Bovendien laat hoofdstuk 3 zien dat er innerlijk gemotiveerde en strategisch gemotiveerde beleggers zijn. Banken kunnen deze bevindingen gebruiken in de ontwikkeling van beleggingsproducten en in hun marketing. De twee duurzame banken in dit proefschrift benadrukken in hun communicatie consequent de sociale kant van bankieren. Zij adverteren niet met rendement of het belastingvoordeel op duurzame fondsen. Ze gebruiken slogans als "voor de wereld van morgen" en "make your money make a difference."

Duurzame banken die ook de strategisch sociale, op rendement gerichte belegger willen bereiken, kunnen beter communiceren in de trant van: "financieel rendement vandaag voor de wereld van morgen." Banken kunnen strategisch 
sociale klanten ook de kans geven om hun sociale gedrag te tonen. Zo kunnen ze evenementen organiseren voor duurzame beleggers, waarbij deze beleggers vrienden mee kunnen nemen. Een ander voorbeeld is dat de pinpas van de ASN Bank middels een afbeelding van een orka de toevallige waarnemer altijd attendeert op het 'groene' karakter van de eigenaar.

Mijn bevindingen zijn relevant voor beleggingsfondsen, maar hebben ook implicaties voor andere financiële instellingen. Pensioenfondsen, bijvoorbeeld, beheren veel van het totaal belegd vermogen in Nederland en in andere landen. In Nederland spaart bijna iedereen verplicht voor zijn pensioen, veelal bij een fonds waarvoor men niet bewust heeft gekozen. De individuele werknemer heeft dan ook geen invloed op de wijze waarop met zijn geld wordt belegd. Daarbij rapporteren pensioenfondsen meestal redelijk vaag over hoe zij met duurzaamheid en maatschappelijk verantwoord ondernemen (MVO) omgaan. De conclusie van dit proefschrift dat de meeste beleggers pro-sociaal gedrag vertonen daagt pensioenfondsen dan ook uit om duidelijker te zijn over MVO.

Een laatste aanbeveling aan banken is om meer te werken met het aanbieden van standaardopties (defaults). In hoofdstuk 2 hebben we immers geleerd dat verschillende groepen beleggers hun portefeuillerisico niet goed afstemmen op hun eigen risicohouding. Om deze discrepantie te verminderen kunnen banken hun klanten defaults van portefeuilles aanbieden die aansluiten op hun risicoprofiel. Risicotolerante beleggers krijgen dan een default met een hoog percentage aandelenfondsen en risicomijdende beleggers een default met een hoog percentage obligatiefondsen. Er is overtuigend bewijs dat defaults erg effectief zijn in het beïnvloeden van de keuzes van mensen. In Nederland is iedereen bijvoorbeeld standaard NIET als orgaan donor geregistreerd, maar in België is de default om WEL orgaan donor te zijn. In 2003 waren in Nederland $27.5 \%$ van de mensen geregistreerd als orgaan donor en in België 90\% (Johnson en Goldstein, 2003). Het aantrekkelijke van defaults is dat zij complete vrijheid geven in de keuze van mensen, maar hen alleen een duwtje in de gewenste richting geven. Als default raad ik iedereen aan om te genieten van de rest van dit proefschrift. 


\section{References}

Agnew, Julie, Pierluigi Balduzzi and Annika Sundén, 2003, "Portfolio Choice and Trading in a Large 401(k) Plan", American Economic Review, 93 (1), 193-215.

Akerlof, George A. and Rachel E. Kranton, 2000, "Economics and Identity", Quarterly Journal of Economics, 115 (3), 715-753.

Akerlof, George A. and Rachel E. Kranton, 2005, "Identity and the Economics of Organizations", Journal of Economic Perspectives, 19 (1), 9-32.

Ameriks, John and Stephen Zeldes, 2004, "How Do Household Portfolio Shares Vary with Age?", TIAA-CREF Working Paper, 6-120101.

Andreoni, James, 1995, "Warm-Glow versus Cold-Prickle: The Effects of Positive and Negative Framing on Cooperation in Experiments", Quarterly Journal of Economics, 110 (1), 1-21.

Bailey, Warren, Alok Kumar and David Ng, 2010, "Behavioral Biases of Mutual Fund Investors", Journal of Financial Economics, 102 (1), 1-27.

Baran, Nicole M., Paola Sapienza and Luigi Zingales, 2010, “Can We Infer Social Preferences from the Lab? Evidence from the Trust Game", NBER Working Papers, 15654

Barber, Brad M. and Terrance Odean, 2001, "Boys will be boys: Gender, Overconfidence, and Common Stock Investment", Quarterly Journal of Economics, 116 (1), 261-292.

Barber, Brad M., Terrance Odean and Lu Zheng, 2005, "Out of Sight, Out of Mind: The Effects of Expenses on Mutual Fund Flows", Journal of Business, 78 (6), 2095-2119.

Barsky, Robert B., F. Thomas Juster, Miles S. Kimball and Matthew D. Shapiro, 1997, "Preference Parameters and Behavioural Heterogeneity: An Experimental Approach in the Health and Retirement Study", Quarterly Journal of Economics, 112 (2), 537-579.

Batson, Daniel C., Jay S. Coke, M. L. Jasnoski and Michael Hanson, 1997, "Buying Kindness: Effects of an Extrinsic Incentive for Helping on Perceived Altruism", Journal of Personality and Social Psychology, 4 (1), 89-91

Bauer, Rob and Paul Smeets, 2012, "Social Preferences and Investor Loyalty", Working paper

Bauer, Rob, Paul Smeets and Leonard Wolk, 2012, "Individuals' Risk Preferences and Mutual Fund Investments", Working paper

Benabou, Roland and Jean Tirole, 2011, "Identity, Morals and Taboos: Beliefs as Assets", Quarterly Journal of Economics, forthcoming

Benz, Matthias and Stephan Meier, 2008, "Do People Behave in Experiments as in the Field? Evidence from Donations", Experimental Economics, 11(3), 268-281

Berg, Joyce, John Dickhaut and Kevin McCabe, 1995, "Trust, Reciprocity and Social History", Games and Economic Behaviour, 10 (1), 122-142

Beshears, John, James J. Choi, David Laibson and Brigitte C. Madrian, 2008, "How Are Preferences Revealed?", Journal of Public Economics, 92 (8-9), 1787-1794

Blanco, Mariana, Dirk Engelmann and Hans Theo Normann, 2011, "A Within-Subject Analysis of Other-Regarding Preferences", Games and Economic Behaviour, 72(2), 321-338

Bollen, Nicolas P. B., 2007, "Mutual Fund Attributes and Investor Behavior", Journal of Financial and Quantitative Analysis, 42, 683-708.

Bolton, Gary, E., and Axel Ockenfels, 2000, "ERC: A Theory of Equity, Reciprocity, and Competition", American Economic Review, 90 (1), 166-193 
Brown, Jeffrey R., Zoran Ivkovich, Paul A. Smith and Scott Weisbenner, 2008, "Neighbors Matter: Causal Community Effects and Stock Market Participation", Journal of Finance, 63 (3), 15091531

Cabral, L., E. Y. Ozbay, and A. Schotter, 2011, "Intrinsic and Strategic Reciprocity: An Experimental Study", Working paper, New York University

Calvet, Laurent E., John Y. Campbell and Paolo Sodini, 2009, "Fight Or Flight? Portfolio Rebalancing by Individual Investors", Quarterly Journal of Economics, 124 (1), 301-348.

Campbell, John Y., 2006, "Household Finance”, Journal of Finance, 61 (4), 1553-1604.

Cesarini, David, Christopher T. Dawes, Magnus Johannesson, Paul Lichtenstein and Björn Wallace, 2011, “Genetic Variation in Preferences for Giving and Risk Taking”, Quarterly Journal of Economics, 124(2), 809-842.

Choi, James J., David Laibson and Brigitte C. Madrian, 2010, "Why Does the Law of One Price Fail? An Experiment on Index Mutual Funds", Review of Financial Studies, 23 (4), 1405-1432.

Cialdini, Robert B., Stephanie L. Brown, Brian P. Lewis, Carol Luce and Steven L. Neuberg, 1997, "Reinterpreting the Empathy-Altruism Relationship: When One into One Equals Oneness", Journal of Personality and Social Psychology, 73(3), 481-494.

Cohen, Lauren, 2009, “Loyalty-Based Portfolio Choice”, Review of Financial Studies, 22 (3), 12131245.

Coval, Joshua D. and Tobias J. Moskowitz, 1999, “Home Bias at Home: Local Equity Preference in Domestic Portfolios", Journal of Finance, 54 (6), 2045-73.

Cox, D. R., 1975, "Partial Likelihood”, Biometrika, 62 (2), 269-276.

Croson, Rachel, and Uri Gneezy, 2009, “Gender Differences in Preferences”, Journal of Economic Literature, 47 (2), 1-27

De Ondernemer, 2011, http://www.deondernemer.nl /deondernemer/555739/ING-klanten-wegom-bonussen.html

Derwall, Jeroen, Nadja Guenster, Rob Bauer and Kees Koedijk, 2005, “The Eco- $\quad$ Efficiency Premium Puzzle", Financial Analyst Journal, 61 (2), 51-63

D’Exelle, Ben and Arno Riedl, 2010, "Directed Generosity and Network Formation: Network Dimension Matters", Working paper

Dohmen, Thomas, Armin Falk, David Huffmann, Juergen Schupp and Uwe Sunde, Gert G. Wagner, 2011, "Individual Risk Attitudes: Measurement, Determinants and Behavioural Consequences", Journal of the European Economics Association, 9 (3), 522-550

Dorn, Daniel and Gur Huberman, 2005, "Talk and Action: What Individual Investors Say and What They Do", Review of Finance, 9 (4), 437-481.

Dorn, Daniel and Gur Huberman, 2010, "Preferred Risk Habitat of Individual Investors”, Journal of Financial Economics, 97 (1), 155-173.

Dreber, Anna, Drew Fudenberg and David G. Rand, 2011, "Who Cooperates in Repeated Games?", Working paper, Harvard University

Eckel, Catherine C. and Philip J. Grossman, 1998, “Are Women Less Selfish than Men? Evidence from Dictator Experiments”, Economic Journal, 108 (448), 726-735

Edmans, Alex, 2010, "Does the Stock Market Fully Value Intangibles? Employee Satisfaction and Equity Prices", Journal of Financial Economics, forthcoming

Egas, Martijn and Arno Riedl, 2008, "The Economics of Altruistic Punishment and the Maintenance of Cooperation", Proceedings of the Royal Society B: Biological Sciences, 275, 871-878

Elton, Edwin E., Martin J. Gruber and Jeffrey A. Busse, 2004, “Are Investors Rational? Choices Among Index Funds", Journal of Finance, 59 (1), 261-288.

EUROSIF, 2010, European SRI Study 2010, http://www.eurosif.org.

Falk, Armin and Florian Zimmerman, 2010, "Preferences for Consistency", working paper

Falk, Armin and James J. Heckmann, 2009, "Lab Experiments Are a Major Source of Knowledge in the Social Sciences", Science 326, 535-538

Falk, Armin, Stephan Meier and Christian Zehnder, 2011, "Do Lab Experiments Misrepresent Social Preferences? The Case of Self-Selected Student Samples", Journal of the European Economic Association, forthcoming 
Falk and Zehnder, 2007, "Discrimination and In-Group Favouritism in a Citywide Trust Experiment", Working paper

Fehr, Ernst and Andreas Leibbrandt, 2011, "A Field Study on Cooperativeness and Impatience in the Tragedy of the Commons", Journal of Public Economics, 95 (9-10), 1144-1155

Fehr, Ernst and John A. List, 2004, "The Hidden Costs and Returns of Incentives - Trust and Trustworthiness Among CEO's", Journal of the European Economic Association, 2 (5), 743-771.

Fehr, Ernst and Klaus M. Schmidt, 1999, “A Theory of Fairness, Competition and Cooperation”, Quarterly Journal of Economics, 114 (3), 817-868

Fischbacher, Urs and Simon Gächter, 2010, "Social Preferences, Beliefs and the Dynamics of Free Riding in Public Goods Experiments", American Economic Review, 100 (1), 541-556

Frazzini, Andrea and Owen A. Lamont, 2008, "Dumb Money: Mutual Fund Flows and the CrossSection of Stock Returns", Journal of Financial Economics, 88 (2), 299-322.

French, Kenneth R., 2008, "Presidential Address: The Cost of Active Investing", Journal of Finance, 63 (4), 1537-1573.

Frey, Bruno and Stephan Meier, 2004, "Social Comparison and Pro-Social Behaviour: Testing Conditional Cooperation in a Field Experiment”, American Economic Review, 94 (5), 1717-1722.

Gächter, Simon and Armin Falk, 2002, "Reputation and Reciprocity: Consequences for the Labour Relation”, The Scandinavian Journal of Economics,104 (1), 1-26

Gaspar, José-Miguel, Massimo Massa and Pedro Matos, 2006, "Favoritism in Mutual Fund Families? Evidence on Strategic Cross-Fund Subsidization", Journal of Finance, 61 (1), 73-104.

Glaeser, Edward L., David I. Laibson, José A. Scheinkman and Christine L. Soutter, 2000, "Measuring Trust", Quarterly Journal of Economics, 115 (3), 811-846.

Glazer, Amihai and Kai A. Konrad, 1996, "A Signalling Explanation for Charity", American Economic Review, 86 (4), 1019-1028.

Gneezy, Ayelet, Alex Imas, Leif D. Nelson, Amber Brown and Michael I. Norton, 2012, "Paying to Be Nice: Consistency and Costly Prosaically Behaviour", Management Science, forthcoming

Goeree, Jacob K., Margaret A. MacConnell, Tiffany Mitchell, Tracey Tromp and Leeat Yariv, 2010, "The 1/d Law of Giving", American Economic Journal: Microeconomics, 2 (1), 183-203.

Goette, Lorenz, David Huffman and Stephan Meier, 2006, "The Impact of Group Membership on Cooperation and Norm Enforcement: Evidence Using Random Assignment to Real Social Groups", American Economic Review, 96 (2), 212-216

Graham, John R., Campbell R. Harvey, Hai Huang, 2009, “Investor Competence, Trading Frequency, and Home Bias", Management Science, 55 (7), 1094-1106.

Green, Paul E. and Vithala R. Rao, 1971, "Conjoint Measurement for Quantifying Judgmental Data”, Journal of Marketing Research, 8 (3), 355-363.

Grinblatt, Mark, and Matti Keloharju, 2001, "How Distance, Language, and Culture Influence Stockholdings and Trades", Journal of Finance, 56 (3), 1053-1073.

Grinblatt, Mark, and Matti Keloharju, 2009, "Sensation Seeking, Overconfidence and Trading Activity", Journal of Finance, 64 (2), 549-578.

Guiso, Luigi, Paola Sapienza and Luigi Zingales, 2008, “Trusting the Stock Market”, Journal of Finance, 63 (6), 2557-2600.

Hagen, Edward H. and Peter Hammerstein, 2006, "Game Theory and Human Evolution: A Critique of Some Recent Interpretations of Experimental Games", Theoretical Population Biology, 69 (3), 339-348.

Hair, Joseph F., William C. Black, Barry Babin, Rolph Anderson and Ronald L. Tatham, 2006, Multivariate Data Analysis, Pearson, Prentice Hall; Upper Saddle River, New Jersey.

Harrison, Glenn W. and John A. List, 2004, "Field Experiments", Journal of Economic Literature, 42, 1009-1055.

Henrich, Joseph, Robert Boyd, Samuel Bowles, Colin Camerer, Ernst Fehr, Herbert Gintis and Richard McElreath, 2001, "In Search of Homo Economicus: Behavioral Experiments in 15 Small Scale Societies", American Economic Review, 91 (2), 73-78.

Holt, Charles A. and Susan K. Laury, 2002, "Risk Aversion and Incentive Effects", American Economic Review, 92 (5), 1644-1655. 
Hong, Harrison, Jeffrey D. Kubik and Jeremy C. Stein, 2004, "Social Interaction and Stock Market Participation", Journal of Finance, 59 (1), 137-163

Hong, Harrison and Leonard Kostovetsky, 2011, "Red and Blue Investing: Values and Finance", Journal of Financial Economics, forthcoming.

Hong, Harrison and Marcin Kacperczyk, 2009, "The Price of Sin: The Effects of Social Norms on Markets", Journal of Financial Economics, 93 (1), 15-36.

Huberman, Gur, 2001, “Familiarity Breeds Investment”, Review of Financial Studies, 14 (3), 659-680.

Ivković, Zoran, and Scott Weisbenner, 2005, "Local Does as Local Is: Information Content of the Geography of Individual Investors' Common Stock Investments", Journal of Finance, 60, 267306.

Ivković, Zoran and Scott Weisbenner, 2009, "Individual Investor Mutual Fund Flows", Journal of Financial Economics, 92 (2), 223-237

Johnson, Woodrow T., 2004, "Predictable Investment Horizons and Wealth Transfers Among Mutual Fund Shareholders", Journal of Finance, 59 (5), 1979-2012.

Karlan, Dean S., 2005, “Using Experimental Economics to Measure Social Capital and Predict Financial Decisions", American Economic Review, 95 (5), 1688-1699.

Kaustia, Markku and Sami Torstila, 2011, "Stock Market Aversion? Political Preferences and Stock Market Participation", Journal of Financial Economics, 100 (1), 98-112.

Kuhnen, Camelia, M. and Brian Knutson, 2011, "The Influence of Affect on Beliefs, Preferences and Financial Decisions", Journal of Financial and Quantitative Analysis, 46 (3), 605-626.

Ledyard, John, O., 1995, "Public Goods: A Survey of Experimental Research", in Handbook of Experimental Economics, edited by J. Kagel and A. Roth, Princeton University Press, 1995.

Leider, Stephan, Markus M. Möbius, Tanya Rosenblat and Quoc-Anh Do, 2009, "Directed Altruism and Enforced Reciprocity in Social Networks", Quarterly Journal of Economics, 124 (4), 815-851

Levitt, Steven D., and John A. List, 2007, "What Do Laboratory Experiments Measuring Social Preferences Reveal About the Real World?", Journal of Economic Perspectives, 21 (2), 153-174.

List, John, 2004, "Young, Selfish and Male: Field Evidence of Social Preferences", Economic Journal, 114 (492), 121-149.

List, John A., 2006, "The Behavioralist Meets the Market: Measuring Social Preferences and Reputation Effects in Actual Transactions", Journal of Political Economy, 114 (1), 1-37.

Massa, Massimo, 2003, "How Do Family Strategies Affect Fund Performance? When PerformanceMaximization Is Not the Only Game in Town”, Journal of Financial Economics, 67 (2), 249-304.

Millward Brown, 2009, Retail Investor 2009, Yearly publication.

Millward Brown, 2011, Retail Investor 2011, Yearly publication.

Ministerie van Volksgezondheid, Welzijn en Sport (Ministry of Health, Wellbeing and Sports), 2011.

Nanda, Vikram, Z. Jay Wang and Lu Zheng, 2004, "Family Values and the Star Phenomenon: Strategies of Mutual Fund Families", Review of Financial Studies, 17 (3), 667-698.

Odean, Terrance, 1998, "Volume, Volatility, Price, and Profit When All Traders Are Above Average", Journal of Finance, 53 (6), 1887-1934.

Rabin, Matthew, 1993, "Incorporating Fairness into Game Theory and Economics", American Economic Review, 83 (5), 1281-1302.

Reuben, Ernesto and Sigrid Suetens, 2011, "Revisiting Strategic versus Intrinsic Cooperation”, Experimental Economics, forthcoming

Riedl, Arno and Paul Smeets, 2012, "Intrinsic and Strategic Pro-Social Behavior of Individual Investors", working paper.

Ross, Lee D., \& Richard E. Nisbett, 1991, "The Person and the Situation: Perspectives of Social Psychology", New York: McGraw-Hill.

Sanfey, Alan G., James K. Rilling, Jessica A. Aronson, Leigh E. Nystrom and Jonathan D. Cohen, 2003, "The Neural Basis of Economic Decision-Making in the Ultimatum Game", Science, 300, 17551758.

Schlag, Karl and Joël van der Weele, 2009, "Efficient Interval Scoring Rules”, Economic Working Papers, 1176 
Selten, Reinhard, 1967, “Die Strategiemethode Zur Erforschung Des Eingeschränkt Rationalen Verhaltens in Rahmen Eimes Oligopolexperiments" in Sauerman, H. (ed) Beiträge Zur Experimentallen Wirtschaftsforschung, Tübingen: J.C.B., Mohr (Paul Siebeck).

Seru, Amit, Tyler Shumway and Noah Stoffman, 2009, "Learning by Trading", Review of Financial Studies, 23 (2), 705-739.

Sirri, Erik R. and Peter Tufano, 1998, “Costly Search and Mutual Fund Flows”, Journal of Finance, 53 (5), 1589-1622.

Sobel, Joel, 2005, "Interdependent Preferences and Reciprocity", Journal of Economic Literature, 43 (2), 392-436.

Social Investment Forum, 2010, Report on Socially Responsible Investing Trends in the United States, http://www.socialinvest.org.

Statman, Meir, 2004, “What Do Investors Want?”, Journal of Portfolio Management, 30, 153-161.

Sutter, M., and Martin G. Kocher, 2007, "Trust and Trustworthiness Among Different Age Groups", Games and Economic Behaviour, 59 (2), 364-382

Tajfel, H., \& Turner, J. C. (1979). An Integrative Theory of Intergroup Conflict. In H. Tajfel, J. C. Turner, W. G. Austin, \& S. Worchel, The Social Psychology of Intergroup Relations (pp. 33-47). Monterey, CA.

Van den Assem, Martijn J., Dennie van Dolder and Richard H. Thaler, 2012, "Split or Steal? Cooperative Behaviour When the Stakes Are Large", Management Science, 58 (1), 2-20

Van Rooij, Maarten, Annamaria Lusardi and Rob Alessie, 2011, "Financial Literacy and Stock Market Participation", Journal of Financial Economics, forthcoming.

Vohs, Kathleen D., Nicole L. Mead, Miranda R. Goode (2006) “The Psychological Consequences of Money", Science, 314, 1154-1156.

Wilcox, Ronald T., 2003, "Bargain Hunting or Star Gazing? Investors' Preferences for Stock Mutual Funds", Journal of Business, 76 (4), 645-663.

Woolridge, Jeffrey M., 2002, Econometric Analysis for Cross Section and Panel Data, The MIT Press. 



\section{Acknowledgements}

I have reached the most enjoyable section to write, because it reminds me of all the nice people that surrounded me during the PhD. A large part of this dissertation deals with pro-social behavior. During the last four years, many people behaved pro-socially towards me. I am very grateful to all of you! Some of the people that contributed to this dissertation deserve some special attention.

First of all, I would like to thank my supervisors Rob Bauer and Piet Eichholtz. Rob, I learned a lot from you in many ways. You taught me how to combine academics with practice, so that research is fun and practically relevant. Above all, it is great to have a supervisor from the same village and to be able to have meetings in Waubach's dialect. I still remember that we forgot to get out of the train in Eindhoven, because we were caught up in a discussion about finance. Or was it gossip about Waubach? Piet, your enthusiasm and optimism have stimulated me from the very first to the last day. During the first week of my $\mathrm{PhD}$ you asked on a daily basis whether I was still happy. And indeed, you made sure that I was very happy in the last four years. Your comments on my papers and presentations were always sharp and constructive.

I would like to thank my committee members: Dennis Bams, John Beshears, Thomas Dohmen and Stephan Meier for their great suggestions for improving my papers.

I greatly benefited from the cooperation with my co-authors Arno Riedl and Leonard Wolk. Arno, because you were a great supervisor of my Master thesis, I was sure that I wanted to work together with you for my PhD dissertation. I benefited from your knowledge about economic experiments and from your critical opinion on my writing. Leonard, you are not only a fantastic co-author, but also a good friend. I enjoyed our numerous 'research' coffees and dinners and I learned a lot from your broad range of skills.

I appreciate the cooperation of Robeco, ASN Bank, Triodos Bank, Loyalis and Deutsche Bank on several research projects, of which some appear in this dissertation. In particular, I am grateful to Manon Middelink (Robeco), Nora Toolens (ASN Bank), Erik-Jan van Asperen (Triodos Bank), Ralph Sevarts and Con Snijders (Loyalis) and Frank Klein (Deutsche Bank). I would also like to thank Mistra (in particular Lars Hassel) for providing me the funding for the research 
conducted in this dissertation. I thank the United Nations Principles of Responsible Investments (UNPRI) for awarding one of my papers.

This dissertation benefited from the research assistance of Paul Berenbroek, Daniel Claes, Tatjana Damm, Oana Floroiu, Tobias Herr, Kamil Kucharczyk, Mohamadreza Maghroor, Matthias Tix, Simone Vermeend, Thorsten Voss and Ruud Wetzels.

Dear finance colleagues, you made sure that I had a very good time in the last four years. I am happy that I will continue to be your colleague in the near future. Some colleagues deserve some special attention. Firstly, Rik Frehen and Mathijs Cosemans, who have unfortunately left the faculty. Rik and Mathijs, you were of great support at the start of my PhD. You provided very insightful and critical ideas. Thanks also go to my friends Gildas Blanchard and Matteo Millone. Gildas, you are the nicest Frenchman I know. I greatly enjoy our academic talks and maybe even more our non-academic talks. Matteo, it is fun to go on a conference with you and to enjoy a beer in one of the many bars in Maastricht. I benefited from your many Italian recipes that are now a hit with my friends and my girlfriend.

Lei, I shared my office with you for three years. Thanks to you, these three years were great fun. You always have a smile on your face; you are a great band member of our duo 'vlaai en bami' and above all a wonderful friend. The choice for you as one of my paranymphs was therewith easily made. Mukul, after Lei left the office, you faced the challenge of filling the empty spot he left. I consider myself a very lucky man, meeting yet another great office mate! I hope we continue to do many nice activities together, like bowling, playing the 'Settlers of Catan' and visiting Pinkpop. Roald, you were my very first office mate. I still remember our daily conversations on the credit crisis that was unfolding at that time. You were a great help for me as a starting PhD student and I enjoyed the game nights you hosted.

I would also like to express my appreciation for some colleagues and friends from other departments. Nicolas Salamanca, I enjoyed our lunches at 'Lunch en Zo' in which we brainstormed about cool research ideas. Lex Borghans, you always took time to have a talk that could sometimes last for more than two hours. You did not only share your academic thoughts with me, but you were also interested in my personal life.

I like to express my gratitude to the finance secretary: Els van Aernsbergen, Francien Masthoff, Cécile Luijten and Carina van der Velde. Nick Hegt and Anja Thijssen from Ideebv created the nice cover of this dissertation. Flycatcher was of great help in administrating my online surveys. Thank you, Miriam de Groot and Anouk Roberts. I also like to thank Jos, Martin and the other Jos from the copy shop for the many big prints they made for me. Dave van Maaren helped me out with all IT needs. Marie-José and Ann always made sure that I had a clean office and they are the nicest cleaning ladies to have. 
I like to thank all my friends for giving me a great time as a $\mathrm{PhD}$ student. These include the 'Heugem gang' plus Anne and Sander, my many friends from improvisation theatre and my team members at the pub quiz nights. I appreciate that Nordin Hanssen, Wim Logister and his family, the family Baumgart, Sanne Jongen, Luc Ploum and Tim Ploum were always particularly interested in my work and commented on my ideas. Wim Senden, thanks for discussing the weekly financial news with me, while we enjoyed a nice glass of wine. Jordi and Tyas, I had a good time at the Stationsstraat. Jordi, I learned a lot from our discussions about science and was honored to be your paranymph.

Volgens de traditie, bedank ik de belangrijkste mensen als laatst. Pap en mam, jullie hebben te veel voor me betekend om hier te kunnen beschrijven. Ik ben jullie ontzettend dankbaar voor alles en in het bijzonder voor de warmte die ik altijd van jullie heb gekregen. Mieke, je bent een geweldig zusje! Ik kan altijd op een telefoontje van je rekenen, of ik nu met een probleem zit of juist mijn vreugde wil delen. Ik ben er trots op dat je mijn paranymph bent. Inge, jij bent pas tegen het eind van het schrijven van dit proefschrift in mijn leven verschenen. Ik kon altijd rekenen op jouw steun en liefde in deze spannende periode. Je betekent ontzettend veel voor me. Nelly, uiteraard verdien jij ook een bedankje, omdat jij altijd voor me klaarstond. 


\section{Curriculum Vitae}

Paul Smeets (Kerkrade, The Netherlands, 1985) followed the Bachelor program in economics at Maastricht University (UM). During his bachelor studies, he spent a semester at the University of California Santa Barbara (UCSB). Paul holds a Master in International Economics from Maastricht University (cum laude), with a specialization in public economics. His master thesis addressed the question whether a fat tax would help to reduce obesity rates. In 2007 he became a PhD candidate at the finance department of Maastricht University. For his $\mathrm{PhD}$ research, he worked together with international finance organizations such as Robeco, ASN Bank, Triodos Bank, Loyalis and Deutsche Bank. Paul obtained an award from the United Nations Principles of Responsible Investments (UNPRI) for one of his research papers: "Social Preferences and Investor Loyalty". He is a regular speaker at international conferences for academics and practitioners. Paul taught the Master courses 'Behavioral Finance' and 'Financial Risk Management' at the School of Business and Economics (SBE). Since June 2012 he is appointed as Assistant Professor at the finance department of Maastricht University. He continues his research in behavioral finance and coordinates the course 'Corporate Finance' at the University College Maastricht (UCM). In his free time, Paul enjoys playing improvisation theatre, participating in pub quizzes and playing the keyboard. 